Universidade de São Paulo

Instituto de Astronomia, Geofísica e Ciências Atmosféricas

Departamento de Geofísica

\title{
Ampliação da Tomografia Sísmica do Manto Superior no Sudeste e Centro-Oeste do Brasil COM ONDAS P
}

\author{
Marcelo Peres Rocha.
}

Orientador: Prof. Dr. Marcelo Sousa de Assumpção.

Dissertação apresentada ao Departamento de Geofísica do Instituto de Astronomia, Geofísica e Ciências Atmosféricas da Universidade de São Paulo como requisito parcial para a obtenção do título de Mestre em Ciências. Área: Geofísica. 
Da minha aldeia vejo quanto da Terra se pode ver no Universo... Por isso a minha aldeia é tão grande como outra terra qualquer Porque eu sou do tamanho do que vejo E não, do tamanho da minha altura...

Fernando Pessoa

Para a minha Família, "Meu Povo". 


\section{SUMÁRIO}

Lista DE FIgURAS

LISTA DE TABELAS

AGRADECIMENTOS $\quad$ IX

RESUMO

ABSTRACT

1 INTRODUÇÃO 1

1.1 Estudos Anteriores . . . . . . . . . . . . . . . . . . . . . . . 1

1.2 Objetivos Deste Trabalho . . . . . . . . . . . . . . . . . . . 3

1.3 Área de Estudo . . . . . . . . . . . . . . . . . . 4

2 Dados: Características e SeleÇão 6

2.1 Características das Estações . . . . . . . . . . . . . . . . . . . . 6

2.2 Características Fundamentais . . . . . . . . . . . . . . . . . . 11

2.2.1 Resíduos Relativos . . . . . . . . . . . . . . . . . . . . . . . . . 11

2.2.2 Obtenção dos Resíduos Relativos: Método MCPCC . . . . . . . . . . . . 12

2.3 Seleção dos Eventos . . . . . . . . . . . . . . . . . . . . . . . 14

2.3 .1 Fases Utilizadas . . . . . . . . . . . . . . . . . . . . . . . . 14

3 DAdos: CONSISTÊNCIA 16

3.1 Estatísticas das Observações . . . . . . . . . . . . . . . . . . 16

3.2 Análises Comparativas . . . . . . . . . . . . . . . . . . . . . . 23

4 INVERSÃO DOS DADOS 29

4.1 Linearização . . . . . . . . . . . . . . . . . . . . . . . . . 29

4.2 Parametrização do Modelo . . . . . . . . . . . . . . . . . . . 30

4.3 Formulação da Inversão . . . . . . . . . . . . . . . . . . . . . . 32

4.4 Consistência da Inversão . . . . . . . . . . . . . . . . . . . . . . . . . . 35

4.5 Testes de Convergência e Regularização . . . . . . . . . . . . . . . . . . . . 37

5 Discussão dos Resultados 41

5.1 Resultados Finais . . . . . . . . . . . . . . . . . . . . . . 41

5.2 Resultados Retirando Estações _ . . . . . . . . . . . . . . . . . . 56 
6 Conclusões e Perspectivas

A Novas Estações

B Eventos Utilizados - 2002

BIBLIOGRAFIA 


\section{Lista DE FiguRAS}

1.1 Mapa da área de estudo contendo as estações utilizadas e algumas das principais estruturas geológicas da região. . . . . . . . . . . . . . . .

1.2 Distribuição dos eventos de 2001 e 2002 com ondas P (círculos vermelhos) e PKPdf (círculos verdes) em relação à área de estudo representada pelo quadrilátero vermelho ao centro. . . . . . . . . . . . . . . . . . . . .

2.1 Sismômetro de banda larga da marca STRECKEISEN, modelo STS-2. Foto da instalação na estação pp1b (Sonora - MS) em uma base de cimento assentada em rocha (arenito). (Foto de José Roberto Barbosa, Laboratório de Sismologia do $\mathrm{IAG} / \mathrm{USP}) \ldots \ldots \ldots \ldots \ldots \ldots \ldots \ldots \ldots \ldots \ldots \ldots \ldots \ldots \ldots \ldots \ldots$

2.2 Sismômetros de período curto da marca MARK PRODUCTS, modelo L4C. Foto da instalação na estação ijuq (Juquiá - SP).(Foto de José Roberto Barbosa, Laboratório de Sismologia do IAG/USP). . . . . . . . . . . . . . .

2.3 Sismômetro de período curto da marca TELEDYNE, modelo S13, sendo utilizado em um teste de ruído na escolha de local para instalação de uma estação. (Foto de José Roberto Barbosa, Laboratório de Sismologia do IAG/USP). . . . . . . .

2.4 Sensor enterrado. Estação pp1b (Sonora - MS). (Foto de José Roberto Barbosa, Laboratório de Sismologia do IAG/USP). . . . . . . . . . . . . . . . . .

2.5 Visão geral da estação pp1b (Sonora - MS). (Foto de José Roberto Barbosa, Laboratório de Sismologia do IAG/USP) . . . . . . . . . . . . . . . . . .

2.6 Exemplo dos passos seguidos para obtenção dos resíduos de tempo de percurso utilizando a correlação MCPCC (Schimmel et al. 2003). A) Sismogramas originais alinhados pelo tempo teórico do modelo IASP91. B) Sismogramas filtrados (0,8 a $1,6 \mathrm{~Hz}$ ) alinhados pelos picks resultantes da correlação cruzada. C) Empilhamento dos traços para verificação da qualidade da pickagem. Sismo ocorrido no Norte do Peru em 21/04/2002 com magnitude $5,0 m_{b} \ldots \ldots$. . . . . . . . . . . . 13

2.7 Triplicação de fases causada pelo forte gradiente na velocidade das ondas sísmicas. 14

2.8 Curva do tempo de percurso, mostrando as triplicações de fase resultantes do abrupto aumento da velocidade das ondas sísmicas nas profundidades de $410 \mathrm{~km}$ (de $15^{0}$ à $17^{0}$ aproximadamente) e $660 \mathrm{~km}$ (de $17^{0}$ a $27^{0}$ aproximadamente) Fonte: Lay \& Wallace (1995). . . . . . . . . . . . . . . . . . .

3.1 Histograma e distribuição gaussiana dos resíduos relativos de tempo de percurso para toda a base de dados (incluindo todas as estações). . . . . . . . . . . . . 17

3.2 Histograma para os resíduos de tempo relativos da estação BDFB. . . . . . . . . 19 
3.3 Histograma para os resíduos de tempo relativos da estação corb. . . . . . . . . 19

3.4 Histograma para os resíduos de tempo relativos da estação cv1b. . . . . . . . . 19

3.5 Histograma para os resíduos de tempo relativos da estação gnsb. . . . . . . . . . 19

3.6 Histograma para os resíduos de tempo relativos da estação pazb. . . . . . . . . 20

3.7 Histograma para os resíduos de tempo relativos da estação porb. . . . . . . . . . 20

3.8 Histograma para os resíduos de tempo relativos da estação pp1b. . . . . . . . . . 20

3.9 Histograma para os resíduos de tempo relativos da estação slmb. . . . . . . . . . 20

3.10 Histograma para os resíduos de tempo relativos da estação IGPB. . . . . . . . . . 21

3.11 Histograma para os resíduos de tempo relativos da estação MIR1. . . . . . . . . . 21

3.12 Histograma para os resíduos de tempo relativos da estação NP4B. . . . . . . . . 21

3.13 Histograma para os resíduos de tempo relativos da estação MAN1. . . . . . . . . 21

3.14 Histograma para os resíduos de tempo relativos da estação MAN2. . . . . . . . . 22

3.15 Histograma para os resíduos de tempo relativos da estação cam3. . . . . . . . . . 22

3.16 Histograma para os resíduos de tempo relativos da estação cam4. . . . . . . . . . 22

3.17 Histograma para os resíduos de tempo relativos da estação vao1. . . . . . . . . . 22

3.18 Histograma para os resíduos de tempo relativos da estação itpb. . . . . . . . . . 23

3.19 Histograma para os resíduos de tempo relativos da estação pdcb. . . . . . . . . . 23

3.20 Comparação da média dos resíduos relativos pelo back azimuth, entre as estações IGPB (UnB; Igarapava - MG; Lat. -20,0000 e Long. -47,7100) e rifb (BLSP; Rifaina - SP; Lat. -20,0737 e Long. -47,5019). . . . . . . . . . . . . . . . . .

3.21 Fases P e PKPdf chegando a uma estação sísmica qualquer, dando uma idéia da diferença entre os ângulos de incidência destas fases em relação à reta normal. . .

3.22 Comparação da média dos resíduos relativos pelo back azimuth, entre as estações pacb (BLSP; Pacaembú - SP; Lat. -21.6074 e Long. -51.2618) e popb (BLSP; Porto Primavera - PR; Lat. -22,4564 e Long. -52,8367). . . . . . . . . . . . . . .

3.23 Comparação da média dos resíduos relativos pelo back azimuth, entre as estações bamb (BLSP; Bambuí- MG; Lat. -20.0398 e Long. -46.0308), frmb (BLSP; Formiga - MG; Lat. -20.4876 e Long. -45.6389) e furb (BLSP; Furnas - MG; Lat. -20.6782 e Long. -46.2779). . . . . . . . . . . . . . . . . . . . .

3.24 Comparação da média dos resíduos relativos pelo back azimuth, entre as estações gns - gnsa/gnsb (BLSP; Goianésia - GO; Lat. -15.2644 e Long. -15.2644), paz - paz4/pazb (BLSP; Araguapaz - GO; Lat. -15.1369 e Long. -50.8634) e slmb (BLSP; São Luis dos Montes Belos - GO; Lat. -16.5705 e Long. -50.3455). . . . .

3.25 Comparação dos resíduos relativos para dois períodos de operação da estação BDFB (GTSN; Brasília, DF; Lat. -15,6418 e Long. -48,0148). BDFB-9 mostra dados no período 1992-1999 e BDFB-0 mostra dados no período 2000-2002 . . . . 
4.1 Limites e espaçamentos horizontais entre os nós do modelo. . . . . . . . . . . . 30

4.2 Parametrização do modelo utilizado na inversão dos dados. Os quadrados brancos representam as estações utilizadas (inclusive as novas estações incluídas neste trabalho - Apêndice A). O volume marcado pelas linhas amarelas é a região com melhor resolução da grade. . . . . . . . . . . . . . . . . . . . . . 3

4.3 Representação esquemática dos tipos de problemas descritos pela teoria da inversão (Menke 1984) . . . . . . . . . . . . . . . . . . . . . . . . .

4.4 Comparação entre as imagens tomográficas geradas pela inversão da base contendo dados com erros (Figuras a, c e e), e da base final depurada (Figuras b, d e f). As iterações referem-se ao processo de diminuição dos pesos para resíduos grandes. . . . . . . . . . . . . .

4.5 Curvas de rms para as iterações com pesos decrescentes (down-weighting) da base de dados total (com erros) e da base final (depurada). Foram utilizados os valores de 90000 e 2800 para suavidade e flatness respectivamente. . . . . . . . . . . . .

4.6 Comparação entre as imagens tomográficas com diferentes valores para os parâmetros de regularização. Para a), c) e e) o valor de suavidade foi 200000 e o de flatness 5000. Para b), d) e f) a suavidade foi 90000 e o flatness 2800 . . . . . . . . . . . . . . . . . . .

4.7 Curvas de rms para iterações de down-weigthing na inversão da base de dados final com dois valores de regularização. Na curva com triângulos vermelhos, os valores de suavidade e flatness foram 90000 e 2800 respectivamente, já na curva com triângulos azuis, estes valores dobraram (suavidade - 200000 e flatness - 5000) 39

4.8 Modelos com diferentes valores para os parâmetros de regularização e com mesmo ajuste (rms) para os dados $(\sigma=0,035 s)$. a) Suavidade 90000 e flatness 2800 . b) Suavidade 200000 e flatness

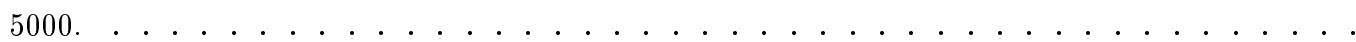

4.9 Distribuição dos ângulos de incidência dos raios a $400 \mathrm{~km}$ de profundidade como função dos back azimuths, e o erro do ajuste para o conjunto de dados de ondas P.

5.1 Imagem tomográfica a uma profundidade de $200 \mathrm{~km}$ para um modelo de Terra, homogênio e isotrópico. . . . . . . . . . . . . . . . .

5.2 Imagem tomográfica horizontal a uma profundidade de $150 \mathrm{~km}$, mostrando anomalias de alta e baixa velocidade em relação ao modelo médio de velocidades. Os círculos amarelos representam as intrusões alcalinas do Cretáceo Superior, os quadrados brancos são estações da rede e as linhas brancas perfis verticais. . . . .

5.3 Imagem tomográfica horizontal a uma profundidade de $200 \mathrm{~km}$, mostrando anomalias de alta e baixa velocidade em relação ao modelo médio de velocidades.

5.4 Imagem tomográfica horizontal a uma profundidade de $300 \mathrm{~km}$, mostrando anomalias de alta e baixa velocidade em relação ao modelo médio de velocidades. Os quadrados brancos são estações da rede e as linhas brancas perfis verticais. . . 
5.5 Imagem tomográfica horizontal a uma profundidade de $400 \mathrm{~km}$, mostrando anomalias de alta e baixa velocidade em relação ao modelo médio de velocidades.

5.6 Imagem tomográfica horizontal a uma profundidade de $500 \mathrm{~km}$, mostrando anomalias de alta e baixa velocidade em relação ao modelo médio de velocidades. 47

5.7 Imagem tomográfica horizontal a uma profundidade de $700 \mathrm{~km}$, mostrando anomalias de alta e baixa velocidade em relação ao modelo médio de velocidades.

5.8 Imagem tomográfica horizontal a uma profundidade de $900 \mathrm{~km}$, mostrando anomalias de alta e baixa velocidade em relação ao modelo médio de velocidades.

5.9 Imagem tomográfica horizontal a uma profundidade de $1100 \mathrm{~km}$, mostrando anomalias de alta e baixa velocidade em relação ao modelo médio de velocidades.

5.10 Imagem tomográfica horizontal a uma profundidade de $1300 \mathrm{~km}$, mostrando anomalias de alta e baixa velocidade em relação ao modelo médio de velocidades.

5.11 Perfil vertical A-A' até uma profundidade de $1400 \mathrm{~km}$ destacando principalmente a anomalia de baixa velocidade de Iporá. . . . . . . . . . . . . . . . . . .

5.12 Perfil vertical A-A' mostrando a distribuição da densidade dos raios (em log10)

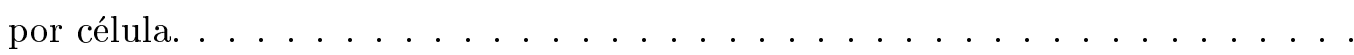

5.13 Perfil vertical B-B' destacando no centro a anomalia de baixa velocidade atribuída à pluma de Tristan da Cunha de acordo com Schimmel et al. (2003) e VanDecar et al. (1995). A placa de Nazca aparece a esquerda da anomalia de Tristan da Cunha como segmentos de alta velocidade separados. . . . . . . . . . . . .

5.14 Perfil vertical B-B' até uma profundidade de $1400 \mathrm{~km}$ mostrando a distribuição da densidade dos raios $($ em $\log 10)$ por célula. . . . . . . . . . . . . . .

5.15 Perfil vertical C-C' até uma profundidade de $1400 \mathrm{~km}$ destacando principalmente anomalias de baixa velocidade relacionadas a intrusões alcalinas datadas de 90-55 Ma.

5.16 Perfil vertical C-C' até uma profundidade de $1400 \mathrm{~km}$ mostrando a distribuição da densidade dos raios $($ em $\log 10)$ por célula. . . . . . . . . . . . . .

5.17 Perfil vertical D-D' até uma profundidade de $1400 \mathrm{~km}$ destacando principalmente as anomalias de baixa velocidade de Iporá e de alta velocidade relacionada à parte sul da Faixa Brasília (Escalante 2002) . . . . . . . . . . . . . . . . . .

5.18 Perfil vertical D-D' até uma profundidade de $1400 \mathrm{~km}$ mostrando a distribuição da densidade dos raios $($ em $\log 10)$ por célula. . . . . . . . . . . . . .

5.19 Perfil vertical E-E' até uma profundidade de $1400 \mathrm{~km}$ mostrando principalmente a junção da anomalia de baixa velocidade atribuída à pluma de Tristan da Cunha com uma anomalia (baixa velocidade) espúria (Escalante 2002) a partir dos 500 $\mathrm{km} \ldots \ldots \ldots \ldots \ldots \ldots \ldots$. . . . . . . . . . . . . . . . . . . 54 
5.20 Perfil vertical E-E' até uma profundidade de $1400 \mathrm{~km}$ mostrando a distribuição da densidade dos raios $($ em $\log 10)$ por célula . . . . . . . . . . . . 54

5.21 Perfil vertical F-F' até uma profundidade de $1400 \mathrm{~km}$ destacando principalmente a anomalia de baixa velocidade de Iporá e a tendência de baixa velocidade da região da Província Ígnea de Poxoréu em Mato Grosso. . . . . . . . . . . . . . . 55

5.22 Perfil vertical F-F' até uma profundidade de $1400 \mathrm{~km}$ mostrando a distribuição da densidade dos raios $($ em $\log 10)$ por célula . . . . . . . . . . . . . . . 55

5.23 Comparação entre as imagens tomográficas geradas para a) todos os dados, b) retirando argb, c) retirando as estações de Manso (1 e 2), d) retirando paz4 e pazb (mesma posição), e) retirando pp1b e f) retirando slmb. . . . . . . . . . . . . . . . . . . . . .

5.24 Comparação entre as imagens tomográficas geradas para a) todos os dados, b) retirando estações UnB, c) retirando canb, d) retirando MAN2, e) retirando rsta e rstb (mesma posição) e f) retirando estações RESUSP e RSBC. 


\section{LisTA DE TABELAS}

1.1 Contribuição de cada trabalho para a base de dados atual. . . . . . . . . . . . . 3

2.1 Período de funcionamento das estações do projeto BLSP (aajjj), relacionado ao tipo de sismômetro (Fonte: José Roberto Barbosa, Laboratório de Sismologia do IAG/USP). . . . . . . . . . . . . . . . . . . . . . 10

3.1 Informações sobre as estações mostradas nos histogramas. O $n .{ }^{0}$ max. de raios é o valor do pico do histograma, isto é, número de raios com resíduos próximos de

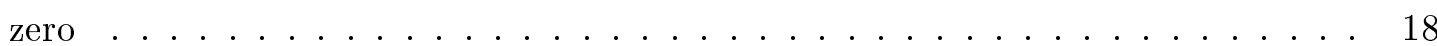

A.1 Localização das novas estações incluídas na rede utilizada. . . . . . . . . . . . . 62

B.1 Novos eventos incluídos durante este trabalho na base de dados total. . . . . . . 63 


\section{AgRAdECIMENTOS}

Primeiramente Agradeço a Deus que me permitiu, apesar de todas as dificuldades, chegar até aqui. Agradeço principalmente aos meus queridos pais, Brasil Gomide Rocha e Sueli Peres Rocha, bem como aos meus irmãos, Brasil Gomide Rocha Júnior e Ricardo Peres Rocha por todo apoio e incentivo durante este período, pois sem eles com certeza eu não conseguiria.

Agradeço de forma especial ao Prof. Dr. Marcelo Sousa de Assumpção pela confiança ao me orientar, considerando o pouco tempo para o desenvolvimento deste projeto; ao amigo Dr. Martin Shimmel pela sua orientação e conselhos, os quais me deram segurança para explorar este novo caminho; ao colega Msc. Christian Escalante Vilca pela constante ajuda, conselhos e por ter sido a primeira pessoa que me mostrou o que é a Tomografia Sísmica e ao amigo José Roberto Barbosa por todos os esclarecimentos em relação aos diversos tipos de estações sismográficas, e principalmente pela paciência.

Agredeço à minha ex-orientadora Prof. Dra. Liliana Alcazar Diogo pelo que me ensinou, e pela compreeção, à Prof. Dra. Naomi Ussami pela ajuda durante o meu ingresso e ao Prof. Dr. Wladimir Shukowsky por todas dúvidas tiradas e pela ajuda na revisão do trabalho. Da mesma maneira agradeço aos meus professores e colegas da época da graduação do curso de Física na UFMT, que me incentivaram e que me mostram que eu poderia conseguir, em especial aos professores Dr. Shozo Shiraiwa, Dr. Sérgio Roberto de Paulo, Dr. Carlos Rinaldi e Dr. Moacir Lacerda por todo incentivo, e ainda aos amigos Abílio Masteus Júnior e Welitom Rodrigues Borges pela amizade e ajuda durante a confecção e revisão desta dissertação.

Ainda agradeço a todos professores, técnicos, funcionários do IAG (de maneira geral), em especial a Maria Perpétua (Teca), e também aos colegas e amigos, Nilton, Henrique, Shimeles, Afonso, D. Beth, Marcelo "Slot", Manuelle, Oleg, Hugo Saar, Fabio Shibata, Paulinho, Miguel, Márcia, Ivan, Mei, Meijian, Marcelo Gomez, Sabrina, George Sand, entre outros que não caberiam nesta dissertação se eu fosse citá-los pelo que representam. Principalmente, agradeço a querida amiga Erika Reyes por toda a força. Muito Obrigado a Todos!!!

De uma maneira toda especial quero agradecer a você Kátia por tudo, particularmente pela sua compreensão e paciência. Ósculos e Amplexos. 


\section{RESUMO}

ROCHA, M. P. Ampliação da Tomografia Sísmica do Manto Superior no Sudeste e Centro-Oeste do Brasil com ondas P. 2003. 71p. Dissertação de Mestrado - Instituto de Astronomia, Geofísica e Ciências Atmosféricas, Departamento de Geofísica, Universidade de São Paulo, São Paulo.

Variações dos tempos de percurso de fases P e PKP foram usados para tomografia sísmica do manto superior sob o sudeste e centro-oeste do Brasil. Os principais objetivos foram: Melhorar a resolução obtida pelos estudos anteriores (VanDecar et al., 1995; Escalante, 2002; Schimmel et al., 2003, feitos de 1992 a 2001) com a inclusão de novos dados e estações, mapear as áreas que não tinham sido cobertas pelas estações anteriores, tentar mostrar a consistência da base de dados, principalmente relacionada às novas estações e verificar a robustez das anomalias encontradas. Fopi estudada a influência das estações localizadas nas regiões anômalas através de inversões secundárias (retirando estações). Nesta base foram incluídos registros recentes do ano 2002 e também registros de 2000 e 2001 para eventos utilizados nos trabalhos anteriores. Os resultados confirmaram as estruturas observadas nos trabalhos anteriores e também revelaram novas regiões anômalas, particularmente no sul do estado de Mato Grosso.

Das anomalias observadas nos trabalhos anteriores, confirmamos em nossos resultados o Cráton do São Francisco como uma anomalia de alta velocidade, com suas raízes chegando a 250 $\mathrm{km}$ de profundidade, a anomalia de baixa velocidade interpretada como resto fóssil da pluma de Tristan da Cunha (VanDecar et al. 1995), a boa correlação das anomalias rasas de baixa 
velocidade com as intrusões alcalinas do Cretáceo Superior (Schimmel et al. 2003), a anomalia de baixa velocidade inferida por Escalante (2002) na região de Iporá em Goiás (possível região do impacto inicial da pluma de Trindade), uma anomalia de alta velocidade sob a região da Bacia do Paraná (profundidades rasas) interpretada inicialmente por Schimmel et al. (2003) como possível núcleo cratônico da Bacia do Paraná e também, nesta mesma região (maiores profundidades), uma anomalia de alta velocidade interpretada como a litosfera subduzida da Placa de Nazca (Schimmel et al., 2003 e Escalante, 2002).

A nova base permitiu a expansão da área de estudo e o imageamento de anomalias de baixa velocidade na província ígnea de Poxoréu em Mato Grosso, as quais são consistentes com o afinamento litosferico proposto no modelo de Thompson et al. (1998).

Palavras-chave: Tomografia Sísmica, Manto Superior, Ondas P, Cráton do São Francisco, Bacia do Paraná, Placa de Nazca, Pluma de Tristan da Cunha, Pluma de Trindade. 


\section{ABstraCt}

ROCHA, M. P. Extension of Upper Mantle Seismic Tomography in Southeast and Central Brazil using P-waves. 2003. 71p. Dissertação de Mestrado - Instituto de Astronomia, Geofísica e Ciências Atmosféricas, Departamento de Geofísica, Universidade de São Paulo, São Paulo.

Variations of P and PKP travel times were used for seismic tomography of the upper mantle beneath southeast and central Brazil. Our principal objectives were: To improve the resolution obtained by the previous studies (carried out by VanDecar et al., 1995; Escalante, 2002; Schimmel et al., 2003 between 1992 and 2001) whith inclusion of new data and stations, to map areas not covered by previous stations, to show the consistency of the database, mainly of the related to the new stations and to verify the robustness of the detected anomalies. The influence of the stations located in the anomalous areas were studied through secondary inversions (removing stations). The new data set includes recent records of 2002 and also new records from 2000 and 2001 for events used in the previous works. Our results confirm the structures observed in the previous works and also revealed new anomalous regions, particularly in the south of the Mato Grosso state.

We confirmed the anomalies observed in the previous works: The São Francisco craton has as a high-velocity anomaly, with roots down to $250 \mathrm{~km}$ depth, the low velocity anomaly interpreted as a fossil remnant of the Tristan da Cunha plume (VanDecar et al. 1995), the good correlation of the shallow low velocity anomalies with the alkaline intrusions of the Late-Cretaceous (Schimmel 
et al. 2003), the low velocity anomaly inferred by Escalante (2002) in the Iporá igneous province in Goiás (possible area of the initial impact of the plume of Trindade), a high-velocity anomaly under the Paraná Basin (shallow depths) interpreted initially by Schimmel et al. (2003) as possible cratonic nucleus of the Paraná Basin and also, in this same area (larger depths), a high-velocity anomaly interpreted as the slab of the Nazca Plate (Schimmel et al., 2003 and Escalante, 2002).

The new data set allowed the expansion of the study area and the imaging of low velocity anomalies in the igneous province of Poxoréu in Mato Grosso, which are consistent with the model of litospheric thinning proposed by Thompson et al. (1998).

Key-words: Seismic Tomography, Upper Mantle, P-waves, São Francisco craton, Parana Basin, Nazca Plate, Tristan da Cunha plume, Trindade plume. 


\section{Capítulo 1}

\section{INTRODUÇÃO}

O estudo dos eventos tectônicos passados e da evolução geológica permitem uma melhor compreensão da estrutura atual da Terra. A crosta e o manto superior contêm feições estruturais relacionadas a antigos processos geodinâmicos. A tomografia sísmica fornece informações destas estruturas através do mapeamento das variações de velocidade das ondas sísmicas. Isto é feito com a inversão dos tempos de percurso das ondas geradas por terremotos que ocorrem em todo o mundo, obtendo assim, informações sobre pequenas variações de velocidade em relação a um modelo médio da Terra. Neste trabalho damos continuidade ao estudo do manto superior sob o sudeste e centro-oeste do Brasil utilizando a tomografia sísmica.

\subsection{Estudos Anteriores}

Desde 1992 o IAG-USP, algumas vezes em conjunto com intituições internacionais, vem realizando estudos tomográficos nas regiões Sudeste e Centro-Oeste do Brasil.

Este estudo é uma continuação dos outros trabalhos de tomografia sísmica utilizando ondas P (VanDecar et al., 1995; Escalante, 2002; Schimmel et al., 2003), todos do projeto "Brazilian Lithospheric Seismic Project" (BLSP92, BLSP95 e BLSP02), e busca adicionar mais informações à base de dados gerada por estes trabalho, para melhorar a resolução das estruturas observadas.

Os estudos tomográficos de VanDecar et al. (1995) revelaram principalmente uma anomalia de baixa velocidade próxima do centro do arranjo utilizado por ele (entre as latitudes $-16^{0} \mathrm{e}$ $-27^{0}$ e entre as longitudes de $-41^{0} \mathrm{e}-55^{0}$ ). Esta anomalia foi interpretada como sendo uma estrutura termal mais quente remanescente da pluma de Tristan da Cunha sob a Bacia do Paraná correlacionada com os derrames de basaltos ocorridos a $\sim 135$ Ma nesta região. O Cráton do São Francisco mostrou velocidades altas no manto superior.

No trabalho de Schimmel et al. (2003) foram investigadas maiores profundidades e novas áreas em relação à área de VanDecar et al. (1995). 
Os resultados de Schimmel et al. (2003) mostraram uma boa correlação entre as províncias de intrusões alcalinas do Cretáceo Superior e as áreas com anomalias de baixa velocidade. Também foi confirmada a anomalia observada anteriormente por VanDecar et al. (1995), sendo interpretada da mesma maneira.

Ainda foi observada neste trabalho uma anomalia de alta velocidade abaixo do Cráton do São Francisco com raizes de aproximadamente 200 km, e uma outra no manto superior na parte oeste da Bacia do Paraná que poderia indicar um núcleo cratônico para esta Bacia conforme inferido por Cordani et al. (1984). Foi encontrada uma região com altas velocidades no manto inferior abaixo da Bacia do Párana. Esta região foi interpretada como sendo a litosfera subduzida da Placa de Nazca, chegando a profundidade de $1300 \mathrm{~km}$.

Os resultados de Escalante (2002) confirmam a presença da anomalia de alta velocidade abaixo do Cráton do São Francisco com raízes entre 200 e 300 km de profundidade e a anomalia de alta velocidade no oeste da Bacia do Paraná como observada por Schimmel et al. (2003). Além destas, as anomalias de altas velocidades referentes à subducção da Placa de Nazca foram observadas.

A anomalia de baixa velocidade interpretada como sendo o conduto fóssil da pluma de Tristan da Cunha, nos resultados do trabalho de Escalante (2002) é notada a partir de $250 \mathrm{~km}$ de profundidade, sendo que a partir dos $500 \mathrm{~km}$ ela cresce em volume e estende-se até uma profundidade de 600 a $700 \mathrm{~km}$.

A principal diferença do trabalho de Escalante (2002) em relação ao de Schimmel et al. (2003) foi o aumento da área de investigação e a maior cobertura de estações, principalmente na região de Goiás. Foi observada uma estrutura de baixa velocidade na região da província ígnea de Iporá em Goiás, que poderia estar relacionada ao efeito inicial da pluma de Trindade. Esta anomalia é consistente com o modelo proposto por Thompson et al. (1998).

Outros trabalhos de tomografia utilizando ondas de superfície foram realizados englobando esta região (Silveira et al. (1998); Heintz et al. (2000); Vdovin et al. (1999); Van der Lee et al. (2001)), e podem ser considerados complementares aos estudos tomográficos na região sudeste e centro-oeste do Brasil. Basicamente, as estruturas observadas nestes trabalhos são rasas (até 300 $\mathrm{km}$ ) devido à menor penetração das ondas de superfície. A resolução lateral deste tipo de onda é pequena considerando seus longos períodos. Desta maneira para este tipo de tomografia são apenas mapeadas estruturas de larga escala (centenas de kilometros). Os resultados principais destes trabalhos são a observação das grandes unidades tectônicas da América do Sul, como o Cráton Amazônico e o Altiplano. No trabalho de Van der Lee et al. (2001) a anomalia de baixa velocidade sob a Bacia do Paraná foi detectada. 


\subsection{Objetivos Deste Trabalho}

Considerando que a resolução tomográfica depende da quantidade e distribuição dos dados na área de estudo (cobertura das estações) temos como objetivo principal incluir novos dados na base existente, principalmente em regiões onde não existiram estações anteriores. Esperamos com a inclusão de novas estações (estações não utilizadas nos trabalhos anteriores) mapear novas áreas e ainda aumentar a precisão dos resíduos relativos no processo de pickagem (Capítulo 2).

Queremos também observar a influência das estações localizadas nas regiões anômalas de maior interesse através de inversões secundárias (testes retirando estações da base), e assim estudar quais anomalias são robustas e quais ainda necessitam de mais estações/dados para serem confirmadas.

TABela 1.1 - Contribuição de cada trabalho para a base de dados atual.

\begin{tabular}{ccccc}
\hline \hline Trabalhos & Fases & Eventos & Chegadas & Estações/Evento \\
\hline (Schimmel et al. 2003) & $\mathrm{P}$ & 656 & 4281 & \\
$(1992-1999)$ & PKP & 152 & 1086 & 6,6 \\
& Total & 808 & 5367 & \\
\hline Escalante 2002) & P & 386 & 1625 & \\
$(2000-2001)$ & PKP & 96 & 496 & $4,4 *$ \\
& Total & 482 & 2121 & \\
\hline Este Trabalho: & P & 234 & 2830 & \multirow{2}{*}{$12,11^{* *}$} \\
(2002) e inclusão & PKP & 34 & 414 & \\
de dados em 2000 e 2001 & Total & 268 & 3244 & \\
\hline TOTAL GERAL & P & 1276 & 8736 & \\
& PKP & 282 & 1996 & \\
& Total & 1558 & 10732 & \\
\hline
\end{tabular}

*** Estes valores não expressam completamente o que ocorre, pois muitas das chegadas atribuídas a este trabalho (e.g. UnB), referem-se a eventos processados inicialmente por Escalante (2002).

A Tabela 1.1 mostra uma comparação dos dados referentes aos trabalhos anteriores e este. O trabalho de Schimmel et al. (2003) utilizou e reprocessou todos os dados utilizados por VanDecar et al. (1995) de 1992 a 1994, e adicionou dados até 1995. As informações deste trabalho, portanto, cobrem o período 1992-1999.

Comparando com os dados de Escalante (2002), observamos que apesar da quantidade de eventos do presente trabalho ser menor (268), a quantidade de raios é maior (3244). Isto se deve à inclusão de outras estações durante este trabalho na base de dados de Escalante (2002) como os da rede USP e da UnB. Ou seja, a quantidade de eventos se manteve para os anos de 2000 e 2001, mas o número de raios aumentou. Cada evento é registrado, em média, por $\sim 7$ estações. 


\section{3 Área de Estudo}

A região estudada compreende principalmente o sudeste e centro-oeste do Brasil, incluindo algumas estruturas geológicas importantes, como o Cráton do São Francisco e a Bacia do Paraná. A área fica entre as Latitudes $-12^{0}$ e $-30^{0}$ e entre as longitudes $-38^{0}$ e $-60^{0}$ (Figura 1.1), e nela estão localizadas cerca de 68 estações (banda larga e período curto) utilizadas neste trabalho e nos anteriores A maior densidade de estações fica na região sudeste.

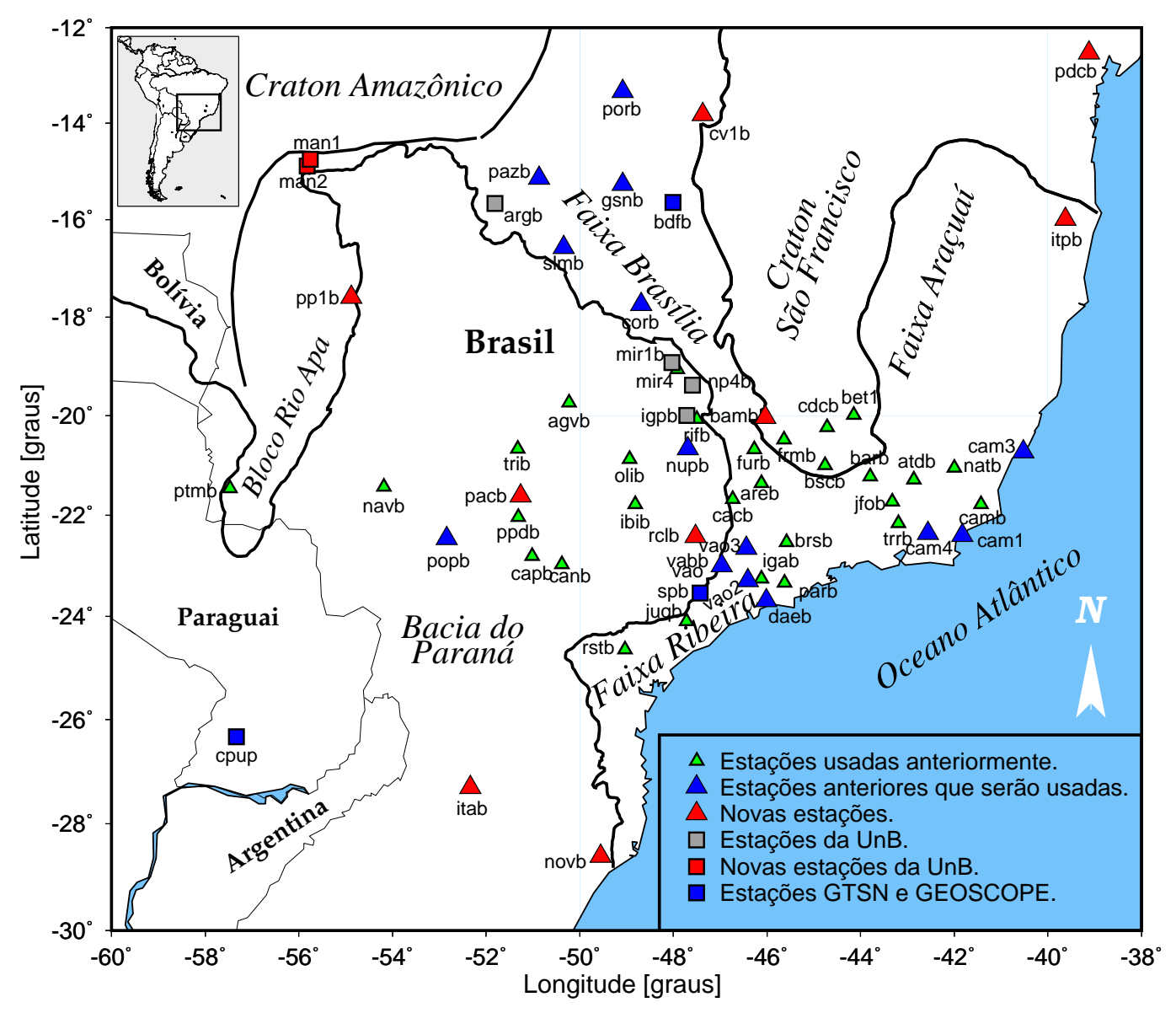

Figura 1.1 - Mapa da área de estudo contendo as estações utilizadas e algumas das principais estruturas geológicas da região.

Na Figura 1.1 as estações representadas por triângulos verdes foram utilizadas principalmente no trabalho de VanDecar et al. (1995) e Schimmel et al. (2003). As em triângulo azul foram utilizadas principalmente no trabalho de Escalante (2002), exceto as estações da rede sismográfica da USP "RESUSP" (vao, vao2 e vao3) e da rede sismográfica da Bacia de Campos "RSBC" (cam1, cam3 e cam4) utilizadas neste trabalho e algumas no trabalho de Schimmel et al. (2003). As estações representadas em vermelho (quadrados e triângulos) foram usadas 
exclusivamente neste trabalho (Apêndice A).

Na Figura 1.2 está mostrada a distribuição azimutal dos eventos com relação à rede. Os eventos mostrados nesta figura são do ano de 2002 (Apêndice B) utilizados somente neste trabalho, e do ano de 2001 no trabalho de Escalante (2002). Os círculos vermelhos representam fases P e os verdes fases PKPdf. A seleção de apenas estas duas fases primárias está justificada no Capítulo 2.

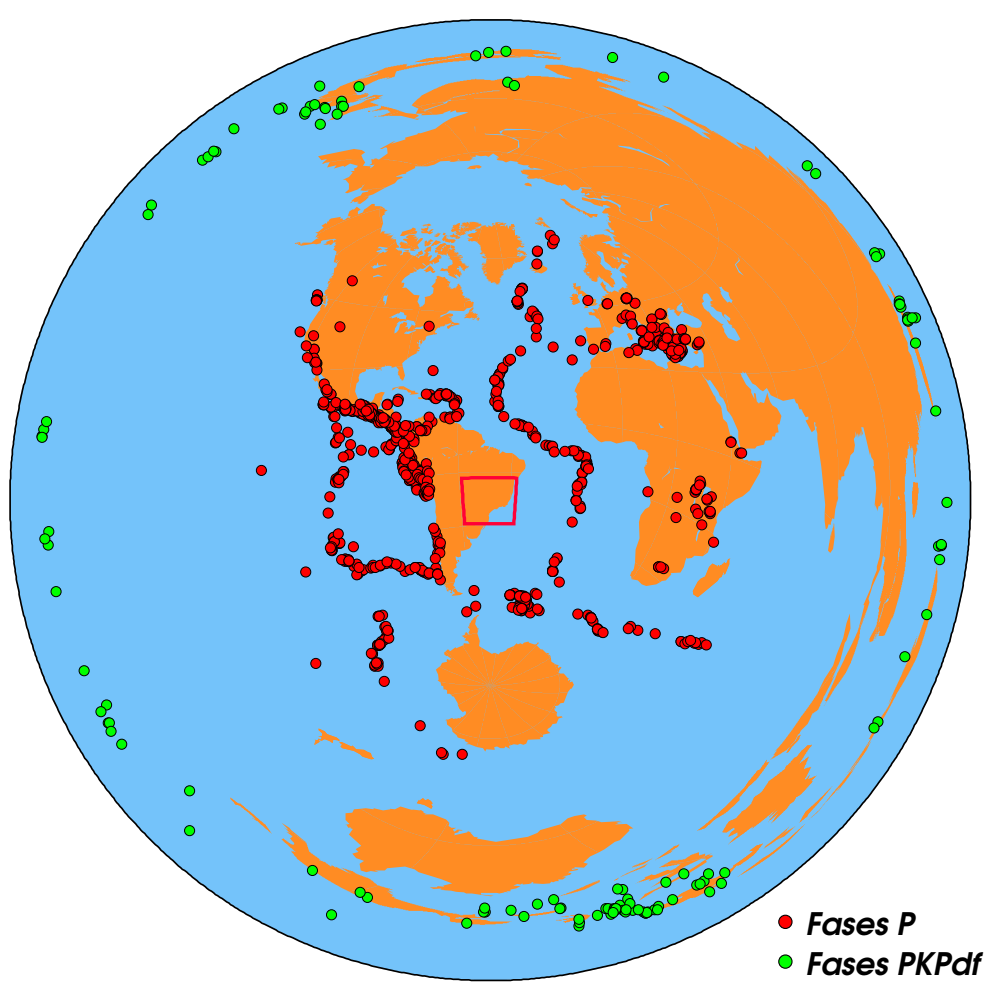

Figura 1.2 - Distribuição dos eventos de 2001 e 2002 com ondas P (círculos vermelhos) e PKPdf (círculos verdes) em relação à área de estudo representada pelo quadrilátero vermelho ao centro.

O contexto tectônico da área de estudo está ligado a diversos eventos ocorridos durante o ciclo Brasiliano/Pan-Africano (Brito Neves et al. 1991). Um detalhamento maior da evolução tectônica da região pode ser encontrado em Escalante (2002). 


\section{CAPÍtulo 2}

\section{Dados: Características E Seleção}

Os dados utilizados neste trabalho são resíduos relativos de tempo de percurso de fases de ondas $\mathrm{P}$ telessísmicas, obtidos da diferença entre o tempo observado e o tempo teórico. Foram utilizadas estações pertencentes a diversos projetos e grupos de pesquisa: IAG/USP (rede temporária BLSP, rede permanente RESUSP e rede permanente RSBC), UnB (rede Amazon Scope), ETH-Zurique (projeto BLSP02) e rede digital mundial.

Será feita neste capítulo uma descrição das características dos dados, como por exemplo as diferenças entre as estações dos diversos grupos de pesquisa e o cálculo dos resíduos relativos. Serão também discutidos os critérios de seleção dos dados, com um enfoque nas fases, nos intervalos de distância selecionados para cada fase, e também na magnitude dos eventos.

\subsection{Características das Estações}

A maioria das estações utilizadas na tomografia do sudeste e centro-oeste brasileiro possuem sismômetro de banda larga ("broadband", Figura 2.1), e seus dados vêm sendo usados no projeto "Brazilian Lithospheric Seismic Project" (BLSP). Na Tabela 2.1 estão as estações que forneceram dados para o projeto BLSP, incluíndo as de período curto (Figura 2.2). Praticamente todas as estações BLSP operaram com o registrador da marca REFTEK. Utilizamos também estações de período curto da Rede Sismográfica da USP (RESUSP) e da Rede Sismográfica da Bacia de Campos (RSBC), e ainda estações de banda larga da Universidade de Brasília (UnB), da Rede GTSN (Global Telemetered Seismograph Network - USGS) e uma da GEOSCOPE (SPB - Sorocaba/SP). As novas estações estão indicadas no Apêndice A.

A Figura 2.1 mostra um sismômetro triaxial de banda larga da marca STRECKEISEN, modelo STS-2, usado na maioria das estações "broadband" do projeto BLSP. Algumas estações utilizam sismômetros triaxiais da marca GURALP com período de 100 segundos. Na Figura 2.2 são mostrados sismômetros de período curto para as três componentes, utilizados nas estações "short period" deste projeto. 
A Figura 2.3 mostra a componente vertical de um sismômetro de período curto da marca TELEDYNE, modelo S13, usados nas redes RESUSP e RSBC. Nesta foto o sismômetro está sendo usado para testes de ruído, feitos para avaliar os locais de instalação das estações.

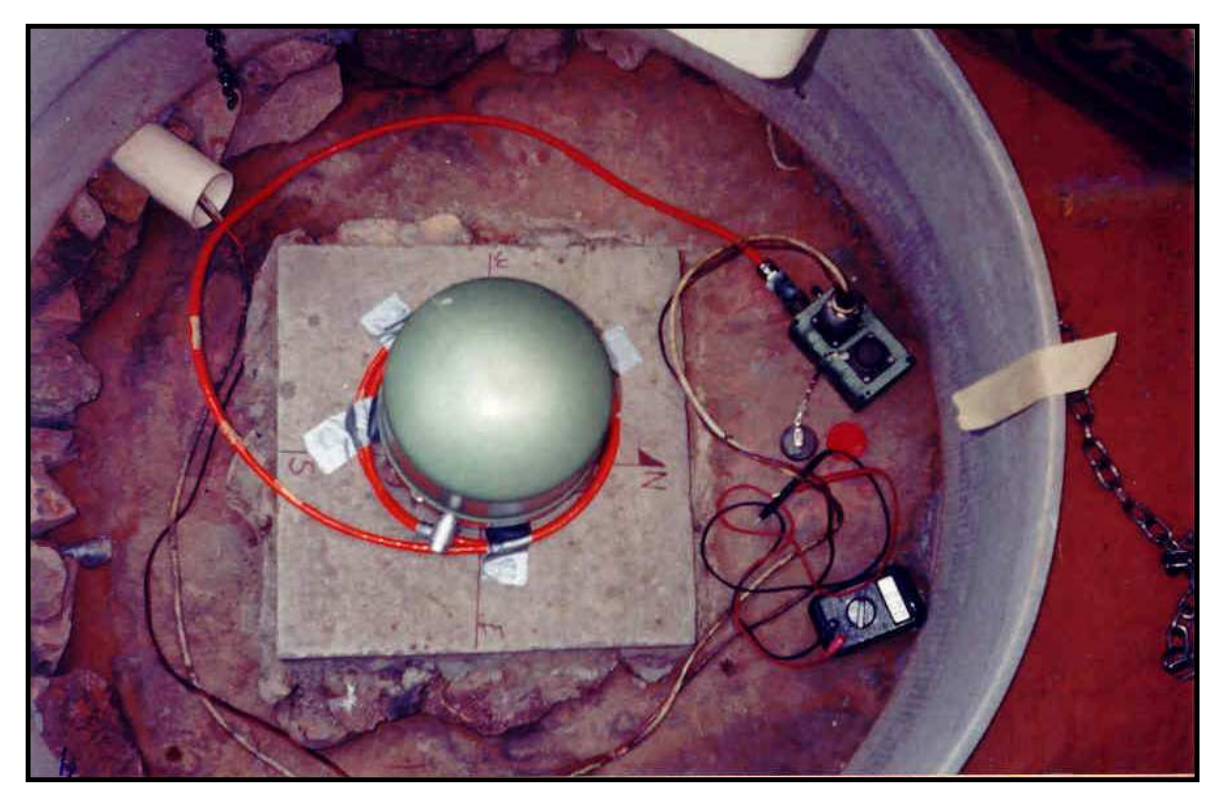

FIgurA 2.1 - Sismômetro de banda larga da marca STRECKEISEN, modelo STS-2. Foto da instalação na estação pp1b (Sonora - MS) em uma base de cimento assentada em rocha (arenito). (Foto de José Roberto Barbosa, Laboratório de Sismologia do IAG/USP).

As estações da UnB possuem sismômetros de banda larga triaxial GURALP com período de 30 segundos.

Para as estações BLSP, os sensores das estações de banda larga foram enterrados, buscando diminuir os efeitos dos ruídos ambientais (temperatura, principalmente) sobre os registros. A Figura 2.4 mostra o sensor soterrado, e a Figura 2.5 mostra uma visão geral da estação.

Os registros de período curto foram transformados para imitar os registros de banda larga, e assim, as formas de onda registradas com intrumentos de período curto e banda larga puderam ser utilizados juntamente durante a marcação das chegadas como veremos mais adiante. O intervalo de freqüência dos dados ficou em torno de $1 \mathrm{~Hz}$.

Todas as estações foram equipadas com receptores GPS, permitindo uma melhor localização e um tempo de registro mais preciso (correção de tempo automática). O tempo da maioria das estações (BLSP) foi corrigido utilizando arquivos com informações da operação do GPS, o que chamamos de correção de tempo controlada. Este tipo de correção garante um tempo ainda mais preciso, diminuindo as inconsistências da base de dados total. Os dados da RESUSP e da RSBC (IAG/USP) são corrigidos automaticamente no registro em tempo real efetuado no IAG. Em princípio, não há necessidade de correção adicional. Não tivemos controle sobre a correção de tempo das estações da UnB. 


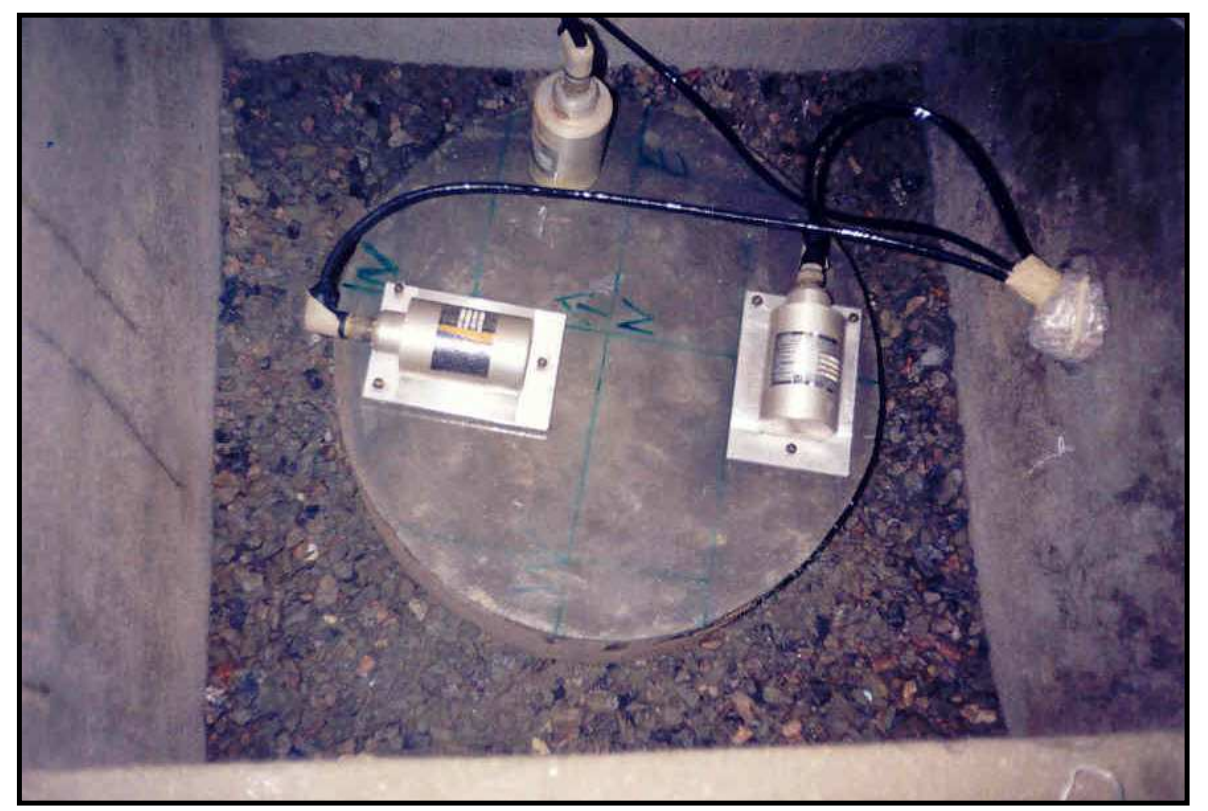

Figura 2.2 - Sismômetros de período curto da marca MARK PRODUCTS, modelo L4C. Foto da instalação na estação ijuq (Juquiá - SP).(Foto de José Roberto Barbosa, Laboratório de Sismologia do IAG/USP).

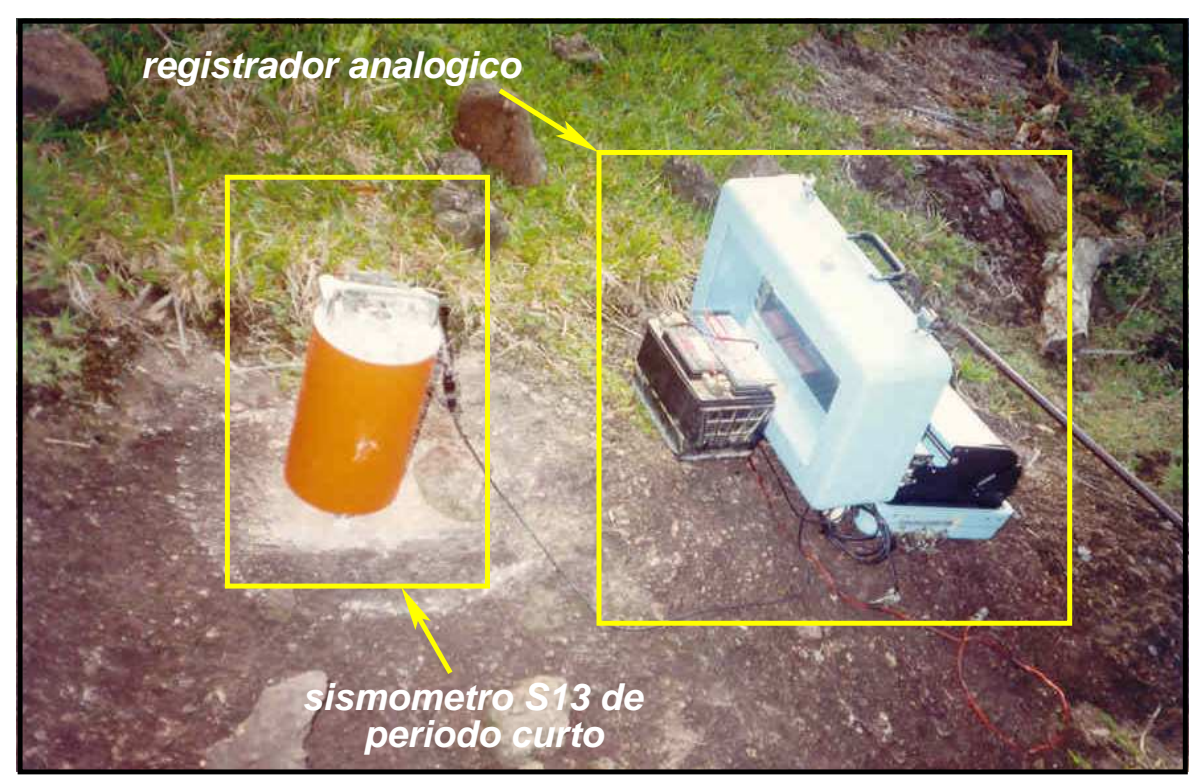

Figura 2.3 - Sismômetro de período curto da marca TELEDYNE, modelo S13, sendo utilizado em um teste de ruído na escolha de local para instalação de uma estação. (Foto de José Roberto Barbosa, Laboratório de Sismologia do IAG/USP). 


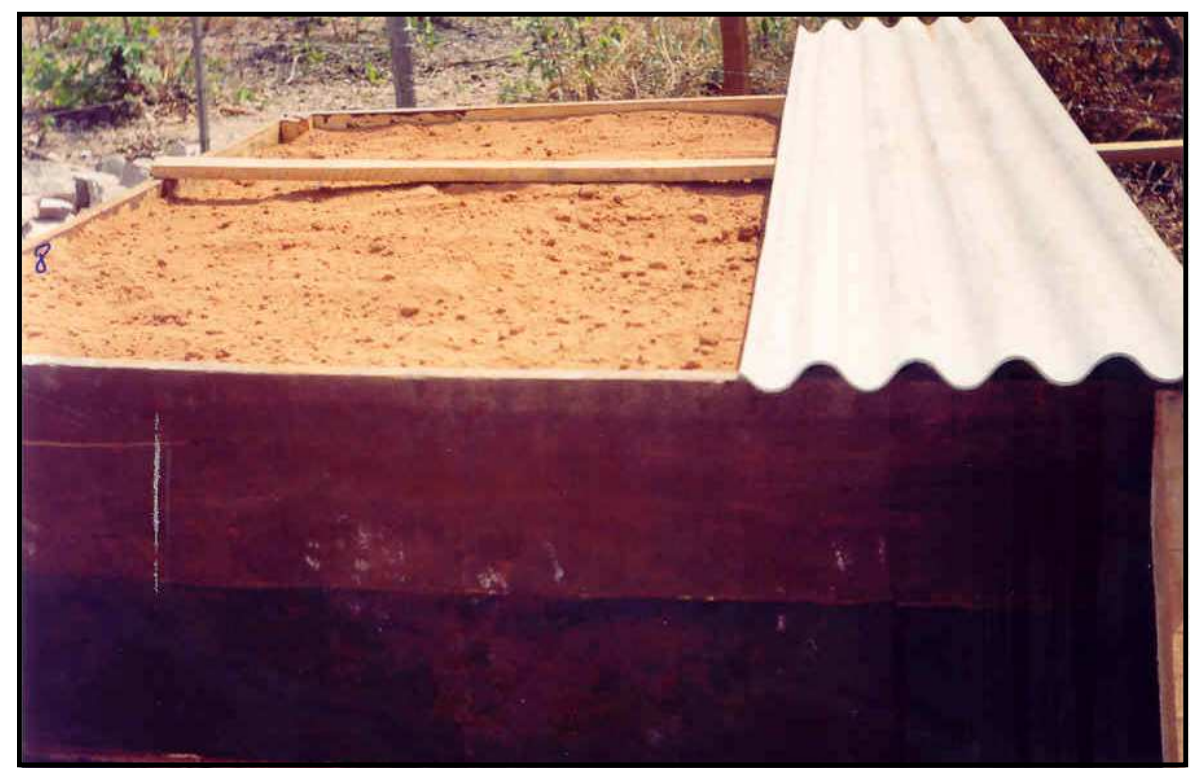

Figura 2.4 - Sensor enterrado. Estação pp1b (Sonora - MS). (Foto de José Roberto Barbosa, Laboratório de Sismologia do IAG/USP).

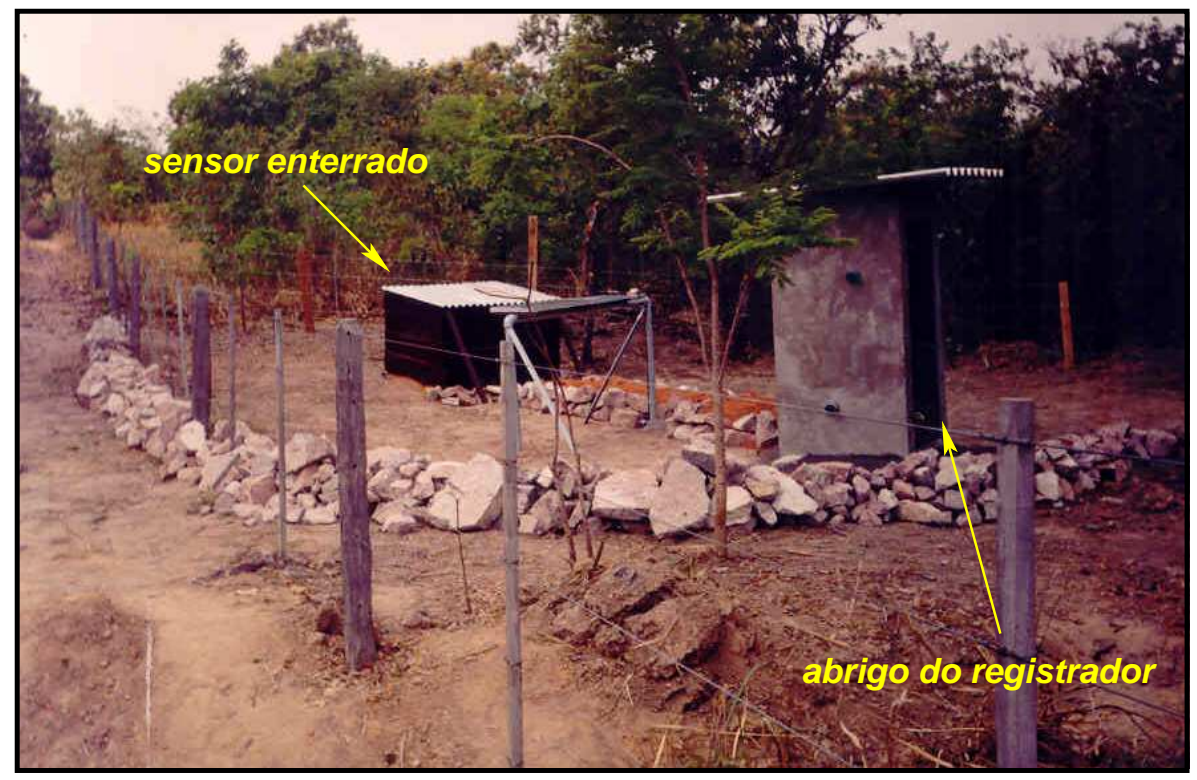

Figura 2.5 - Visão geral da estação pp1b (Sonora - MS). (Foto de José Roberto Barbosa, Laboratório de Sismologia do IAG/USP). 
TABELA 2.1 - Período de funcionamento das estações do projeto BLSP (aajjj), relacionado ao tipo de sismômetro (Fonte: José Roberto Barbosa, Laboratório de Sismologia do IAG/USP).

\begin{tabular}{|c|c|c|c|c|c|}
\hline Localidade & Nome & Tipo & Modelo & Período & Situação (20/06/03) \\
\hline \multirow{2}{*}{ Goianésia - GO } & gnsa & $\mathrm{PC}$ & $\mathrm{L} 4 \mathrm{C}$ & $01257-01314$ & \multirow[t]{2}{*}{ Ativada } \\
\hline & gnsb & $\mathrm{BL}$ & STS-2 & 01314-presente & \\
\hline \multirow[t]{2}{*}{ São Luis de Montes Belos - GO } & slmb & $\mathrm{PC}$ & $\mathrm{L} 4 \mathrm{C}$ & $01174-01258$ & \multirow[t]{2}{*}{ Ativada } \\
\hline & $\operatorname{slmb}$ & $\mathrm{BL}$ & STS-2 & 02085-presente & \\
\hline Porangatú - GO & porb & $\mathrm{BL}$ & STS-2 & $00217-02087$ & Desativada \\
\hline \multirow[t]{2}{*}{ Caldas Novas, Corumba - GO } & cor2 & $\mathrm{PC}$ & S13 & $99280-00144$ & \multirow[t]{2}{*}{ Desativada } \\
\hline & corb & $\mathrm{BL}$ & GURALP & 00144-03072 & \\
\hline \multirow[t]{2}{*}{ Araguapaz, Aruanã - GO } & paz4 & $\mathrm{PC}$ & $\mathrm{L} 4 \mathrm{C}$ & $99282-00146$ & \multirow[t]{2}{*}{ Desativada } \\
\hline & pazb & $\mathrm{BL}$ & GURALP & $00146-02255$ & \\
\hline Ponte de Pedra, Sonora - MS & pp1b & $\mathrm{BL}$ & STS-2 & 02272-presente & Ativada \\
\hline \multirow[t]{2}{*}{ Nova Veneza - SC } & novb & $\mathrm{PC}$ & $\mathrm{L} 4 \mathrm{C}$ & $02173-02285$ & \multirow[t]{2}{*}{ Ativada } \\
\hline & novb & $\mathrm{BL}$ & STS-2 & 02285-presente & \\
\hline \multirow[t]{2}{*}{ Rio Claro - SP } & rcla & $\mathrm{PC}$ & $\mathrm{L} 4 \mathrm{C}$ & $02243-02310$ & \multirow[t]{2}{*}{ Ativada } \\
\hline & $\mathrm{rclb}$ & $\mathrm{BL}$ & GURALP & 02295-presente & \\
\hline Bambuí- MG & bamb & $\mathrm{BL}$ & STS-2 & 02063-presente & Ativada \\
\hline \multirow{3}{*}{ Nuporanga - SP } & nupb & $\mathrm{BL}$ & GURALP & 01283-01355 & \multirow{3}{*}{ Ativada } \\
\hline & nupb & $\mathrm{BL}$ & STS-2 & $01355-02306$ & \\
\hline & nupa & $\mathrm{PC}$ & $\mathrm{L} 4 \mathrm{C}$ & 02306-presente & \\
\hline Porto Primavera - SP & popb & $\mathrm{BL}$ & STS-2 & 99237-02266 & Desativada \\
\hline DAEE, Mogi das Cruzes - SP & daeb & $\mathrm{BL}$ & STS-2 & 00321-02079 & Desativada \\
\hline Canoas, Itambaracá - PR & canb & $\mathrm{BL}$ & STS-2 & $99235-01211$ & Desativada \\
\hline \multirow[t]{2}{*}{ Tijuco Alto, Adrianopolis - PR } & rsta & $\mathrm{PC}$ & $\mathrm{L} 4 \mathrm{C}$ & $98234-99300$ & \multirow[t]{2}{*}{ Desativada } \\
\hline & rstb & $\mathrm{BL}$ & STS-2 & $00271-01226$ & \\
\hline Nova Alvorada - MS & navb & $\mathrm{BL}$ & STS-2 & $94273-95166$ & Desativada \\
\hline Porto Murtinho - MS & ptmb & $\mathrm{BL}$ & STS-2 & $94275-95167$ & Desativada \\
\hline Ibitinga - SP & ibib & $\mathrm{BL}$ & STS-2 & $94208-95164$ & Desativada \\
\hline Olímpia - SP & olib & $\mathrm{BL}$ & STS-2 & $94214-95047$ & Desativada \\
\hline \multirow[t]{2}{*}{ Juquiá - SP } & ijuq & $\mathrm{PC}$ & $\mathrm{L} 4 \mathrm{C}$ & 99294-99336 & \multirow[t]{2}{*}{ Desativada } \\
\hline & juqb & $\mathrm{BL}$ & STS-2 & 99336-01157 & \\
\hline Campos - RJ & $\mathrm{cmpb}$ & $\mathrm{BL}$ & STS-2 & 99041-99??? & Desativada \\
\hline \multirow[t]{2}{*}{ Igaratá - SP } & igab & $\mathrm{PC}$ & $\mathrm{L} 4 \mathrm{C}$ & 99023-99072 & \multirow[t]{2}{*}{ Desativada } \\
\hline & igab & $\mathrm{BL}$ & STS-2 & $99072-01233$ & \\
\hline Brasópolis - MG & brsb & $\mathrm{BL}$ & STS-2 & $96174-98291$ & Desativada \\
\hline Tres Rios - RJ & trrb & $\mathrm{BL}$ & STS-2 & $95277-98275$ & Desativado \\
\hline & vaob & $\mathrm{PC}$ & S13 & 94291-94293 & \\
\hline & vaob & $\mathrm{PC}$ & Willmore & 94293-95271 & \\
\hline Valinhos - SP & vabb & $\mathrm{BL}$ & STS-2 & $95271-98086$ & Desativada \\
\hline & vabb & $\mathrm{PC}$ & $\mathrm{L} 4 \mathrm{C}$ & $98155-98175$ & \\
\hline & vabb & $\mathrm{BL}$ & STS-2 & $98293-98296$ & \\
\hline Barbacena - MG & barb & $\mathrm{BL}$ & STS-2 & $98097-00181$ & Desativada \\
\hline Juiz de Fora - MG & jfob & $\mathrm{PC}$ & $\mathrm{L} 4 \mathrm{C}$ & $98142-98276$ & Desativada \\
\hline & jfob & $\mathrm{BL}$ & STS-2 & $98276-00184$ & \\
\hline & are-1 & $\mathrm{PC}$ & $\mathrm{L} 4 \mathrm{C}$ & $96295-96306$ & \\
\hline Areado-MG & are-1 & $\mathrm{PC}$ & Willmore & $96352-97085$ & Desativada \\
\hline & areb & $\mathrm{BL}$ & STS-2 & $97085-99229$ & \\
\hline Bom Sucesso - MG & $\mathrm{bscb}$ & $\mathrm{BL}$ & STS-2 & $97309-98278$ & Desativada \\
\hline Natividade - RJ & natb & $\mathrm{BL}$ & STS-2 & $95337-97308$ & Desativada \\
\hline Astolfo Dutra - MG & atdb & $\mathrm{BL}$ & STS-2 & $95342-97072$ & Desativada \\
\hline Betim - MG & bet1 & $\mathrm{PC}$ & Willmore & $95192-96104$ & Desativada \\
\hline Capivara - PR & capb & $\mathrm{BL}$ & STS-2 & $94384-95170$ & Desativada \\
\hline Miranda, Uberlândia - MG & $\operatorname{mir} 4$ & $\mathrm{PC}$ & $\mathrm{L} 4 \mathrm{C}$ & $98187-99019$ & Desativada \\
\hline
\end{tabular}




\subsection{CARACTERÍsticas Fundamentais}

\subsubsection{Resíduos Relativos}

Muitas técnicas de inversão tomográfica utilizam resíduos de tempo de percurso das ondas sísmicas para imagear estruturas de velocidade no interior da Terra. Basicamente, os resíduos de tempo são as variações no tempo de percurso das ondas telessísmicas em relação a um modelo médio da Terra, e são utilizados para restringir o modelo tomográfico (modelo de anomalias) ao segmento terminal dos raios sísmicos.

Definimos os resíduos absolutos de tempo de percurso como sendo a diferença entre o tempo observado e o tempo calculado (teórico), onde o tempo observado é obtido pela marcação visual das chegadas (picking) e o tempo teórico é obtido de tabelas de interpolação de tempo de percurso, em profundidade e distância, conhecidas como modelos de referência da Terra. Assim, de uma fonte $j$ qualquer até um receptor $i=1, \ldots, I_{j}$, o resíduo absoluto de tempo será dado da seguinte forma,

$$
r_{i j}=t_{o_{i j}}-t_{c_{i j}}
$$

onde $t_{o_{i j}}$ é o tempo de percurso observado e $t_{c_{i j}}$ é o tempo de percurso calculado para o modelo médio da Terra, no nosso caso o IASP91 (Kenneth \& Engdahl 1991). De acordo com a Equação 2.1, atrasos de tempo da fase observada produzirão resíduos absolutos positivos, caso contrário, estes serão negativos.

Os resíduos absolutos possuem grandes contribuições de erro relacionados à fonte e ao percurso das ondas telessísmicas (caminho da fonte ao receptor), os quais são chamados de erros de fonte e percurso, respectivamente (Evans \& Achauer 1993). Como a distância entre a fonte e o receptor é muito grande, estas contribuições podem ser consideradas aproximadamente constantes no segmento final dos raios sísmicos (próximos do arranjo de receptores), e podem ser removidos pela formulação dos resíduos relativos da forma,

$$
r r_{i j}=r_{i j}-r_{r e f_{j}}
$$

onde $r_{r e f_{j}}$ é a média dos resíduos em todas as estações que registraram o mesmo evento $j$. Desta maneira, os resíduos relativos de tempo de percurso podem ser apresentados da seguinte forma, 


$$
r r_{i j}=r_{i j}-\frac{1}{I_{j}} \sum_{i=1}^{I_{j}} r_{i j}
$$

sendo esta a forma final dos dados que serão utilizados nas inversões tomográficas (ver Capítulo 04).

\subsubsection{ObtençÃo dos Resíduos Relativos: Método MCPCC}

Entre os processos envolvidos na edição dos dados, a marcação dos tempos de chegada $t_{o_{i j}}$ para a obtenção dos resíduos relativos é o mais importante e crítico. Nem sempre é possível observar claramente as primeiras quebras nos sismogramas devido à presença de ruído no sinal, o que dificulta a marcação das fases e consequentemente diminui a precisão dos resíduos. Isto pode acarretar erros na base final de dados.

Uma forma de diminuir os erros e inconsistências nos tempos de chegada, é a utilização de métodos numéricos de correlação cruzada durante a pickagem (Evans \& Achauer 1993). O método utilizado neste trabalho é o MCPCC (Multichannel Phase Cross-Correlation) elaborado por Schimmel et al. (2003), que incorpora o método PCC (Phase Cross-Correlation) de Schimmel (1999) ao método MCCC de (VanDecar \& Crosson 1990).

A principal vantagem do método $\mathrm{MCPCC}$ é a não dependência da identificação das primeiras quebras, muitas vezes influenciadas pela presença de ruído no sinal. O método MCPCC determina a similaridade das formas de onda através do maior número de amostras coerentes ao invés de usar a soma de produtos, e sendo assim, permite que não ocorra influência de porções de maior amplitude na janela de correlação.

O método MCPCC utiliza, portanto, a coerência das formas de onda observadas em estações diferentes (no nosso caso, no mínimo 4 estações) relacionadas a um mesmo evento, com ajustes por mínimos quadrados para determinação dos tempos de chegada das fases.

A Figura 2.6 mostra graficamente os passos seguidos para a obtenção dos resíduos relativos. A Figura 2.6A mostra o alinhamento dos traços (não filtrados) pela marca do tempo calculado $\left(t_{c}\right)$, buscando identificar inicialmente as chegadas e principalmente observar a priori a existência de coerência entre as fases. Depois é selecionado um filtro passa-banda adequado para realçar o máximo possível o sinal em todos os traços simultaneamente, e logo em seguida é feita visualmente ${ }^{1}$ uma marca inicial para o tempo observado. Estas marcas serão ajustadas e refeitas pelo programa de correlação. A Figura 2.6B mostra os traços filtrados e alinhados pelo tempo marcado após a correlação $\left(t_{0}\right)$. Durante o processo de marcação do tempo observado,

\footnotetext{
${ }^{1}$ Utilizamos o programa Seismic Analise Code - SAC - para o procedimento de "pickagem".
} 

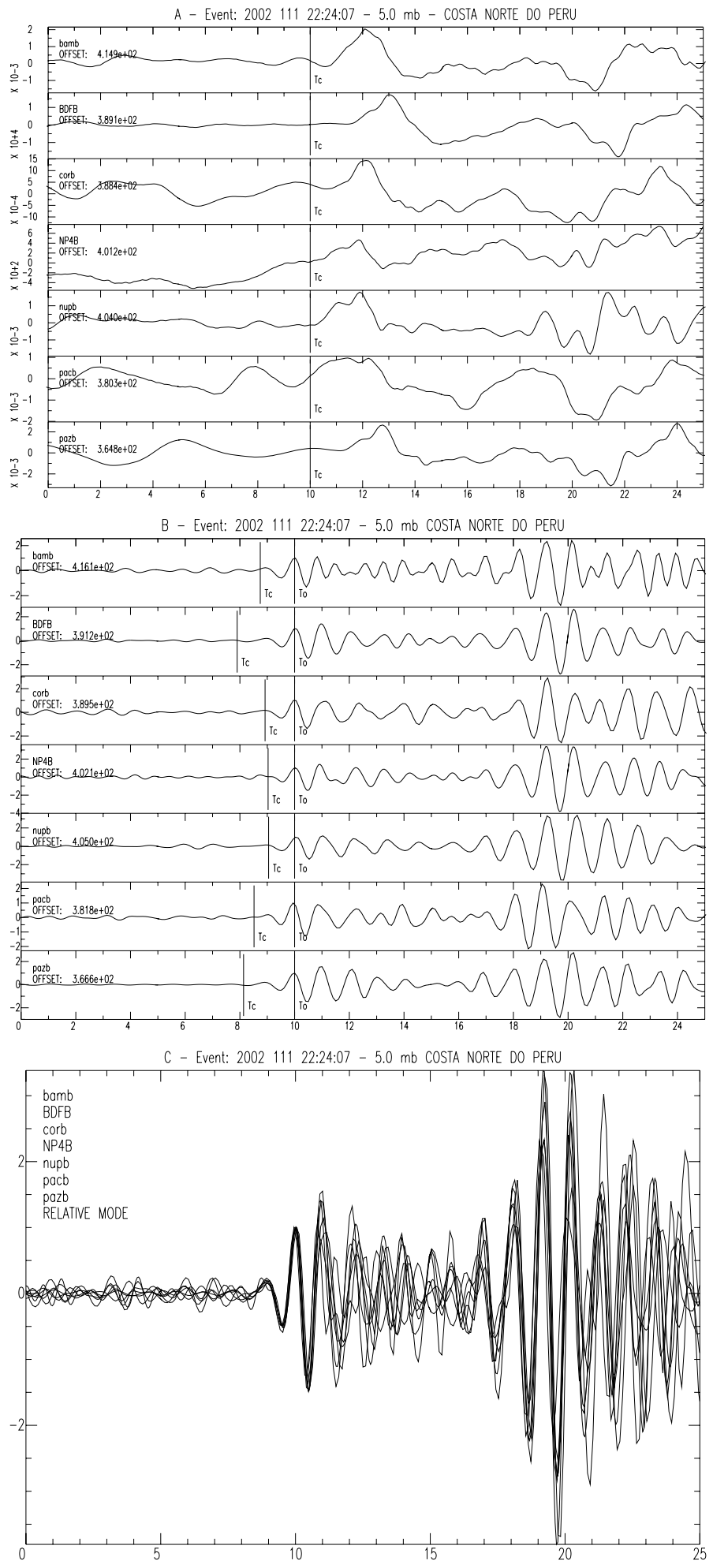

Figura 2.6 - Exemplo dos passos seguidos para obtenção dos resíduos de tempo de percurso utilizando a correlação MCPCC (Schimmel et al. 2003). A) Sismogramas originais alinhados pelo tempo teórico do modelo IASP91. B) Sismogramas filtrados $(0,8$ a $1,6 \mathrm{~Hz})$ alinhados pelos picks resultantes da correlação cruzada. C) Empilhamento dos traços para verificação da qualidade da pickagem. Sismo ocorrido no Norte do Peru em 21/04/2002 com magnitude 5,0 $m_{b}$. 
a correlação muitas vezes é refeita para encontrar um filtro mais adequado. O indicador de qualidade da pickagem está mostrado na Figura 2.6C, onde os traços, filtrados e alinhados pelo tempo observado, são empilhados para observar a coerência dos picos relativos.

\subsection{Seleção dos Eventos}

\subsubsection{FASES Utilizadas}

Os eventos utilizados são fases de onda $\mathrm{P}$ telessísmica. Nós utilizamos a fase $\mathrm{P}$ direta e a fase PKPdf (PKIKP).

Como a obtenção dos resíduos relativos necessita principalmente de clareza nas chegadas, é necessário que sejam utilizados eventos com grande conteúdo de energia, o que permite a observação de chegadas com maiores amplitudes e consequentemente mais evidentes. Por isso, selecionamos eventos com magnitudes superiores a $4,6 m_{b}$ para as fases $\mathrm{P}$ e superiores a $5,4 m_{b}$ para as fases PKPdf.

Para evitar os efeitos relacionados à triplicação e à sobreposição de fases, foram selecionados intervalos de distância angular adequados para cada fase. Para as fases P foram selecionados eventos com distâncias entre $30^{0}$ e $95^{0}$, e para as fases PKPdf, as distâncias ficaram entre $158^{0}$ e $180^{0}$.

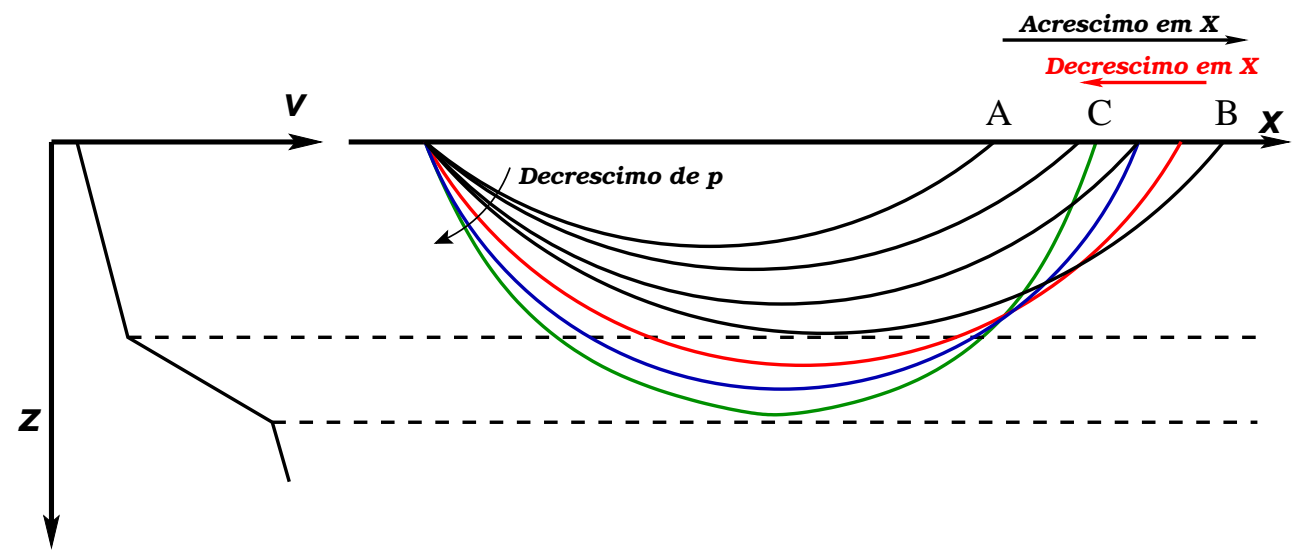

Figura 2.7 - Triplicação de fases causada pelo forte gradiente na velocidade das ondas sísmicas.

A triplicação de fases é resultado do aumento rápido do gradiente de velocidade das ondas sísmicas em algumas profundidades (camadas) no interior da Terra. Isto causa raios sísmicos com diferentes parâmetros de raio chegando em uma mesma estação em tempos aproximadamente iguais. Este efeito é observado nos sismogramas como chegadas muito próximas, ou mesmo sobrepostas, prejudicando a marcação da primeira fase para sismos com estas distâncias. A 
Figura 2.7 ilustra o percurso feito pelos raios refratados nas zonas de alto gradiente e dificultando a identificação do percurso correto.

As zonas de aumento do gradiente de velocidade ocorrem a aproximadamente 410 e 650 kilometros de profundidade, e provavelmente representam transformações nas fases mineralógicas das rochas do manto, influenciando chegadas que ocorrem entre 20 e 30 graus de distância aproximadamente. A Figura 2.8 mostra o gráfico de tempo de percurso pela distância, e o efeito do forte gradiente de velocidade que gera a triplicação de fases.

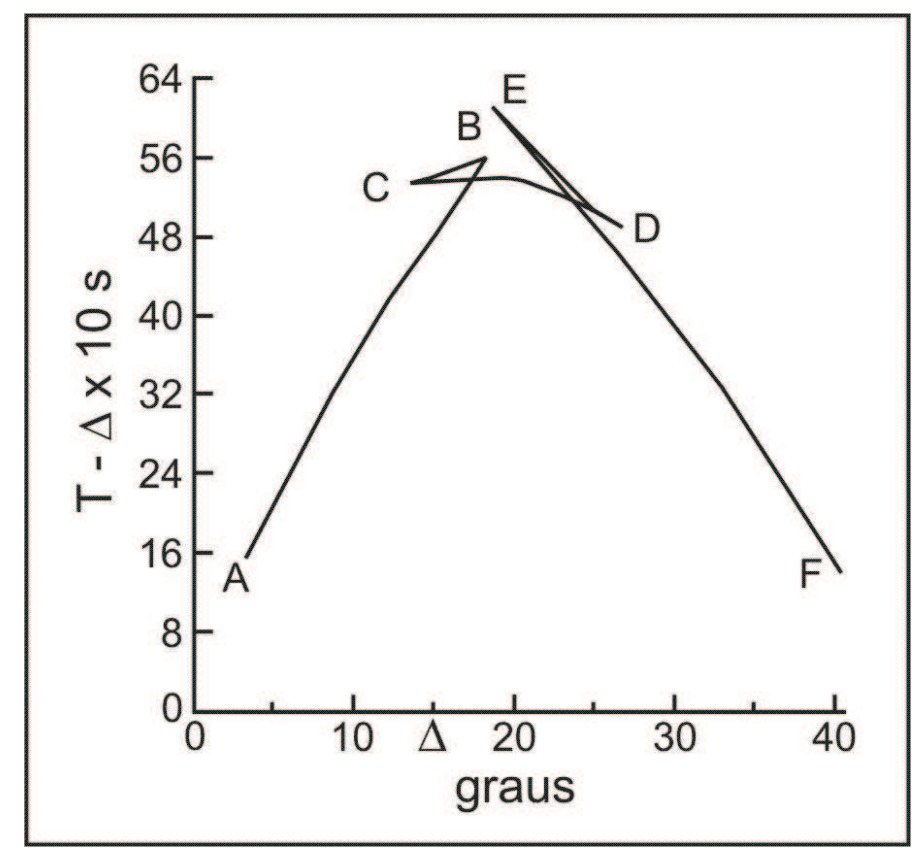

Figura 2.8 - Curva do tempo de percurso, mostrando as triplicações de fase resultantes do abrupto aumento da velocidade das ondas sísmicas nas profundidades de $410 \mathrm{~km}$ (de $15^{0}$ à $17^{0}$ aproximadamente) e $660 \mathrm{~km}$ (de $17^{0}$ a $27^{0}$ aproximadamente) - Fonte: Lay \& Wallace (1995). 


\section{Capítulo 3}

\section{DAdOS: CONSISTÊNCIA}

Para dar uma maior credibilidade aos resultados finais da tomografia sísmica, são necessários testes de consistência na base de dados que gerou estes resultados. Estes testes visam comparar o comportamento (estatístico ou não) dos registros de diversas estações do arranjo.

Neste capítulo serão mostrados os resultados dos testes feitos para a base como um todo, e para cada estação individualmente.

\subsection{Estatísticas das Observações}

Nossos dados seguem uma distribuição aproximadamente normal, por isso podemos fazer algumas análises comparando esta distribuição a uma função de Gauss correspondente, obtendo estimativas do desvio padrão de toda a base ou de parte dela. Este procedimento foi feito antes da inversão para observar os dados inconsistentes (outliers) que prejudicam a qualidade dos resultados finais, já que na inversão por mínimos quadrados (Capítulo 4) estes recebem maiores pesos. A inversão de dados com erros muito grandes gera instabilidade nas reconstruções tomográficas, e desta maneira, com base nestas análises, a base de dados foi depurada.

A Figura 3.1 mostra o histograma dos resíduos relativos de tempo de percurso das fases $\mathrm{P}$ (em roxo) e PKPdf (em rosa) para a base de dados depurada. Antes da depuração o desvio padrão era $\sigma=5,560$ s e após caiu para $\sigma=0,418 \mathrm{~s}$. Foram retirados 211 raios, dos quais alguns diretamente devido a inconsistências e outros por consequência da retirada destes (após a retirada de um ou mais raios com erros, para um mesmo evento podem sobrar menos que quatro raios, que é o mínimo para uma boa determinação das chegadas - Capítulo 2).

Foram feitos também histogramas para algumas estações (Figuras 3.2 à 3.19 ) localizadas em regiões importantes para a interpretação dos resultados. As informações contidas em todos os histogramas apresentados neste capítulo estão reunidas na Tabela 3.1. De uma forma geral o rms para cada estação possui valor em torno de 0,4s (aproximadamente o rms para a base total depurada), com algumas exceções. 


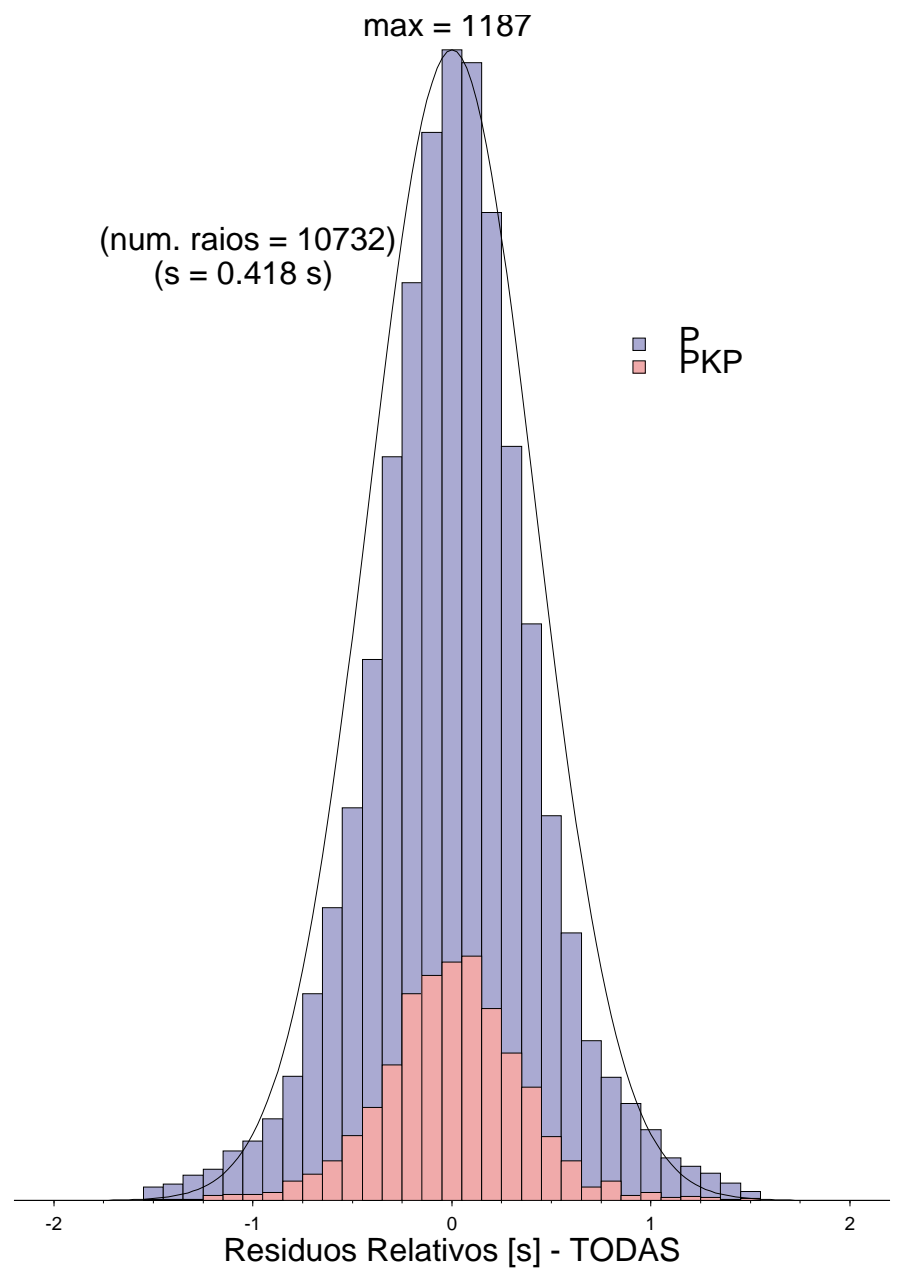

FigURA 3.1 - Histograma e distribuição gaussiana dos resíduos relativos de tempo de percurso para toda a base de dados (incluindo todas as estações).

Nas Figuras 3.2 até 3.9 são mostrados os histogramas para as estações instaladas na região de Iporá em Goiás. Para algumas estações deste grupo (corb, slmb - Figuras 3.3 e 3.9 respectivamente) podemos observar que existe uma tendência dos resíduos relativos serem negativos. Isto sugere que abaixo destas estações, na média, os raios chegam antes do tempo esperado (tempo teórico), ou seja, existem anomalias positivas de velocidade. Para as estações gnsb e pazb (Figuras 3.5 e 3.6) no entanto, as médias são positivas mostrando uma tendência da região abaixo desta estação ser de baixa velocidade (anomalia de Iporá - GO).

Neste mesmo grupo, as estações BDFB e porb (Figuras 3.2 e 3.7) parecem não possuir nenhuma tendência para a média dos resíduos relativos, ficando estes em torno de zero. Consequentemente para estas estações a média das anomalias de velocidade abaixo delas deve ser próxima de zero. Para as estações cv1b e pp1b (Figuras 3.4 e 3.8) não é possível se tirar nenhuma conclusão definitiva devido à pouca quantidade de dados. Estas estações até o momento do processamento possuiam pouco tempo de operação. 
TABELA 3.1 - Informações sobre as estações mostradas nos histogramas. O n. ${ }^{0}$ max. de raios é o valor do pico do histograma, isto é, número de raios com resíduos próximos de zero

\begin{tabular}{|ccccc|}
\hline Estações & $\begin{array}{c}\text { rms } \\
\text { (seg.) }\end{array}$ & $\begin{array}{c}\text { média } \\
\text { (seg.) }\end{array}$ & $n{ }^{0}$ raios & $n .^{0}$ max.raios \\
\hline BDFB & 0,403 & 0,041 & 1013 & 110 \\
CAM3 & 0,432 & 0,020 & 52 & 09 \\
CAM4 & 0,496 & 0,071 & 56 & 08 \\
CORB & 0,400 & $-0,215$ & 585 & 79 \\
CV1B & 0,450 & 0,037 & 64 & 10 \\
GNSB & 0,352 & 0,153 & 260 & 43 \\
IGPB & 0,415 & 0,011 & 260 & 36 \\
ITPB & 0,508 & $-0,038$ & 74 & 10 \\
MAN1 & 0,510 & 0,183 & 22 & 05 \\
MAN2 & 0,615 & 0,340 & 78 & 06 \\
MIR1 & 0,445 & $-0,265$ & 148 & 23 \\
NP4B & 0,434 & $-0,102$ & 324 & 42 \\
PAZB & 0,372 & 0,105 & 443 & 60 \\
PDCB & 0,514 & $-0,235$ & 65 & 09 \\
PORB & 0,394 & $-0,092$ & 306 & 40 \\
PP1B & 0,515 & $-0,113$ & 94 & 12 \\
SLMB & 0,413 & $-0,068$ & 276 & 41 \\
VAO & 0,383 & 0,069 & 84 & 14 \\
Todas & 0,418 & $-6,7089 \times 10^{-9}$ & 10732 & 1187 \\
\hline
\end{tabular}

Em outro agrupamento, os histogramas para as estações MIR1 e NP4B (Figuras 3.11 e 3.12), possuem muitos dados e encontram-se localizadas em regiões próximas. Observamos uma tendência negativa para os resíduos destas estações, principalmente MIR1, indicando abaixo destas estações regiões de maior velocidade. No entanto, a estação IGPB (Figura 3.10) possui média de resíduos positivos, ou seja, está sobre uma região de velocidades negativas, o que poderá ser observado nos resultados finais (ver Capítulo 5). As estações MAN1 e MAN2 (Figuras 3.13 e 3.14) possuem poucos dados, no entanto podemos observar (principalmente para MAN2) uma tendência positiva dos resíduos, indicando que estas estações estão sobre uma região de baixa velocidade. A estação MAN2, tem uma variação muito maior dos dados ( $\mathrm{rms}=0,615$ ) o que pode indicar problemas de tempo na estação. Devido à pouca quantidade de dados nesta região, ainda são necessários mais estudos para obter uma maior confiança nos resultados observados.

As estações cam3, cam4 e vao1 (Figuras 3.15, 3.16 e 3.17) não possuem grandes variações, e as estações itpb e pdcb (Figuras 3.18 e 3.19) não possuem dados suficientes para conclusões significativas, apesar de pdcb possuir uma média muito negativa. As estações MAN1, MAN2, pp1b, pdcb e itpb possuem desvio padrão dos dados acima do desvio de todas as estações (Tabela 3.1). Isto pode indicar problemas de controle de tempo ou então uma maior variabilidade das estruturas abaixo destas estações. 


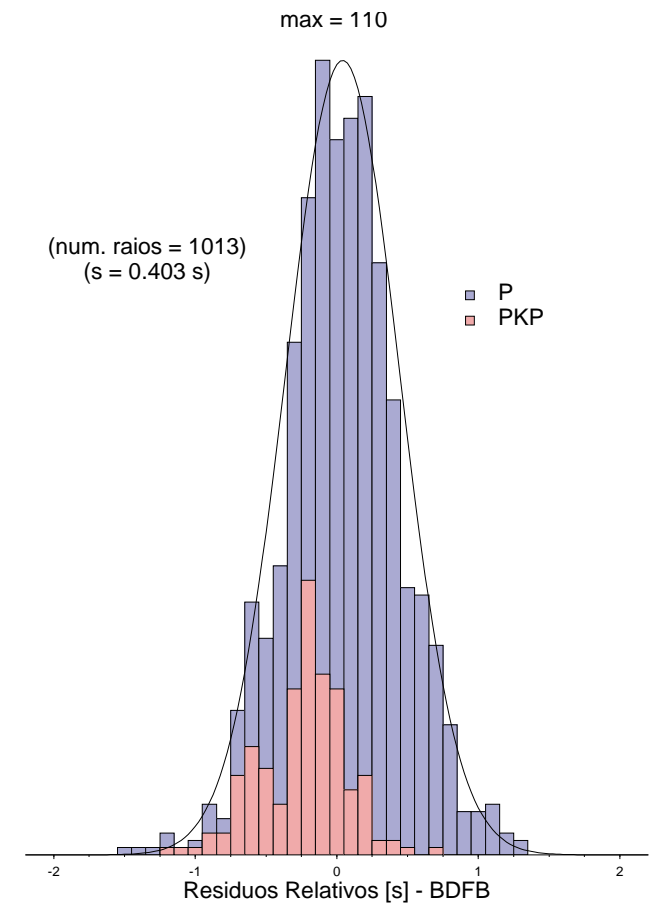

Figura 3.2 - Histograma para os resíduos de tempo relativos da estação BDFB.

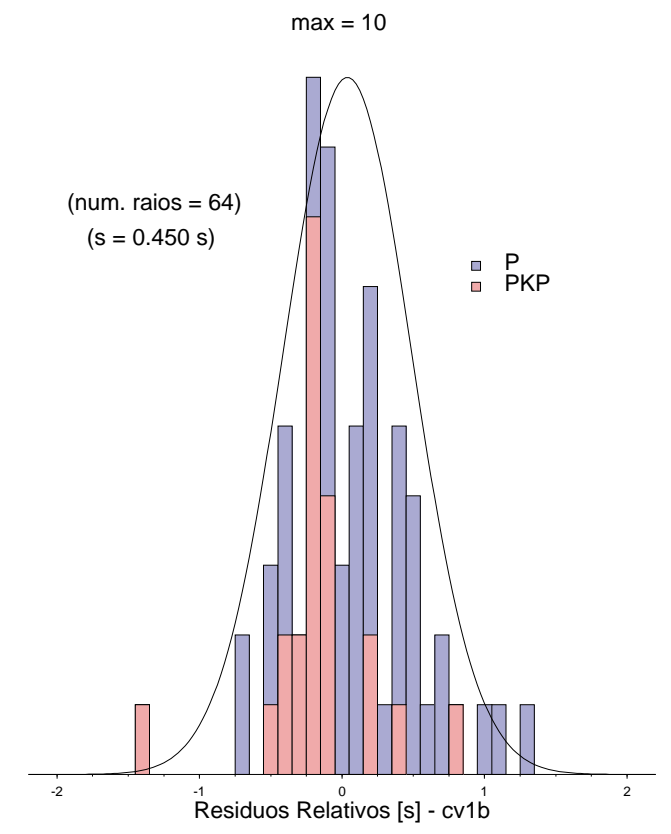

FiguRA 3.4 - Histograma para os resíduos de tempo relativos da estação cv1b.

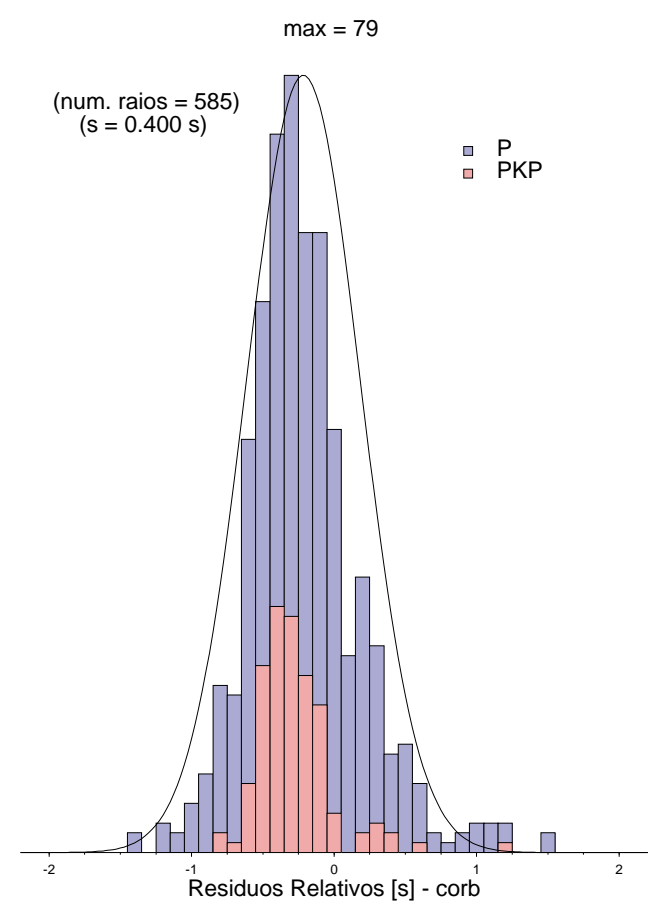

FigurA 3.3 - Histograma para os resíduos de tempo relativos da estação corb.

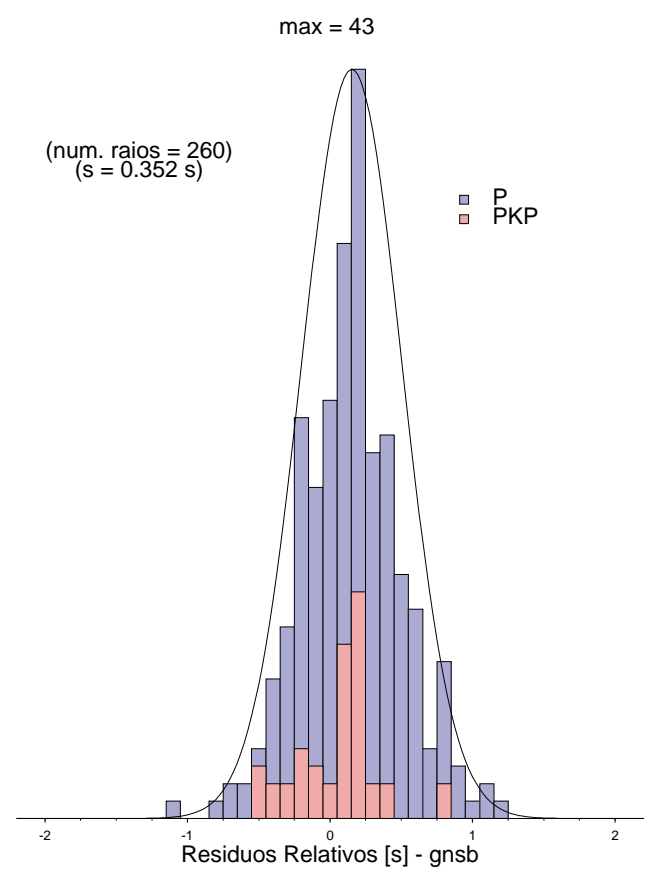

FiguRA 3.5 - Histograma para os resíduos de tempo relativos da estação gnsb. 
$\max =60$

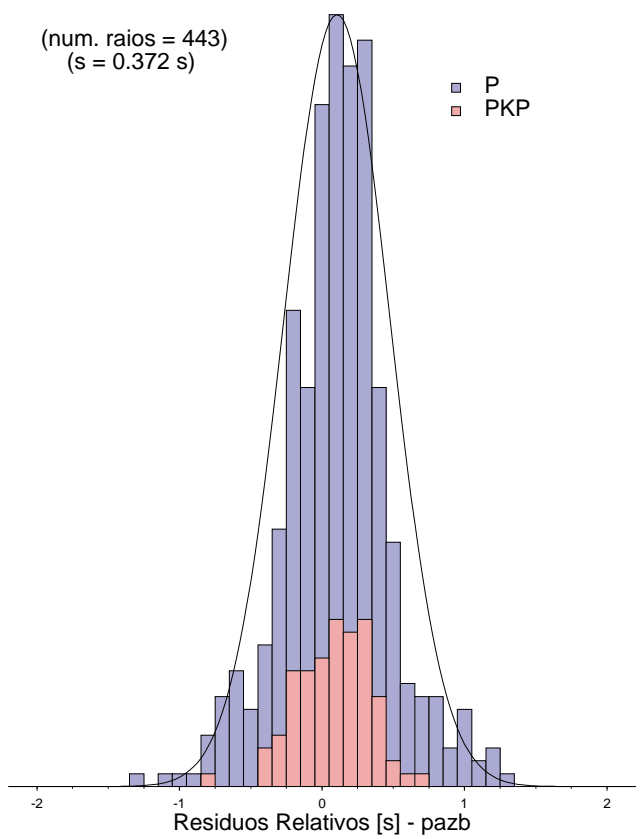

FigurA 3.6 - Histograma para os resíduos de tempo relativos da estação pazb.

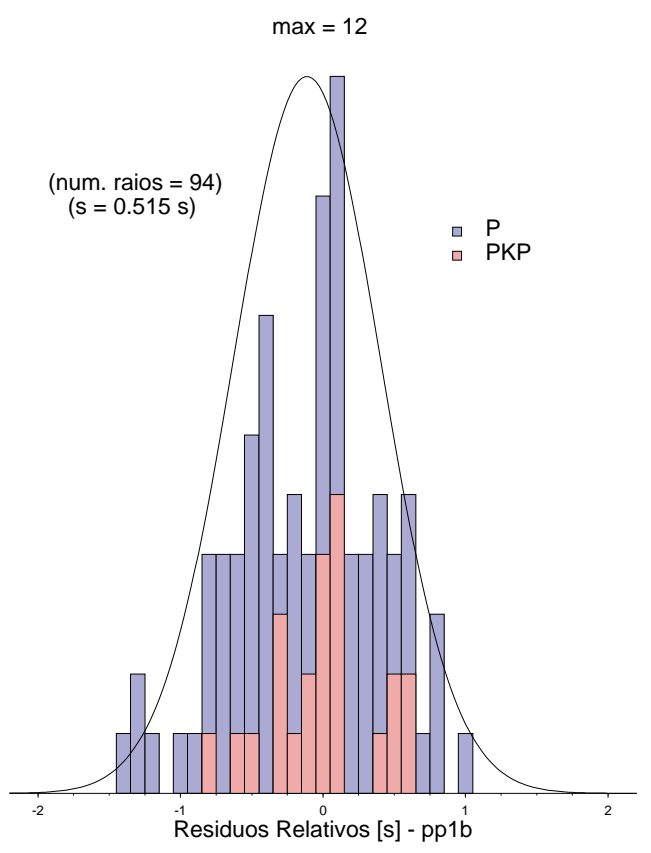

FigurA 3.8 - Histograma para os resíduos de tempo relativos da estação pp1b. $\max =40$

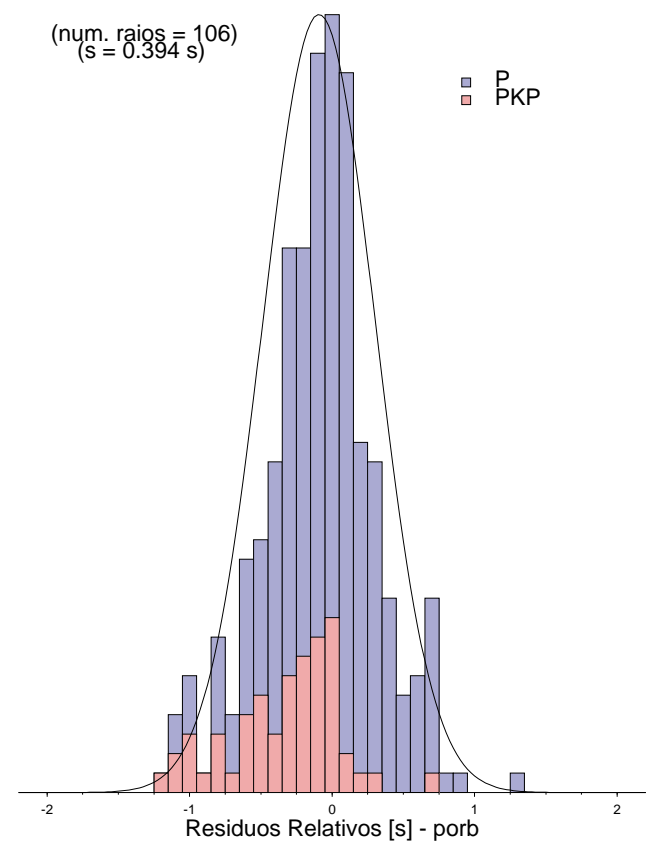

Figura 3.7 - Histograma para os resíduos de tempo relativos da estação porb.

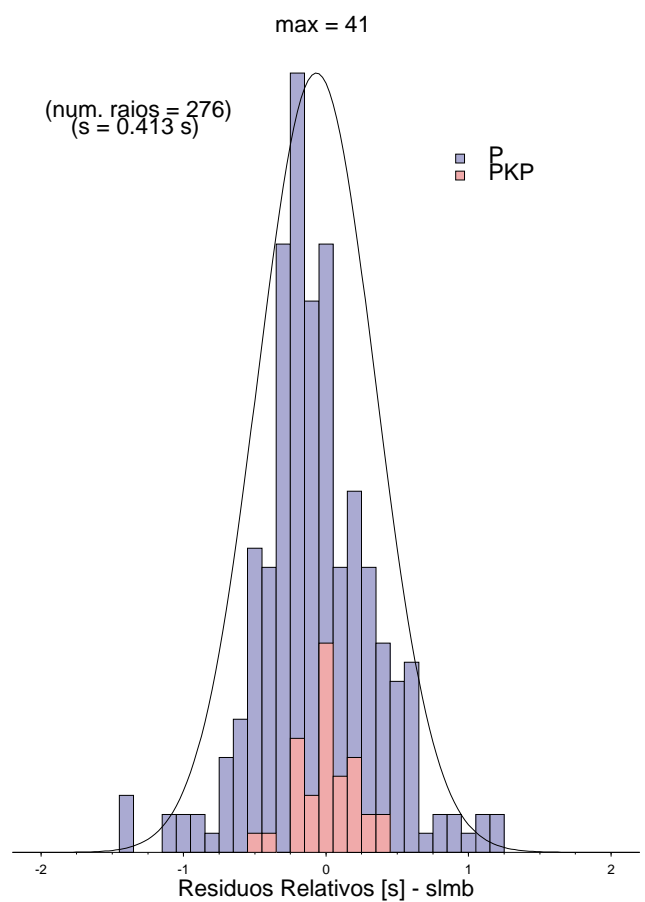

Figura 3.9 - Histograma para os resíduos de tempo relativos da estação slmb. 


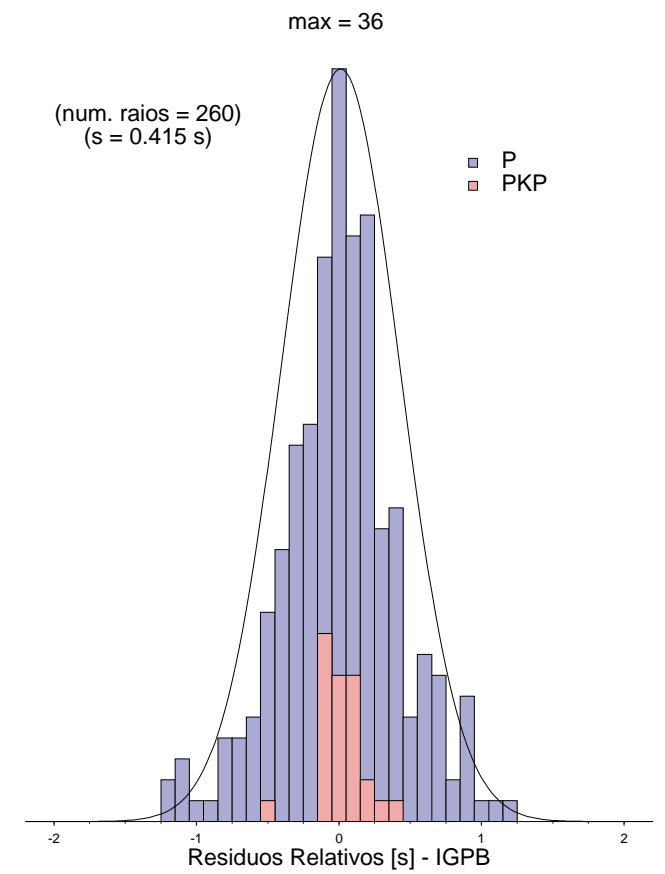

FiguRA 3.10 - Histograma para os resíduos de tempo relativos da estação IGPB.

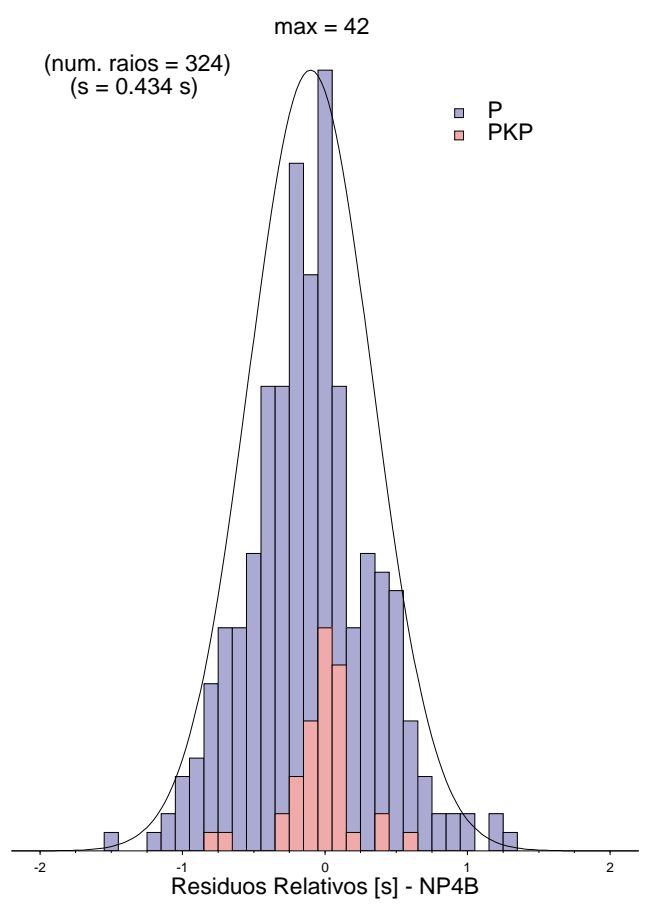

FigurA 3.12 - Histograma para os resíduos de tempo relativos da estação NP4B.

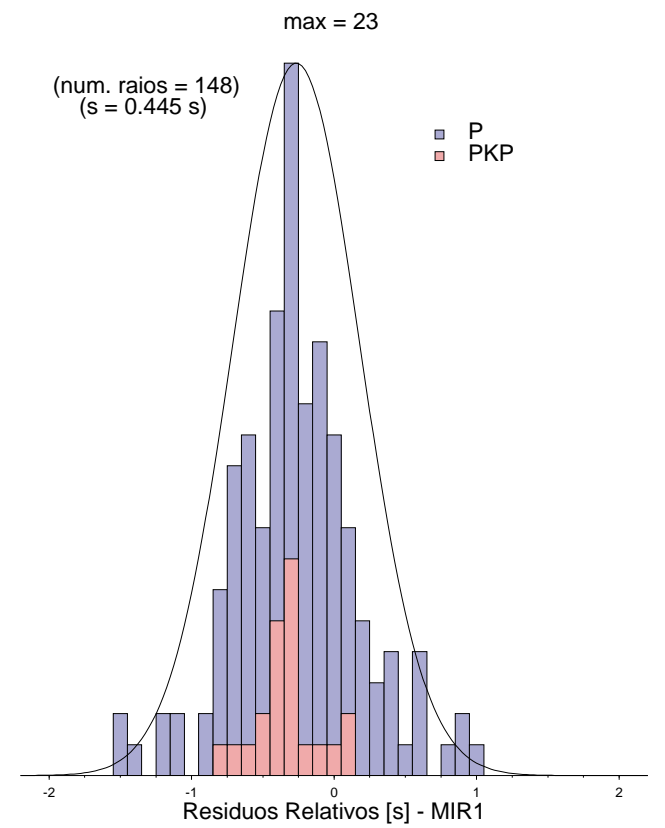

Figura 3.11 - Histograma para os resíduos de tempo relativos da estação MIR1.

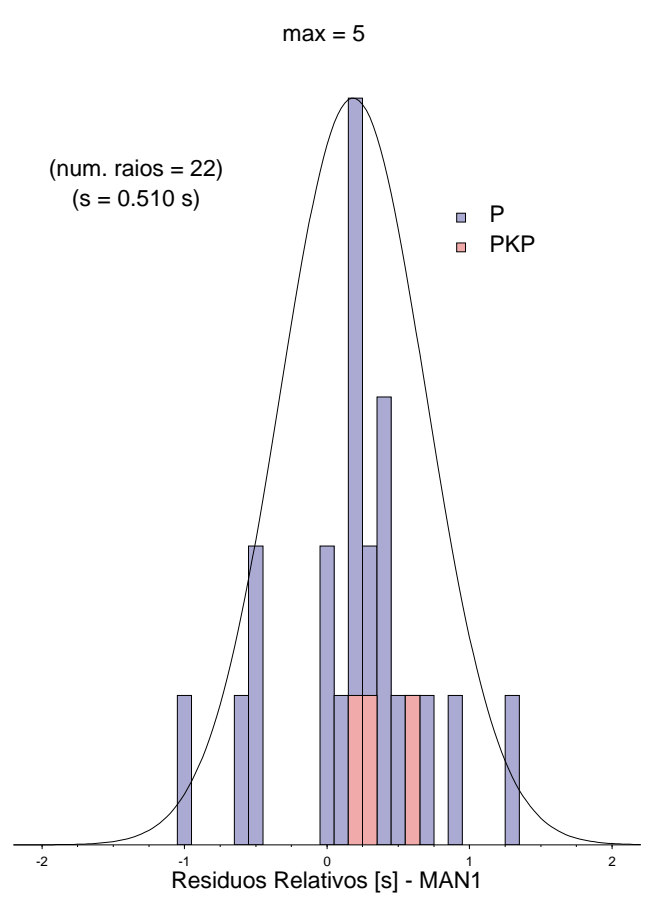

Figura 3.13 - Histograma para os resíduos de tempo relativos da estação MAN1. 


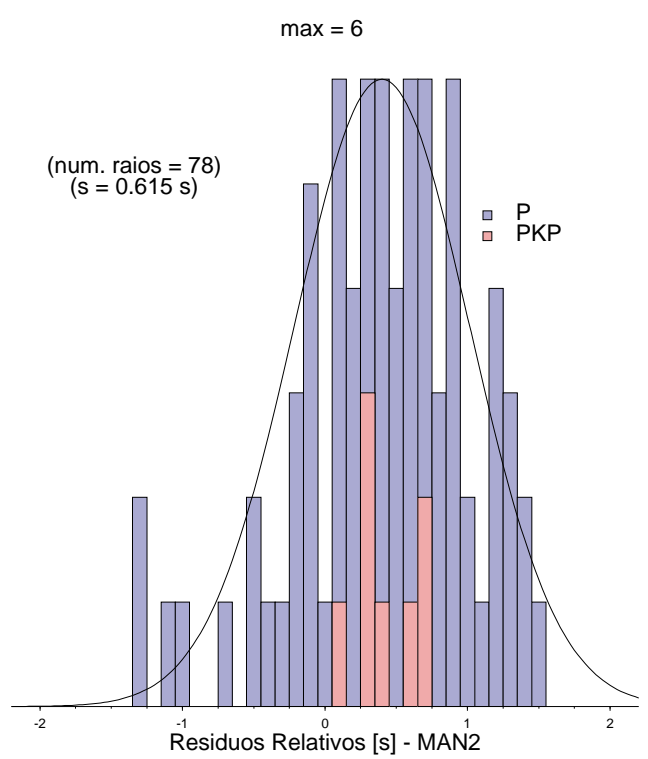

FigurA 3.14 - Histograma para os resíduos de tempo relativos da estação MAN2.

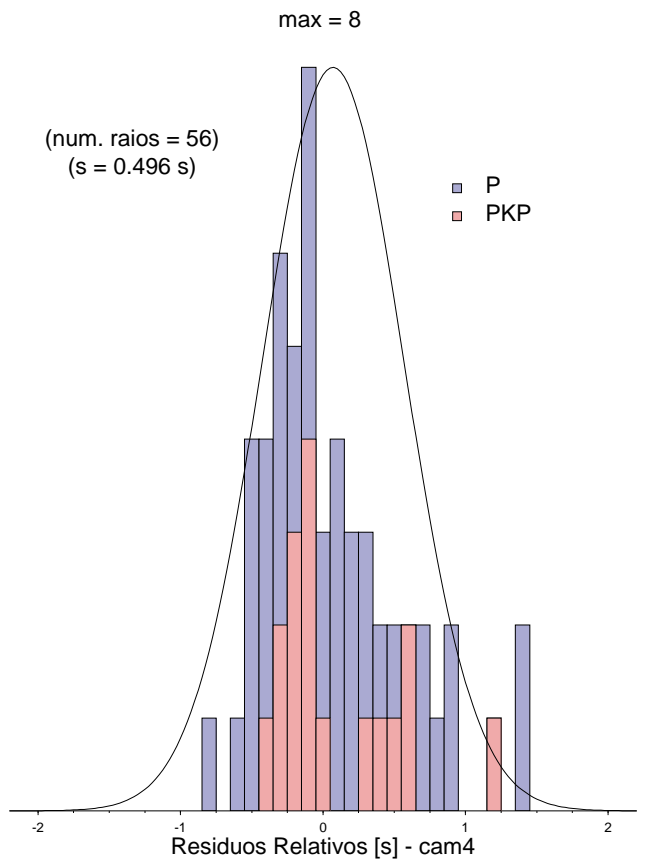

FigurA 3.16 - Histograma para os resíduos de tempo relativos da estação cam4.

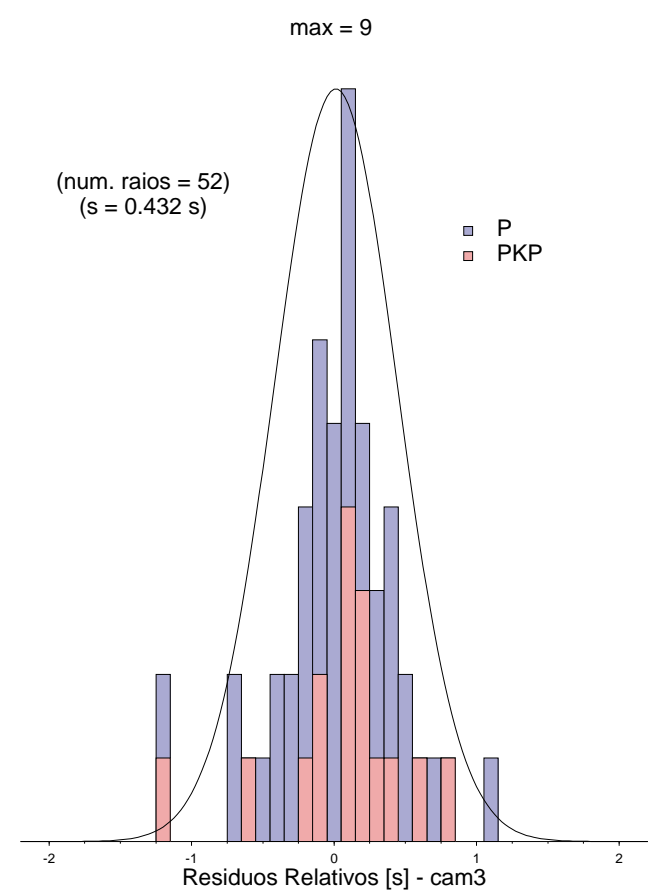

Figura 3.15 - Histograma para os resíduos de tempo relativos da estação cam3.

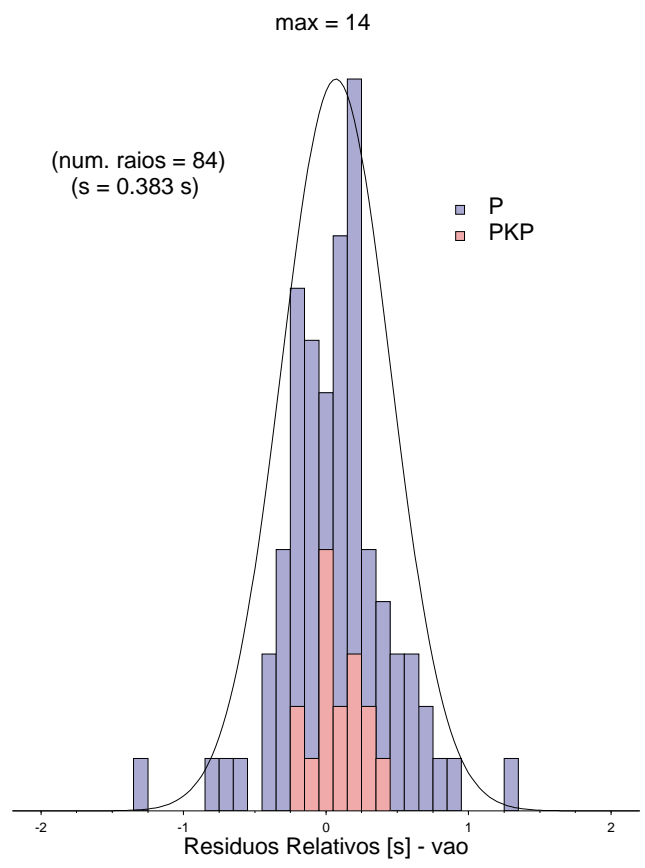

Figura 3.17 - Histograma para os resíduos de tempo relativos da estação vao1. 


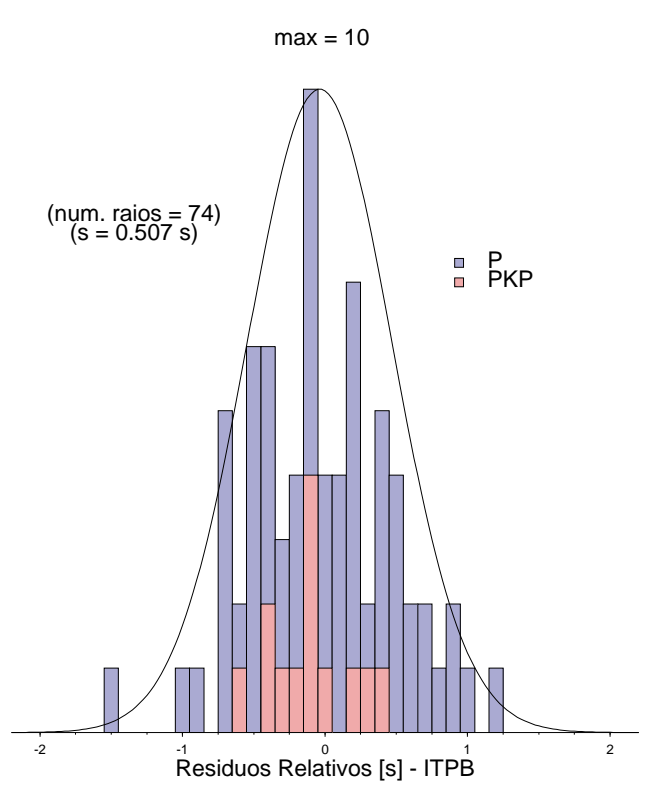

FigurA 3.18 - Histograma para os resíduos de tempo relativos da estação itpb.

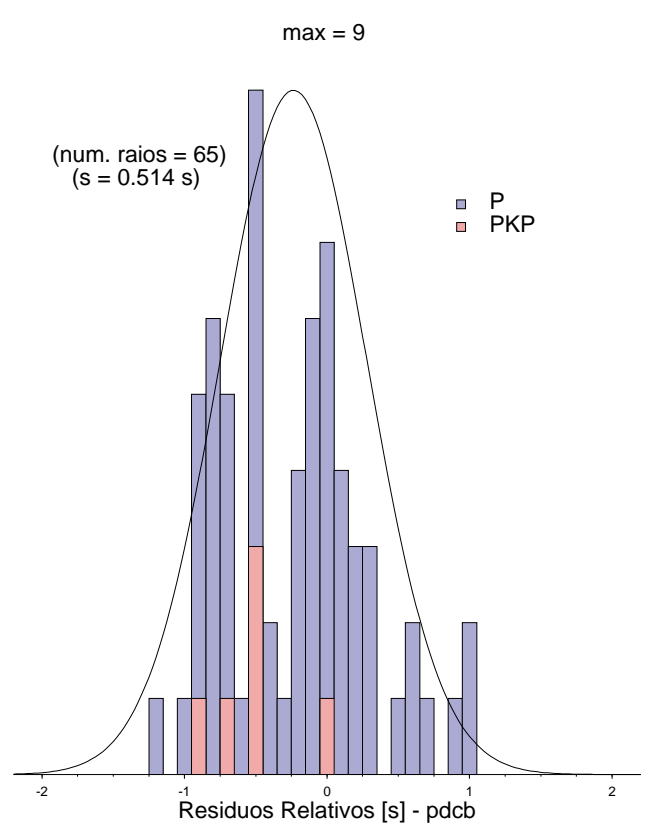

Figura 3.19 - Histograma para os resíduos de tempo relativos da estação pdcb.

\subsection{Análises Comparativas}

Para duas ou mais estações próximas, espera-se que os tempos de percurso das ondas sísmicas (representados pelos resíduos relativos), vindas de uma mesma direção sejam semelhantes, principalmente se estas estações estiverem operando simultaneamente (Rocha \& Assumpção 2003).

A Figura 3.20 mostra a comparação dos resíduos relativos entre as estações IGPB e rifb, localizadas muito próximas e distanciadas de $23 \mathrm{~km}$.

Podemos observar uma boa correlação entre os resíduos médios das duas estações, tanto para fases P como para PKPdf, o que indica que o banco de dados tem informações estruturais de larga escala. Existem algumas diferenças, mas na média o teste demonstra uma boa correlação entre os dados destas estações. Observa-se também que o erro é maior para as fases $\mathrm{P}$ do que para as fases PKPdf. Isto pode ser explicado pelo maior intervalo de distância angular em um mesmo azimute para as fases $\mathrm{P}$, as quais possuem maiores ângulos de incidência, e uma maior variação deste ângulo para sismos vindos de uma mesma direção (Figura 3.21). As fases PKPdf, por sua vez, chegam praticamente na vertical, com uma variação bem menor da incidência. 
A distribuição residual mostrada na Figura 3.20 é baseada na média de todos os resíduos para raios vindos de uma mesma direção (azimute), e sendo assim, a maior variação do ângulo de incidência para as fases $\mathrm{P}$ causa o maior desvio padrão observado.

Podemos observar ainda na Figura 3.20 um erro muito maior para as fases P da estação IGPB do que para a estação rifb. A estação IGPB possui diferenças no procedimento de instalação em relação à estação rifb, pois seus sensores não foram enterrados, deixando-a mais sensível a ruídos ambientais. Isto poderia explicar a maior variação média dos resíduos relativos da fase $\mathrm{P}$ para a estação IGPB, embora a variação da PKPdf seja pequena.

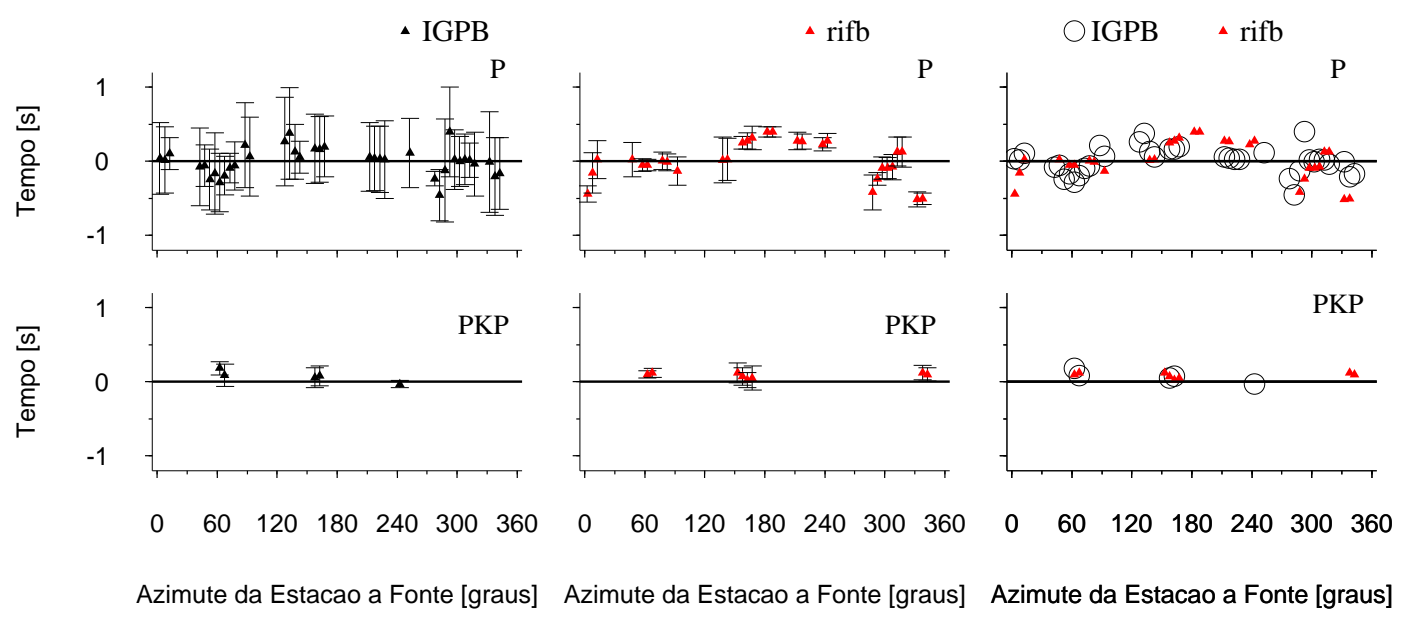

FIGURA 3.20 - Comparação da média dos resíduos relativos pelo back azimuth, entre as estações IGPB (UnB; Igarapava - MG; Lat. -20,0000 e Long. -47,7100) e rifb (BLSP; Rifaina - SP; Lat. -20,0737 e Long. -47,5019).

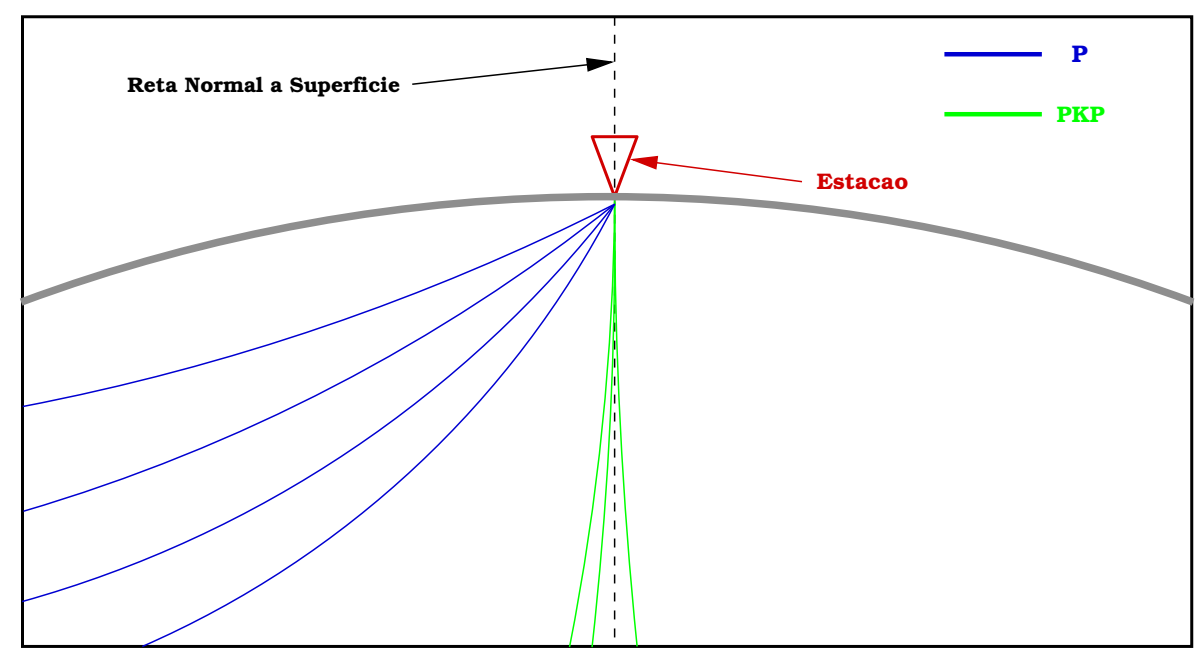

Figura 3.21 - Fases P e PKPdf chegando a uma estação sísmica qualquer, dando uma idéia da diferença entre os ângulos de incidência destas fases em relação à reta normal.

A Figura 3.22 compara os resíduos das estações pacb e popb, distanciadas de $188 \mathrm{~km}$. 
Observamos o mesmo comportamento descrito no caso anterior, porém a estação popb possui um ligeiro aumento dos rms médios dos resíduos para as fases PKP, o que pode ser explicado como erros de leitura das chegadas devido a ruídos causados por problemas nesta estação.

Foram feitas comparações dos resíduos para três estações na borda do Cráton do São Fransisco. A Figura 3.23 mostra a comparação entre as estações bamb, frmb e furb. Estas estações encontram-se distanciadas entre si da seguinte forma:

\begin{tabular}{|c|c|c|}
\hline bamb & frmb & $64 \mathrm{~km}$ \\
\hline bamb & furb & $75 \mathrm{~km}$ \\
\hline furb & frmb & $70 \mathrm{~km}$ \\
\hline
\end{tabular}

Podemos observar uma boa correlação entre os dados destas estações, mesmo a estação bamb não tendo funcionado simultaneamente com as outras duas. Os dados de furb e frmb têm uma distribuição mais coerente. Estas duas estações operaram juntas em 1993. A estação bamb é mais recente e pode estar registrando eventos de distâncias diferentes, o que ajudaria a explicar a correlação inferior com o padrão das outras duas. Esta estação tem uma tendência a ser ruidosa, já que foi instalada próximo a uma estrada. Isto pode ocasionar dificuldades na visualização das chegadas e consequentemente erros nas leituras, explicando o ligeiro aumento dos erros médios para esta estação.

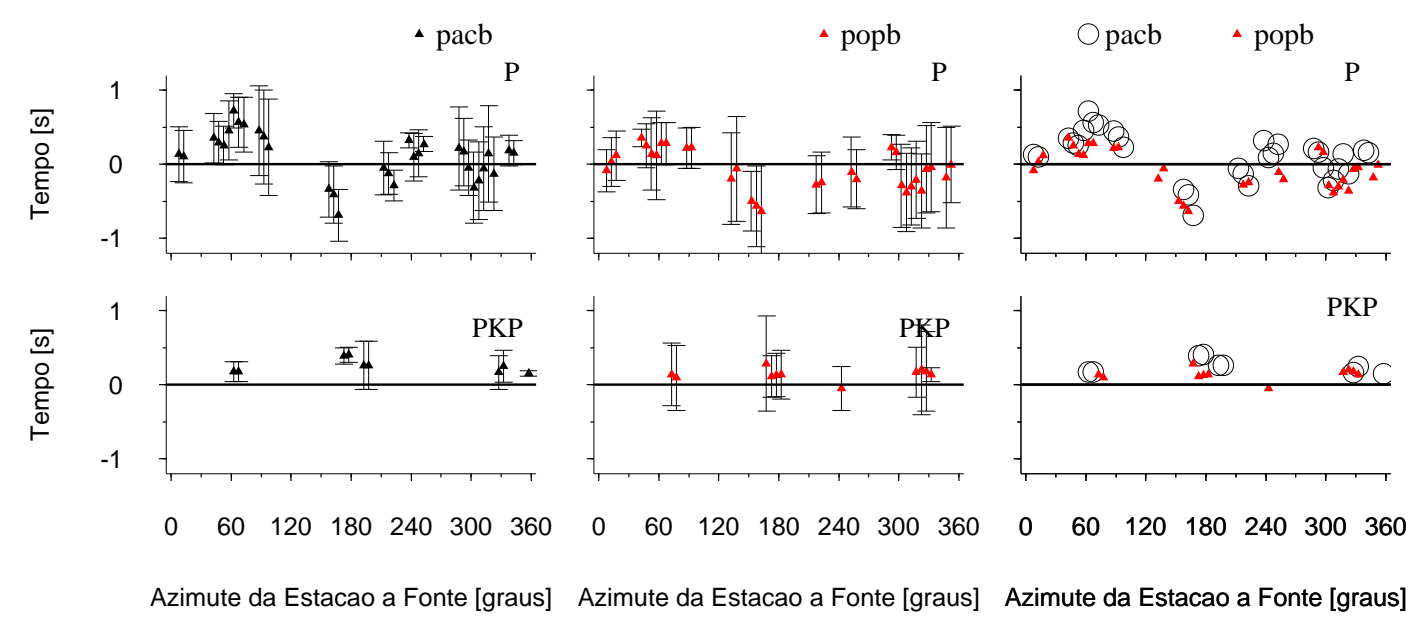

FIgURA 3.22 - Comparação da média dos resíduos relativos pelo back azimuth, entre as estações pacb (BLSP; Pacaembú - SP; Lat. -21.6074 e Long. -51.2618) e popb (BLSP; Porto Primavera - PR; Lat. -22,4564 e Long. -52,8367).

Outro teste foi feito para as estações localizadas na região de Iporá, onde foi inferida uma grande anomalia de baixa velocidade por Escalante (2002). A Figura 3.24 mostra a comparação entre os resíduos relativos para as estações gns (gnsa e gnsb), paz (paz4 e pazb) e slmb. Estas estações estão distanciadas da seguinte maneira: 


\begin{tabular}{|c|c|c|}
\hline gnsb & pazb & $\rightarrow 191 \mathrm{~km}$ \\
\hline gnsb & $\operatorname{slmb}$ & $197 \mathrm{~km}$ \\
\hline slmb & pazb & $\rightarrow 168 \mathrm{~km}$ \\
\hline
\end{tabular}

A distribuição dos dados das três estações é diferente, especialmente para a fase P. Para a fase PKPdf há uma ligeira correlação. Apenas para a direção $270^{0}$ a $330^{\circ}$, as três estações mostram resíduos relativos parecidos. Para outras direções os comportamentos são distintos. Os raios vindos das direções entre $270^{\circ}$ e $330^{0}$ são originados nas regiões andinas, onde existe uma grande quantidade de eventos.
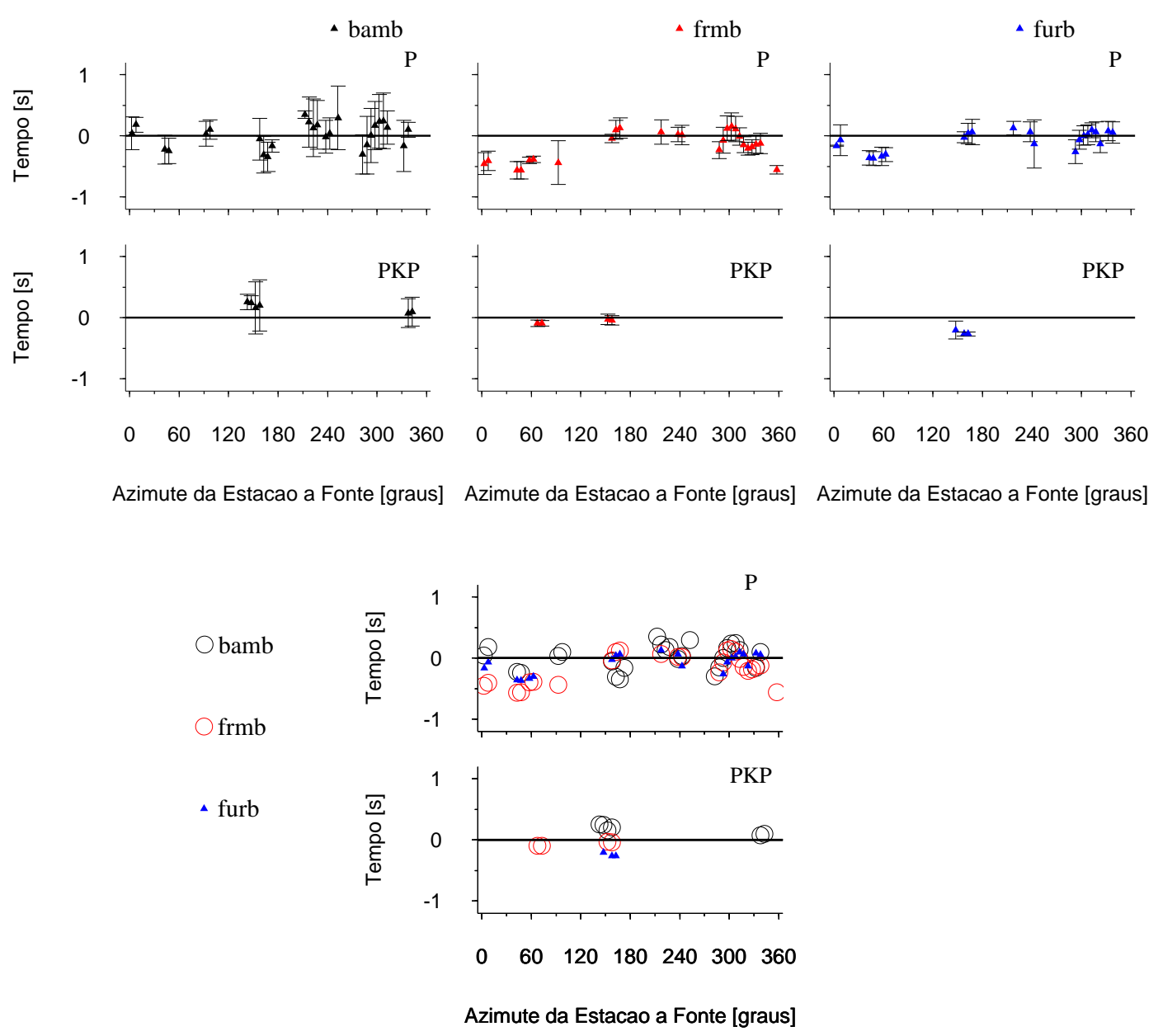

FIgURA 3.23 - Comparação da média dos resíduos relativos pelo back azimuth, entre as estações bamb (BLSP; Bambuí- MG; Lat. -20.0398 e Long. -46.0308), frmb (BLSP; Formiga - MG; Lat. -20.4876 e Long. -45.6389) e furb (BLSP; Furnas - MG; Lat. -20.6782 e Long. -46.2779). 

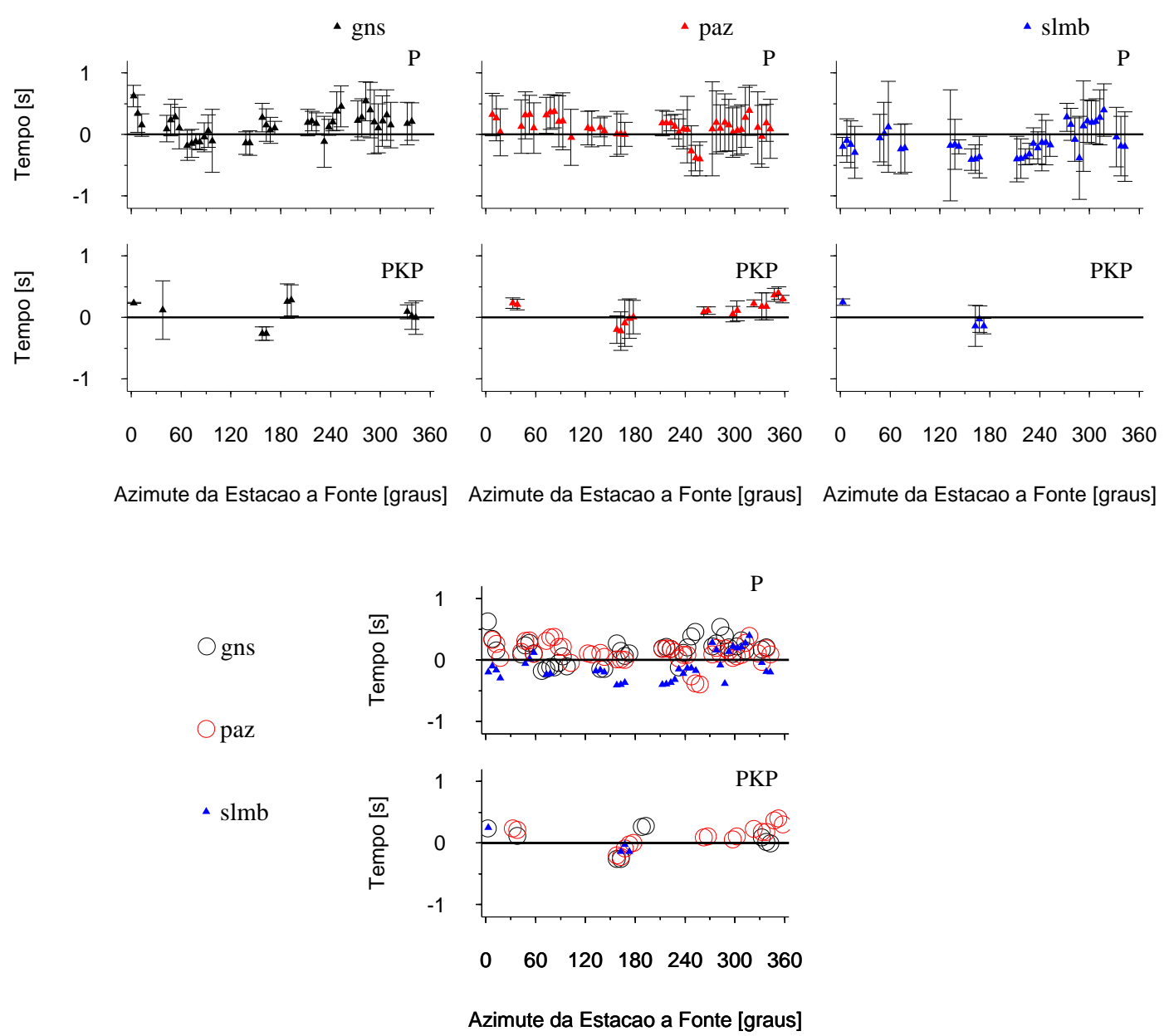

FiguRA 3.24 - Comparação da média dos resíduos relativos pelo back azimuth, entre as estações gns - gnsa/gnsb (BLSP; Goianésia - GO; Lat. -15.2644 e Long. -15.2644), paz - paz4/pazb (BLSP; Araguapaz - GO; Lat. -15.1369 e Long. -50.8634) e slmb (BLSP; São Luis dos Montes Belos - GO; Lat. -16.5705 e Long. -50.3455).

A Figura 3.25 mostra a comparação entre os resíduos relativos para uma mesma estação (BDFB) em períodos diferentes. Os gráficos mostram a distribuição da média dos resíduos relativos em relação ao azimute, para o período de 1992-1999 (BDFB-9) com dados processados por Schimmel et al. (2003) e para o período de 2000-2002 (BDFB-0), com dados processados por Escalante (2002) e neste trabalho.

Na Figura 3.25 observa-se que para as fases PKPdf do período BDFB-0 o desvio padrão médio dos resíduos é muito maior do que para o período BDFB-9, o que pode ser explicado também por problemas durante a leitura das chegadas. Os maiores desvios padrão BDFB-0 sugerem que pode ter ocorrido mais erros de leitura dos sismogramas durante este período do que para BDFB-9. Alternativamente a maior dispersão pode ser devido ao maior número médio de estações no período mais recente. De qualquer maneira o padrão é bastante parecido para os dois períodos. Para a fase P, observa-se média próximo de zero até $180^{0}$, negativa para SW e positiva para NW. 
Testes desta natureza ajudam não só a observar possíveis problemas com as estações, mas ainda inconsistências na determinação dos tempos relativos.

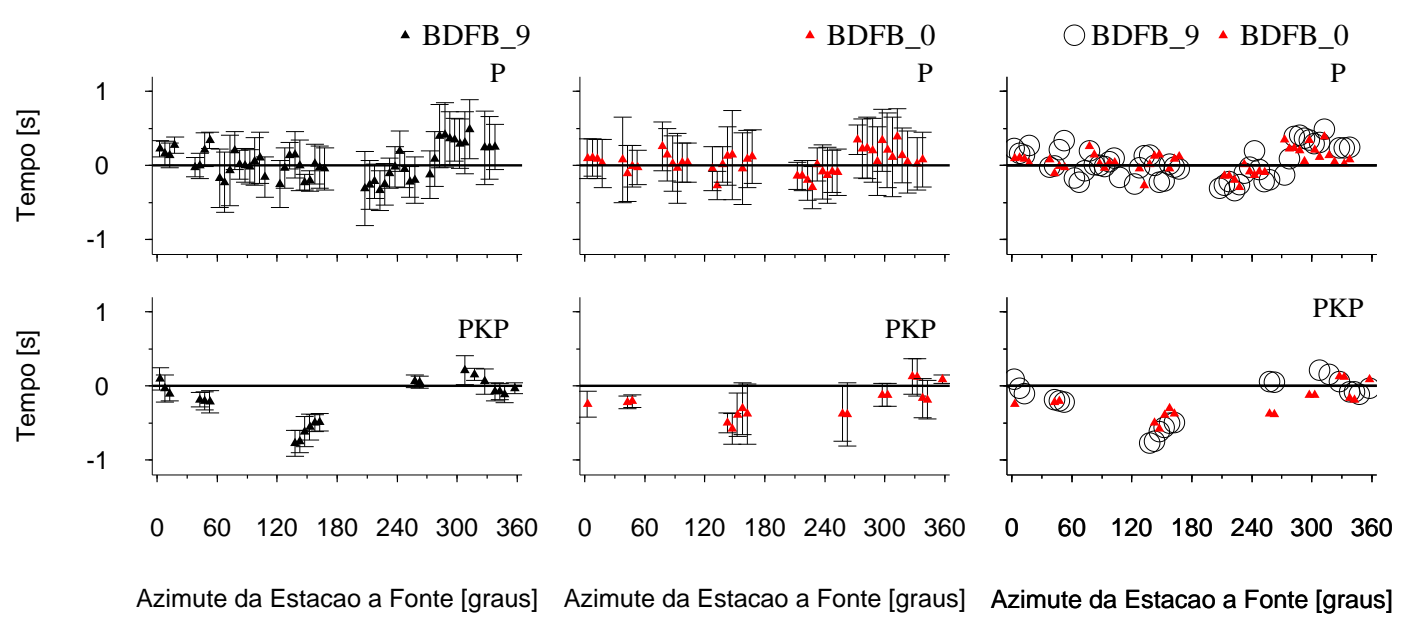

Figura 3.25 - Comparação dos resíduos relativos para dois períodos de operação da estação BDFB (GTSN; Brasília, DF; Lat. -15,6418 e Long. -48,0148). BDFB-9 mostra dados no período 1992-1999 e BDFB-0 mostra dados no período 2000-2002 . 


\section{CAPÍtulo 4}

\section{INVERSÃO DOS DADOS}

Neste capítulo serão abordados alguns conceitos sobre a teoria da inversão. Serão mostradas as principais características do método utilizado neste trabalho, como os critérios de minimização da função objetivo e da linearização do problema inverso. Também serão discutidos alguns detalhes acerca da grade do modelo e da técnica utilizada para sua parametrização. Ainda serão mostrados alguns exemplos para ilustrar a evolução da minimização durante a inversão dos dados e as diferenças entre os resultados com diferentes graus de regularização.

\subsection{LineARIZAÇÃo}

O tempo de percurso $t$ de raio sísmico entre uma fonte sísmica e um receptor ao longo do caminho $L$, para um campo contínuo de velocidade $v(x, z)$, é dado por:

$$
t=\int_{L} \frac{1}{v(x, z)} d l
$$

Esta integral pode ser calculada de forma aproximada computacionalmente e sua forma discreta é:

$$
t_{i}=\sum_{j=1}^{m} \frac{L_{i j}}{v_{j}} ; \quad i=1,2, \ldots, n
$$

onde $L_{i j}$ é o percurso do raio $i$ na célula de velocidade $v_{j}$. Nota-se que o tempo de percurso na Equação 4.2 é inversamente proporcional à velocidade $v$, sendo então esta uma relação não-linear.

Para converter a Equação 4.2 para forma linear $\mathbf{d}=\mathbf{G m}$, podemos definir o modelo de parâmetros como sendo $s_{j}=1 / v_{j}$, onde $s_{j}$ representa a vagarosidade das ondas sísmicas. 
Assim a Equação 4.2 é linearizada e toma a seguinte forma:

$$
t_{i}=\sum_{j=1}^{m} L_{i j} s_{j}
$$

Neste caso, o campo de vagarosidade $s_{j}$ está representado como um conjunto de parâmetros discretos.

\subsection{Parametrização do Modelo}

Nosso modelo é feito com uma grade de 36 nós em profundidade, 64 em longitude e 56 em latitude, e vai até uma profundidade máxima de $1600 \mathrm{~km}$, possuíndo 129.024 parâmetros (nós). A velocidade varia uniformemente e é interpolada entre os pontos da grade por splines sob tensão (Cline 1981), de acordo com o procedimento descrito por Escalante (2002).

Nas Figuras 4.1 e 4.2, estão mostrados os limites do modelo e os espaçamentos dos nós. O volume central marcado pelas linhas amarelas representa a região com maior resolução da malha. Nesta região, o espaçamento entre os nós é de aproximadamente $33,3 \mathrm{~km}$ em profundidade e de $1 / 3$ de grau em latitude e longitude. Os diferentes espaçamentos mostrados na Figura 4.1 são utilizados para diminuir a influência de estruturas fora do volume estudado.

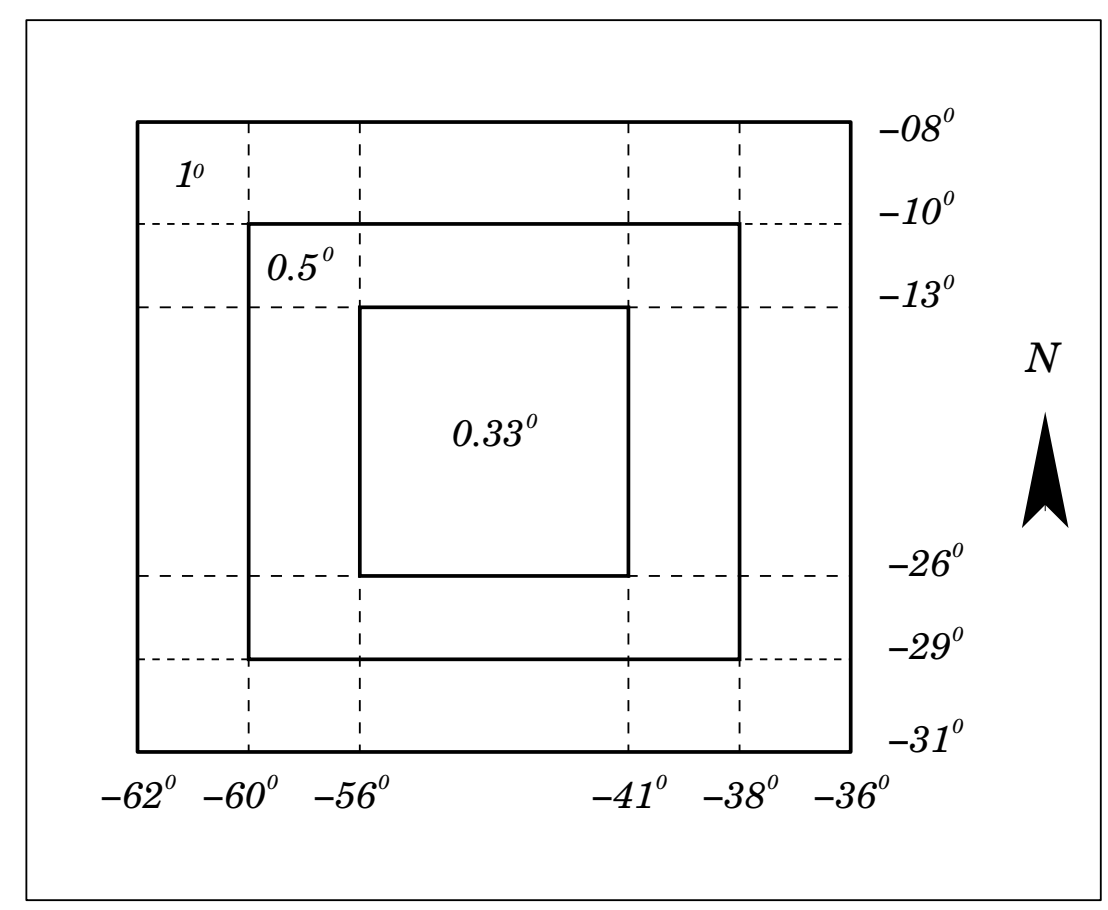

FIgURA 4.1 Limites e espaçamentos horizontais entre os nós do modelo. 


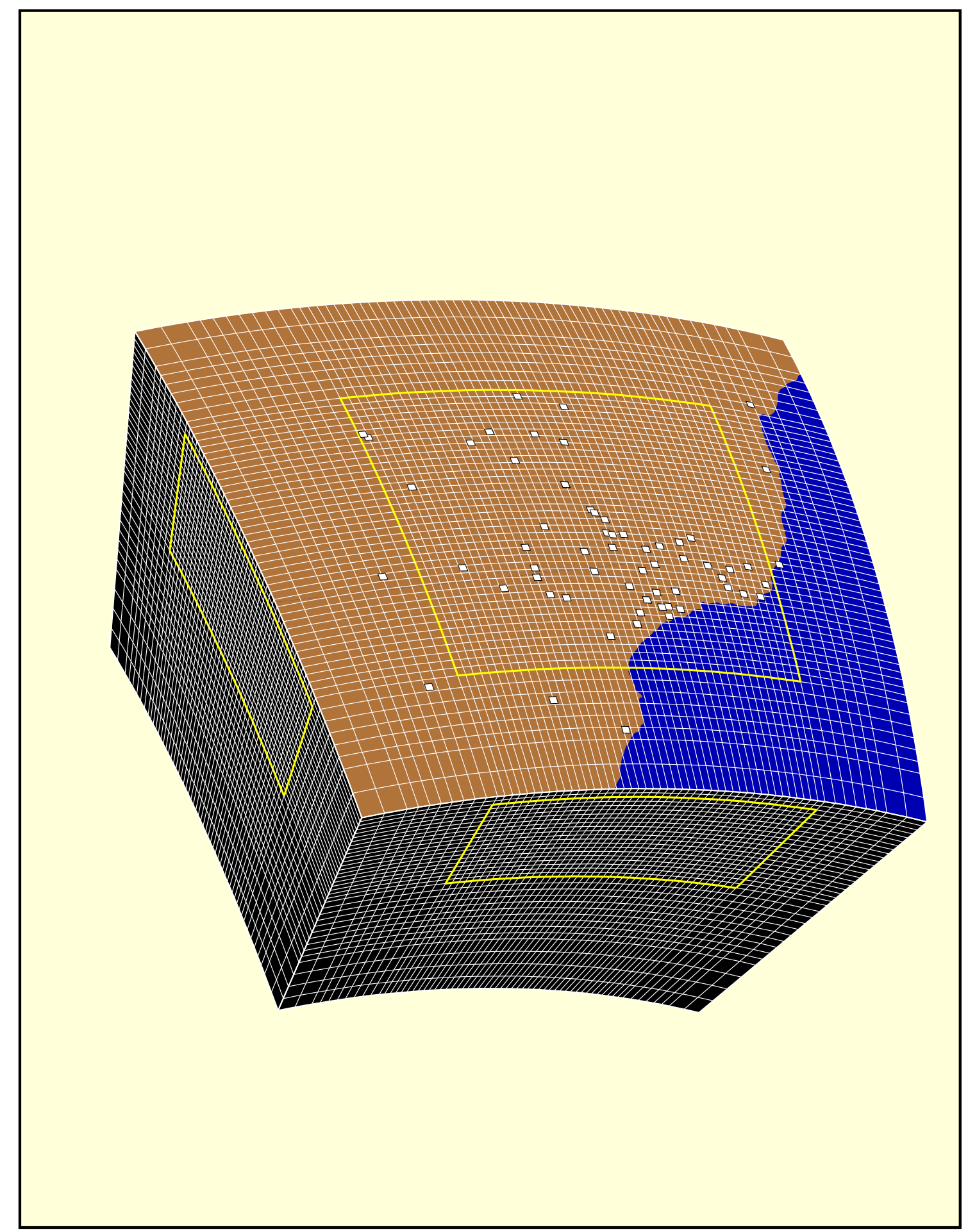

FigurA 4.2 - Parametrização do modelo utilizado na inversão dos dados. Os quadrados brancos representam as estações utilizadas (inclusive as novas estações incluídas neste trabalho - Apêndice A). O volume marcado pelas linhas amarelas é a região com melhor resolução da grade. 


\subsection{FormulaÇÃo DA INVERs̃̃o}

Segundo Menke (1984), o objetivo da teoria da inversão é fazer inferências sobre as propriedades físicas de um modelo a partir de dados observados. Para isso é necessário relacionar os parâmetros do modelo aos dados através de um modelo matemático (modelo teórico).

O uso dos parâmetros físicos e de um modelo teórico, no contexto da teoria da inversão, para a predição de dados é conhecido como problema direto. Já o cômputo dos parâmetros usando as observações e o modelo teórico é chamado de problema inverso. A Figura 4.1 mostra um esquema básico sobre estes dois problemas.

\section{Problema Direto}

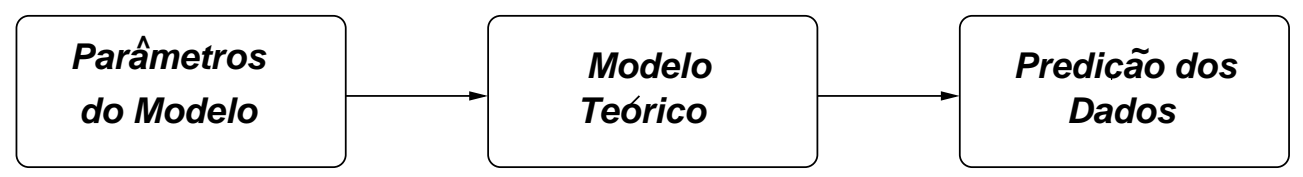

\section{Problema Inverso}

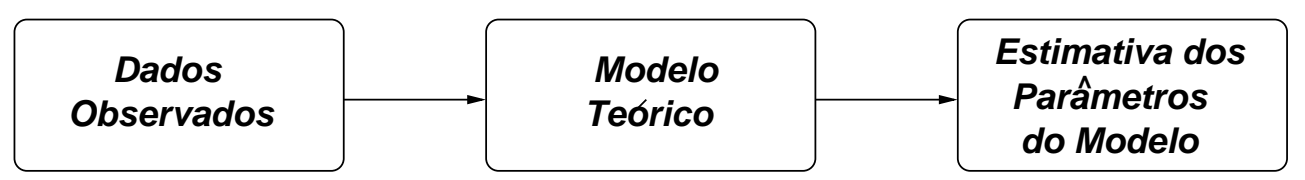

Figura 4.3 - Representação esquemática dos tipos de problemas descritos pela teoria da inversão (Menke 1984).

Estes problemas podem ser lineares ou não. Os problemas lineares podem ser representados pela equação abaixo (Menke 1984).

$$
\mathrm{Gm}=\mathbf{d}
$$

Na Equação 4.4, $\mathbf{d}$ é um vetor de comprimento $\mathrm{N}$ que representa as medidas (dados) feitas em um determinado experimento, e o vetor $\mathbf{m}$ tem comprimento $\mathrm{M}$ e representa os parâmetros do modelo. A matriz $\mathbf{G}$ é chamada matriz Kernel ou matriz de Sensibilidade, e descreve o mapeamento que relaciona $\mathbf{m}$ e $\mathbf{d}$.

O problema direto consiste em calcular $\mathbf{d}$ quando $\mathbf{m}$ e $\mathbf{G}$ são conhecidos. O problema inverso, por sua vez, consiste em calcular $\mathbf{m}$, dados $\mathbf{G}$ e $\mathbf{d}$.

Considerando que as incertezas dos dados possuam distribuições Gaussianas, o estimador do 
modelo mais provável será o que minimize a função objetivo $\phi$ (Menke 1984).

$$
\phi=(\mathbf{G m}-\mathbf{d})^{T}(\mathbf{G m}-\mathbf{d})
$$

Utilizando os mínimos quadrados (Equação 4.6), podemos realizar a minimização de $\phi$ (Menke 1984).

$$
\mathbf{m}^{\mathrm{est}}=\left(\mathbf{G}^{\mathrm{T}} \mathbf{G}\right)^{-1} \mathbf{G}^{\mathrm{T}} \mathbf{d}
$$

Como temos 129.024 parâmetros do modelo e apenas 10.732 tempos de percurso, nosso problema é sub-determinado (mal posto), pois existem muito mais parâmetros do que dados. Isto provoca instabilidade na inversão, gerando a não-unicidade dos resultados. Desta forma a inversão deve ser regularizada utilizando vínculos que aumentem a sua estabilidade (Marquardt, 1963 e Lawson \& Hanson, 1974), não necessitando de uma sub-parametrização ${ }^{1}$.

A inversão Occam, descrita por Constable (1987), representa conceitualmente o vínculo mais importante e mais significativo de nossa regularização. Este princípio busca o modelo com o mínimo de estrutura (mais simples) para explicar os dados, considerando um erro padrão definido. Normalmente na regularização estes vínculos podem ser baseados na Física do problema ou em considerações geológicas (Meju 1994).

Como exemplo, podemos minimizar as diferenças entre os parâmetros adjacentes $\left(m_{1}-m_{2}\right)$, $\left(m_{2}-m_{3}\right), \ldots,\left(m_{p-1}-m_{p}\right)$, ou seja, fazer a minimização da $1^{a}$ derivada do modelo. Estas diferenças podem ser mostradas da forma $\mathbf{D m}=\mathbf{h}$, ou ainda,

$$
\begin{aligned}
& {\left[\begin{array}{cccccc}
1 & -1 & & & & \\
& 1 & -1 & & & \\
& & & \ddots & & \\
& & & & 1 & -1
\end{array}\right]\left[\begin{array}{c}
m_{1} \\
m_{2} \\
\vdots \\
m_{p}
\end{array}\right]=\left[\begin{array}{c}
h_{1} \\
h_{2} \\
\vdots \\
h_{p-1}
\end{array}\right]} \\
& \mathrm{D} \quad \mathrm{m}=\mathrm{h}
\end{aligned}
$$

onde D é o operador diferença conhecido como matrix suavidade, e Dm é a suavidade de primeira ordem (flatness) do vetor solução m. Para medir a suavidade de nossa solução, usamos

\footnotetext{
${ }^{1}$ Diminuição da quantidades de parâmetros de um modelo buscando sua estabilidade
} 
a medida quadrática dada por:

$$
\mathbf{h}^{\mathrm{T}} \mathbf{h}=\mathbf{m}^{\mathrm{T}} \mathbf{D}^{\mathrm{T}} \mathbf{D m}
$$

E assim adicionando o termo de suavidade na função objetivo (Equação 4.5) temos:

$$
\phi=(\mathbf{G m}-\mathbf{d})^{T}(\mathbf{G m}-\mathbf{d})+\beta^{2} \mathbf{m}^{\mathbf{T}} \mathbf{D}^{\mathbf{T}} \mathbf{D m}
$$

onde $\beta$ define o grau de suavização de primeira ordem do vetor $\mathbf{m}$. Com a adição do termo de regularização, a equação 4.6 torna-se:

$$
\mathbf{m}^{\text {est }}=\left(\mathbf{G}^{\mathbf{T}} \mathbf{G}+\beta^{2} \mathbf{D}^{\mathbf{T}} \mathbf{D}\right)^{-1} \mathbf{G}^{\mathbf{T}} \mathbf{d}
$$

Embora a regularização traga estabilidade ao problema, em contrapartida existirá uma perda de resolução, e nos resultados, apenas estruturas de larga escala serão robustas. Quanto maior $\beta$, maior a perda de resolução.

Como o cálculo da matriz inversa da Equação 4.10 é computacionalmente difícil, dado o seu tamanho e esparsidade, é mais eficiente minimizar a função objetivo (Equação 4.9) pelo método dos Gradientes Conjugados (e.g. LSQR - Reweighted Least Squares - Paige \& Saunders, 1982). Utilizamos o método de gradientes conjugados conforme descrito em Escalante (2002). Neste método as iterações são calculadas recursivamente com armazenamento em memória apenas da última iteração anterior sem a necessidade das outras, o que diminui muito o tempo computacional. Para todas as inversões, foram executadas 2000 iterações do procedimento dos gradientes conjugados.

Para inversão do modelo são usados pesos menores nas equações que têm resíduos maiores que 1,5 vezes o desvio padrão $(\sigma)$ do ajuste. Isto é feito de forma iterativa, com a inversão sendo recalculada por várias iterações (até 20 ou 30) com pesos dados conforme os resíduos do ajuste anterior, exceto na primeira iteração (Hubert 1981). Assim os resultados foram conduzidos 
para soluções com minimização por norma $L_{2}$ (média) para os dados com erros menores que $1,5 \sigma$, e por norma $L_{1}$ (mediana) para dados com desvios maiores (Schimmel et al. 2003). Este procedimento é bem descrito em Pulliam et al. (1993).

O problema real (VanDecar et al. 1995) é mais complexo que o da Equação 4.1, pois inclui regularização pela segunda derivada e correções de estação e epicentro.

\subsection{CONSISTÊNCIA DA INVERSÃO}

No Capítulo 3, foram mostradas algumas análises estatísticas feitas antes da inversão, buscando observar a consistência na base de dados. Aqui será mostrada a influência da presença de dados com erro (inconsistências), sobre os resultados da inversão.

Observamos que existem oscilações da amplitude das anomalias nos resultados tomográficos, de uma iteração para outra, quando invertemos dados inconsistentes. A Figura 4.4 mostra um exemplo destas oscilações, e ainda a comparação dos resultados entre as inversões da base de dados com erro, e da base de dados depurada (base final). Nas Figuras 4.4a, 4.4c e 4.4e (base com erros) observam-se oscilações na região de Iporá, onde ocorre uma mudança brusca de intensidade (aumento de 28 para 29 e diminuição de 29 para 30) da anomalia de baixa velocidade proposta por Escalante (2002). Observamos ainda oscilações em outras regiões, como na Bacia do Paraná (anomalias de alta e baixa velocidade).

As Figuras 4.4b, 4.4d e 4.4f mostram a sequência de imagens geradas para as iterações 28 , 29 e 30 respectivamente, resultantes da inversão da base final. Nesta sequência observamos a suavização gradual da iteração 28 para a 30 . Isto se deve ao seguinte processo. Resíduos grandes geralmente produzem anomalias fortes no modelo (mais estrutura). Ao se diminuir o peso dos dados com resíduos altos, a regularização consegue impor uma maior suavidade no modelo (menos estrutura), ou seja a suavização passa a ter importância relativamente maior, uma vez que o ajuste tem peso menor.

A Figura 4.5 mostra as curvas do ajuste do rms pelas iterações para as inversões da base de dados com erros (triângulos azuis) e da base final (triângulos vermelhos). Observamos que o ajuste a partir da iteração 14 não se torna tão significativo, o que significa que as imagens tomográficas, a partir desta iteração, não deveriam possuir grandes diferenças. Acreditamos que os dados inconsistentes, provavelmente gerados por problemas durante o processo de marcação das chegadas (Capítulo 2) ou por problemas na correção de tempo das estações (problemas no GPS) sejam responsáveis pela instabilidade durante a inversão.

Nesta figura observamos ainda que o rms do ajuste diminui muito rapidamente para os dados depurados em relação aos não depurados, mostrando a necessidade das análises feitas no Capítulo 3 para obtenção de resultados mais precisos e confiáveis. 

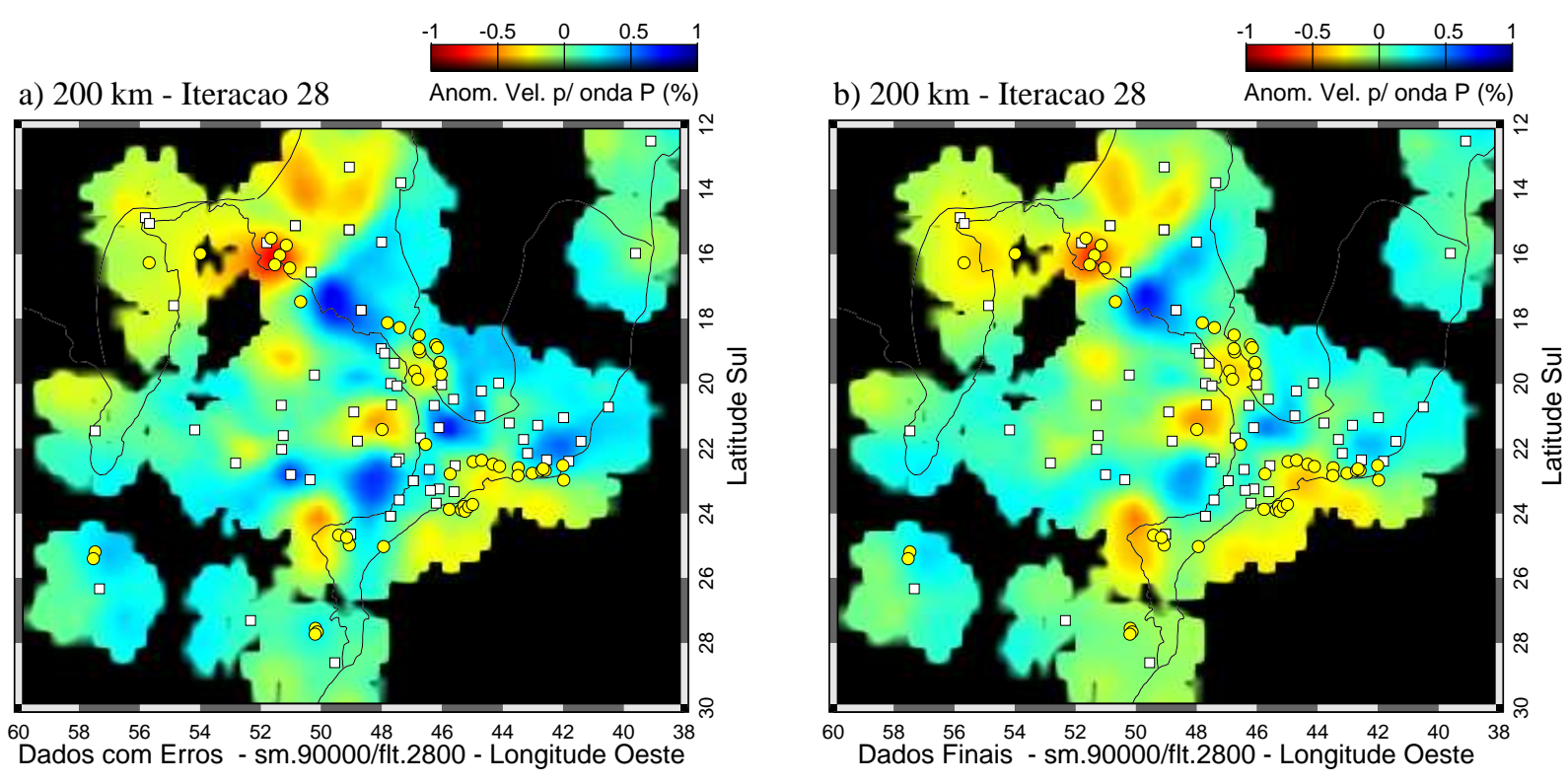

c) $200 \mathrm{~km}$ - Iteracao 29
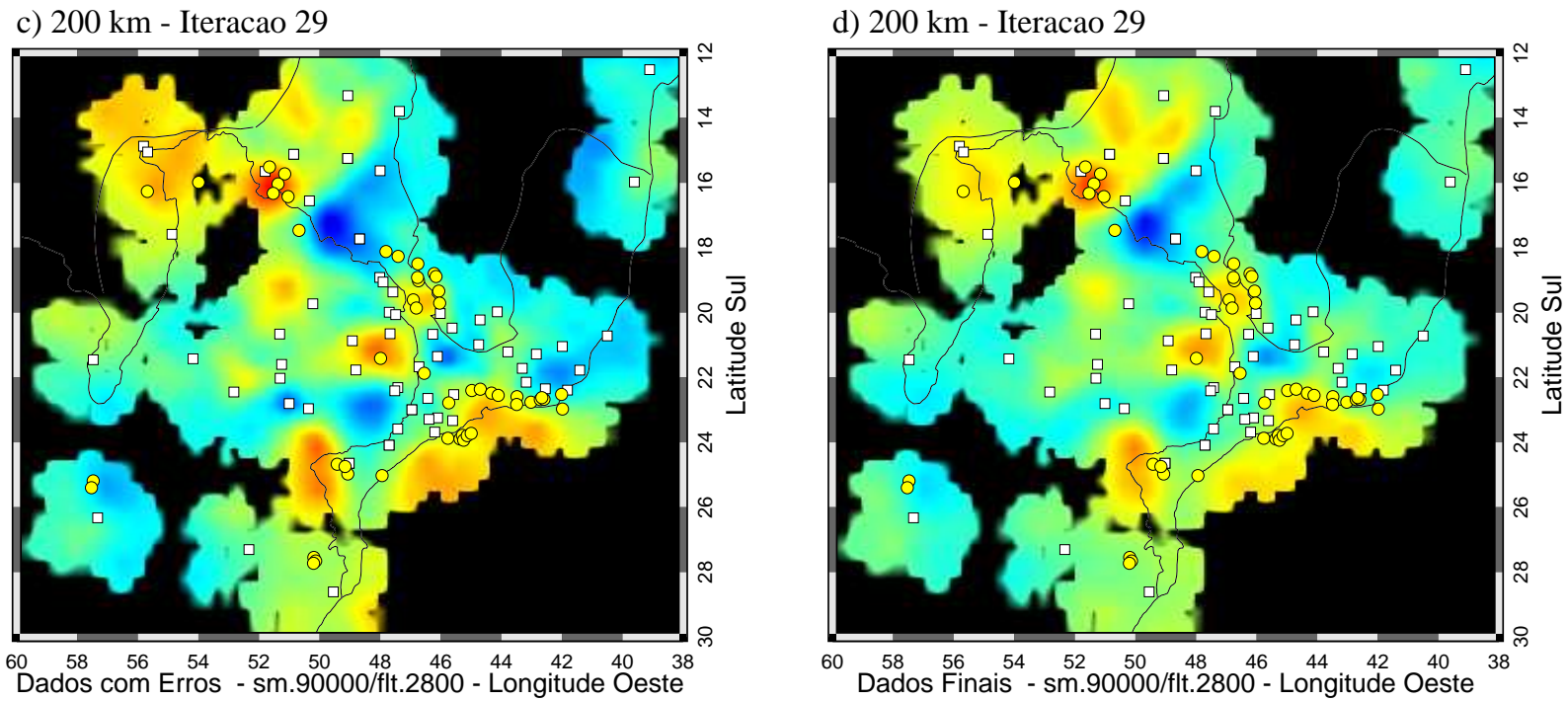

e) $200 \mathrm{~km}$ - Iteracao 30

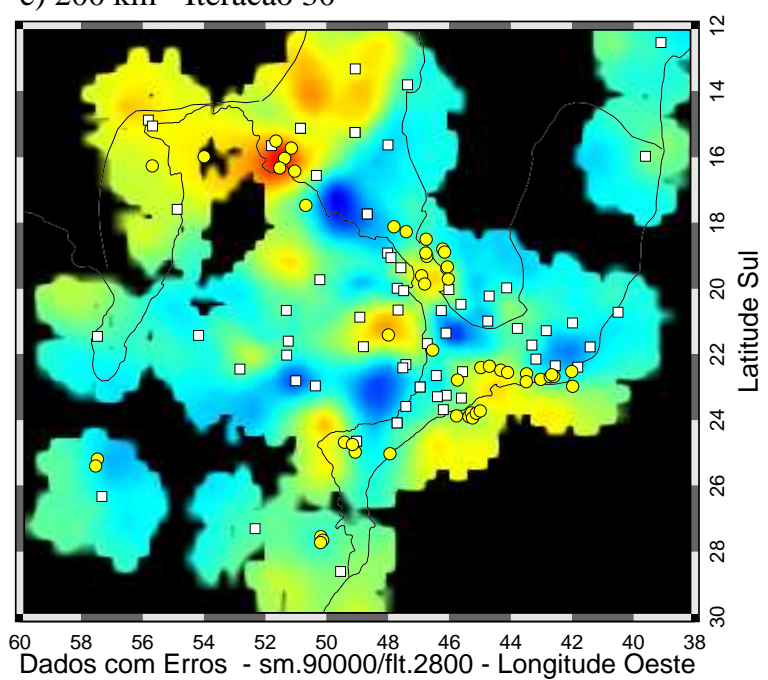

f) $200 \mathrm{~km}$ - Iteracao 30

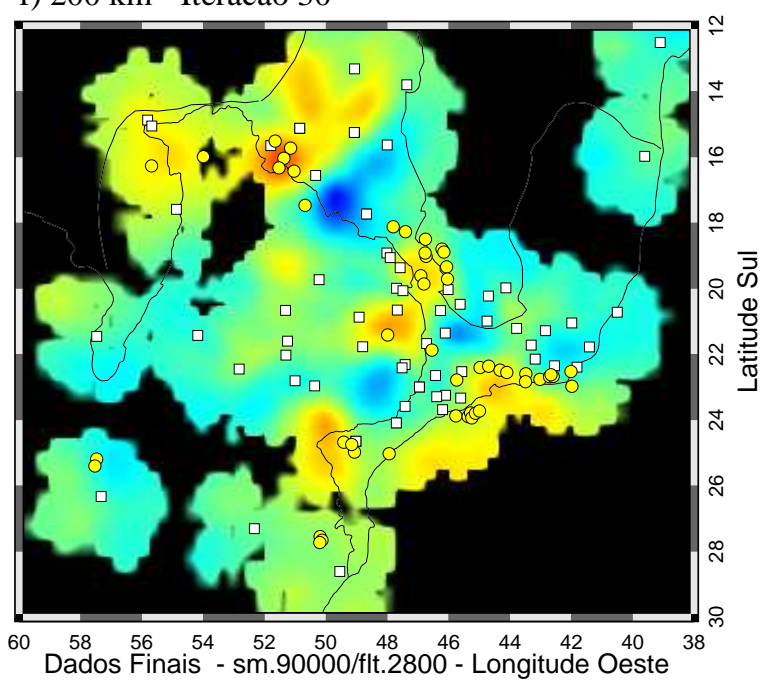

FiguRA 4.4 - Comparação entre as imagens tomográficas geradas pela inversão da base contendo dados com erros (Figuras a, c e e), e da base final depurada (Figuras b, d e f). As iterações referem-se ao processo de diminuição dos pesos para resíduos grandes. 


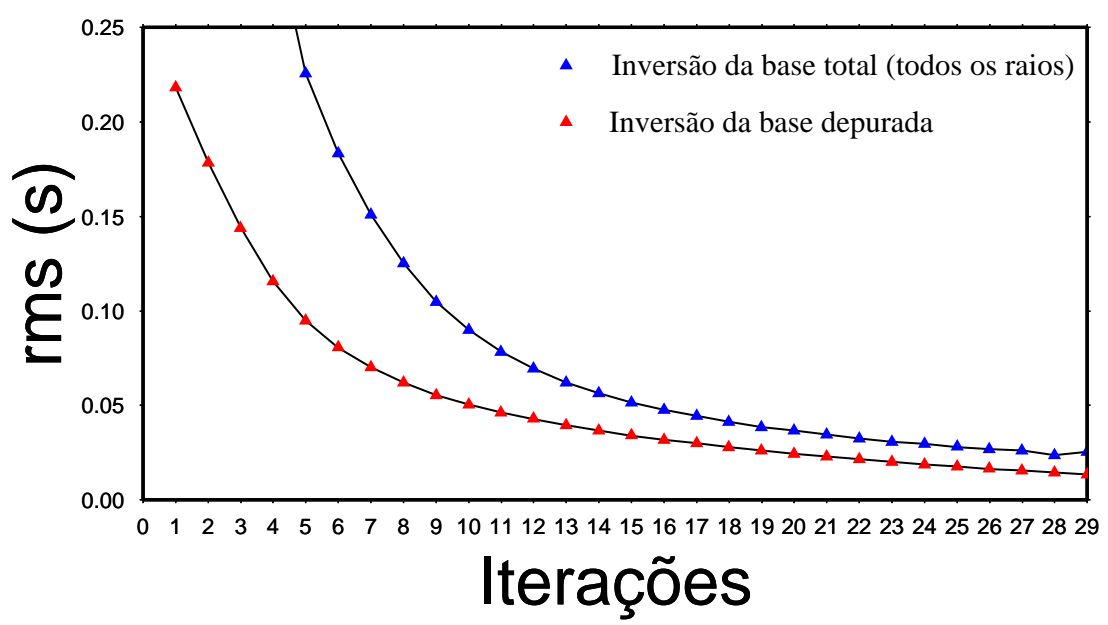

FiguRA 4.5 - Curvas de rms para as iterações com pesos decrescentes (down-weighting) da base de dados total (com erros) e da base final (depurada). Foram utilizados os valores de 90000 e 2800 para suavidade e flatness respectivamente.

\subsection{Testes de Convergência e RegularizaÇÃo}

Foram feitos alguns testes para observar os efeitos de diferentes valores para os vínculos de regularização. Na Figura 4.6 são mostradas imagens tomográficas resultantes das inversões da base final (depurada) para as iterações 10, 20 e 30 a uma profundidade de $200 \mathrm{~km}$, com dois valores de regularização.

Nas Figuras 4.6b, 4.6d e 4.6f foram utilizados os valores de 90000 para suavidade e 2800 para flatness $^{2}$ sugeridos em estudos anteriores. Nas Figuras 4.6a, 4.6c e 4.6e, os valores foram praticamente duplicados (suavidade - 200000 e flatness - 5000). As imagens mostram os efeitos da diminuição dos pesos dos resíduos maiores. Com o aumento do número de iterações, os resultados tornaram-se mais suaves, como era esperado.

Podemos observar pela comparação destas imagens que nas regiões onde existe uma maior densidade de estações, não ocorrem diferenças significativas de suavidade entre os resultados, o que sugere que não são necessárias muitas iterações de down-weighting. Para regiões com menos estações as diferenças são maiores, no entanto as anomalias mais robustas se mantêm. Nestas regiões, para dar uma maior confiança às estruturas anômalas, seria interessante ter mais estações para uma maior cobertura de dados.

A Figura 4.7 mostra as curvas de minimização para estes dois modelos. Nota-se que o rms do ajuste aumenta sutilmente para o modelo com maior suavidade em relação ao de menor. Esse aumento reflete o maior "esforço" do algoritmo da inversão para suavizar mais o modelo, sob a pena de aumento do desvio padrão do ajuste.

\footnotetext{
${ }^{2}$ Suavização de $1^{a}$ ordem (planificação)
} 

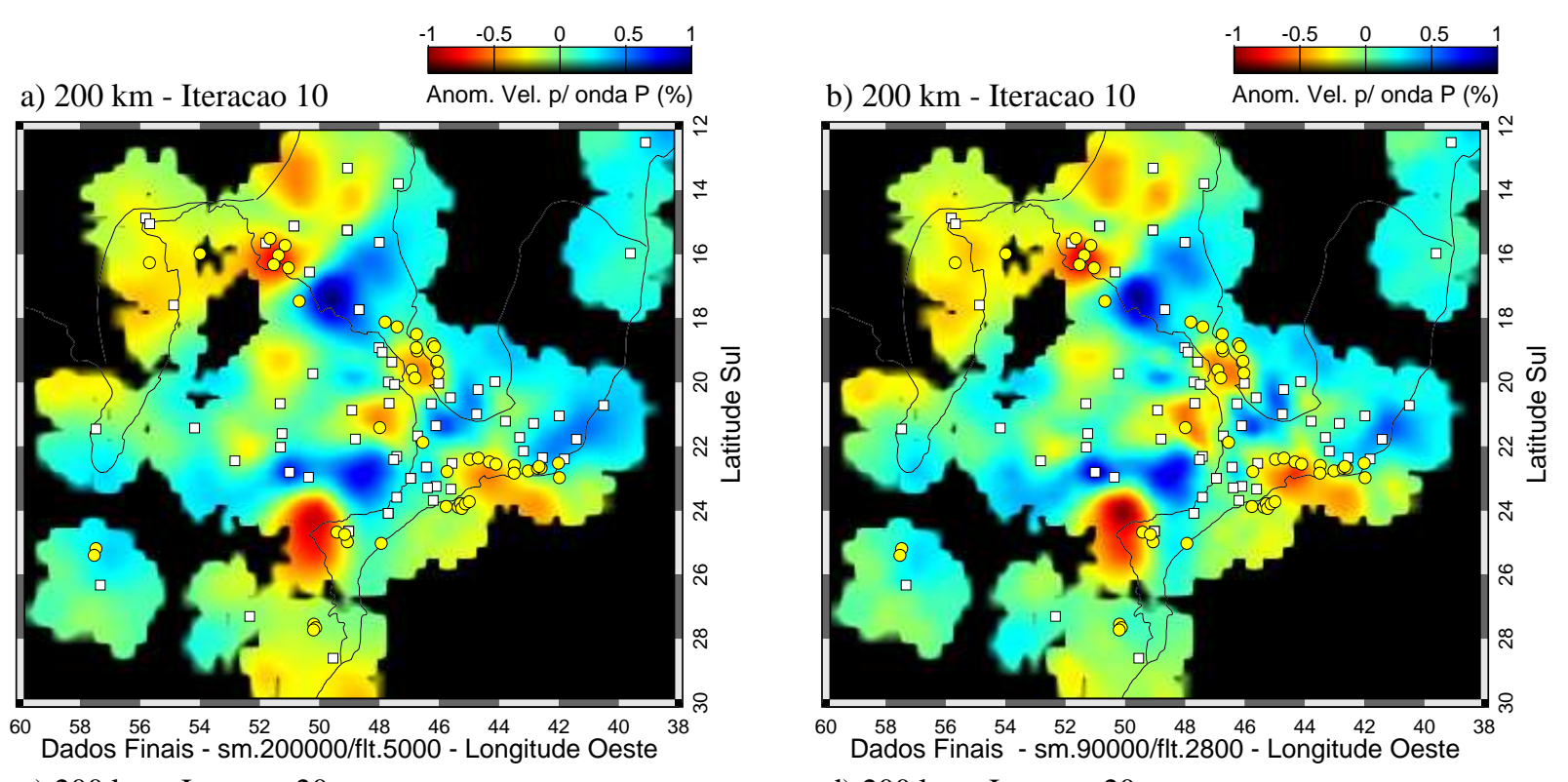

c) $200 \mathrm{~km}$ - Iteracao 20
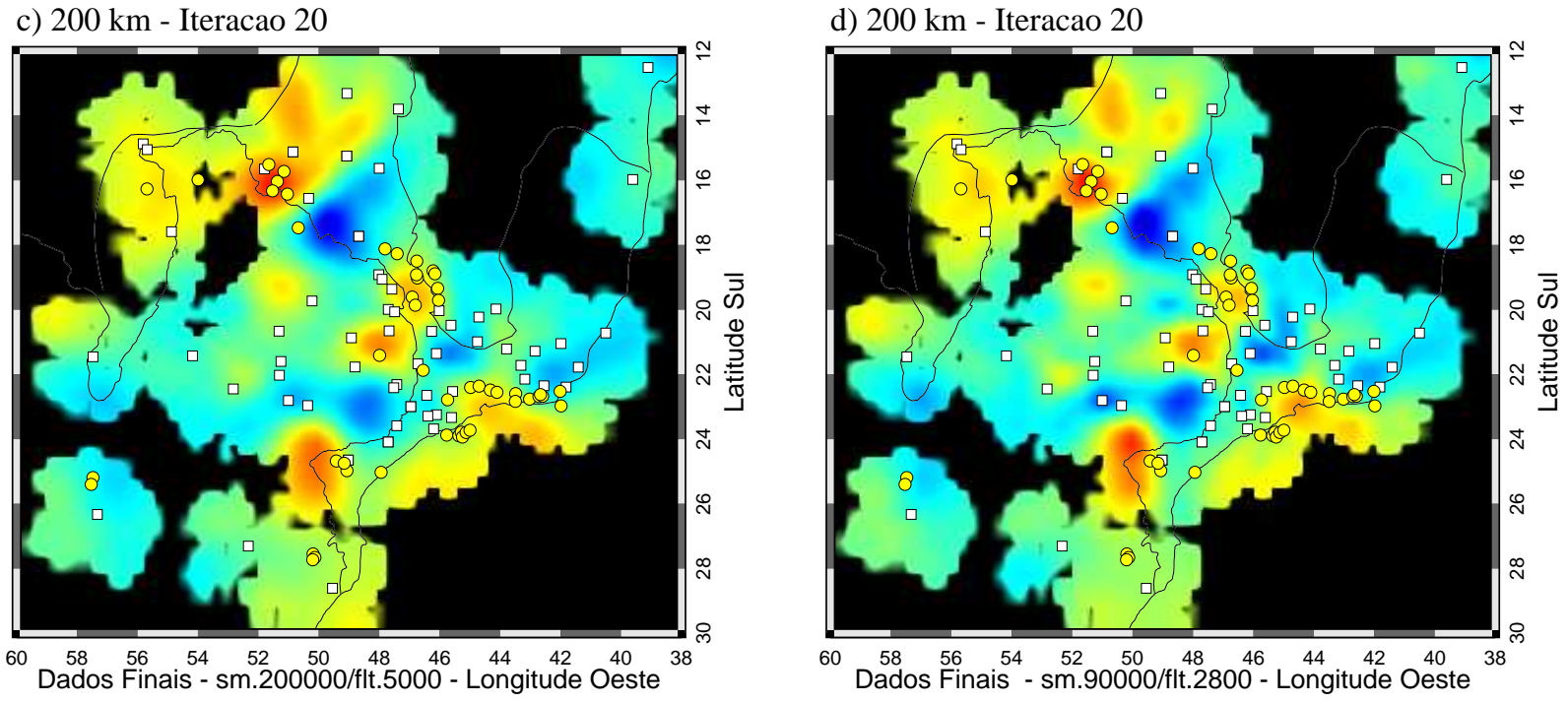

e) $200 \mathrm{~km}$ - Iteracao 30

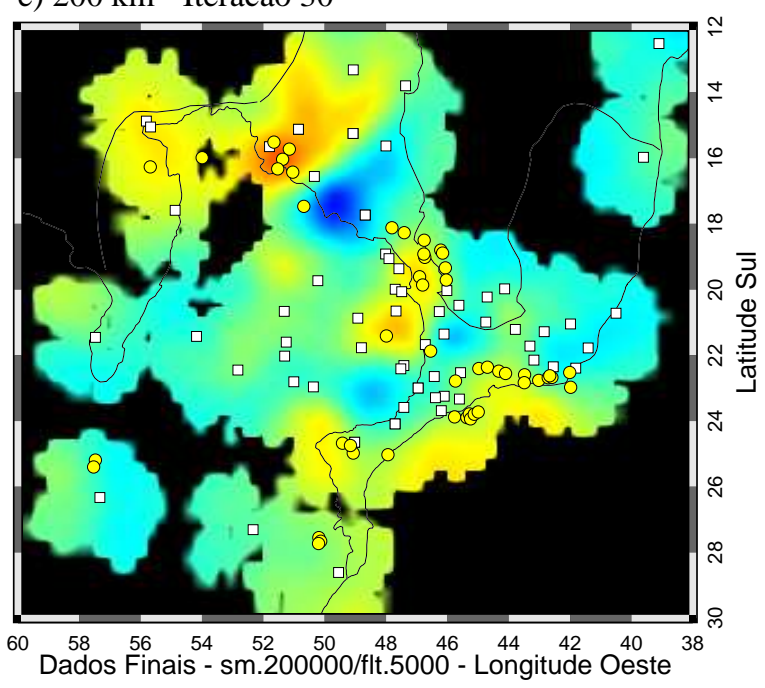

f) $200 \mathrm{~km}$ - Iteracao 30

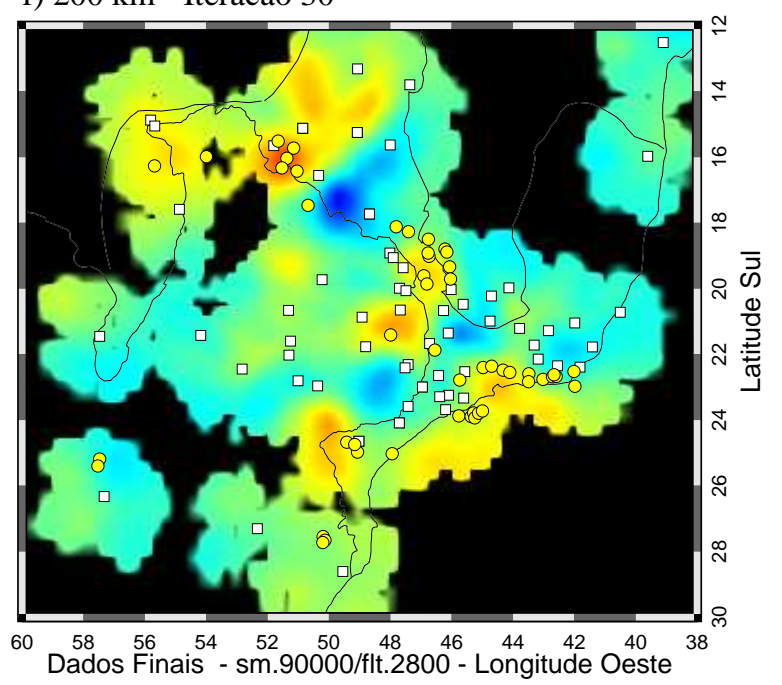

FiguRA 4.6 - Comparação entre as imagens tomográficas com diferentes valores para os parâmetros de regularização. Para a), c) e e) o valor de suavidade foi 200000 e o de flatness 5000 . Para b), d) e f) a suavidade foi 90000 e o flatness 2800 . 
Consideramos que as duas curvas possuem o mesmo comportamento, ou seja, os dois modelos podem ser usados para as interpretações dos resultados.

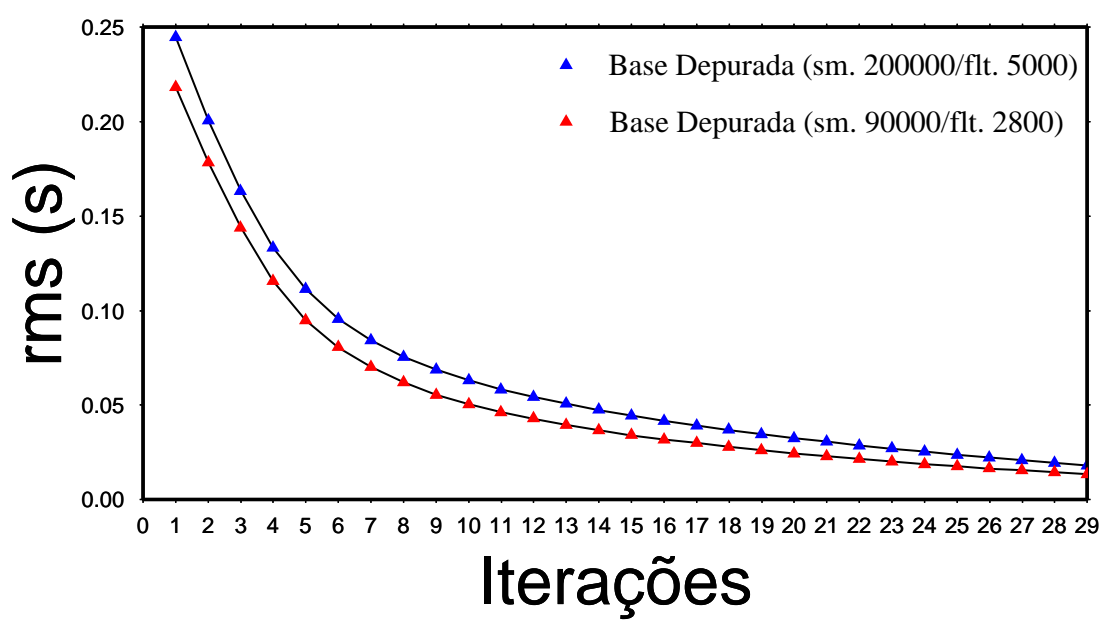

FIguRA 4.7 - Curvas de rms para iterações de down-weigthing na inversão da base de dados final com dois valores de regularização. Na curva com triângulos vermelhos, os valores de suavidade e flatness foram 90000 e 2800 respectivamente, já na curva com triângulos azuis, estes valores dobraram (suavidade - 200000 e flatness - 5000)
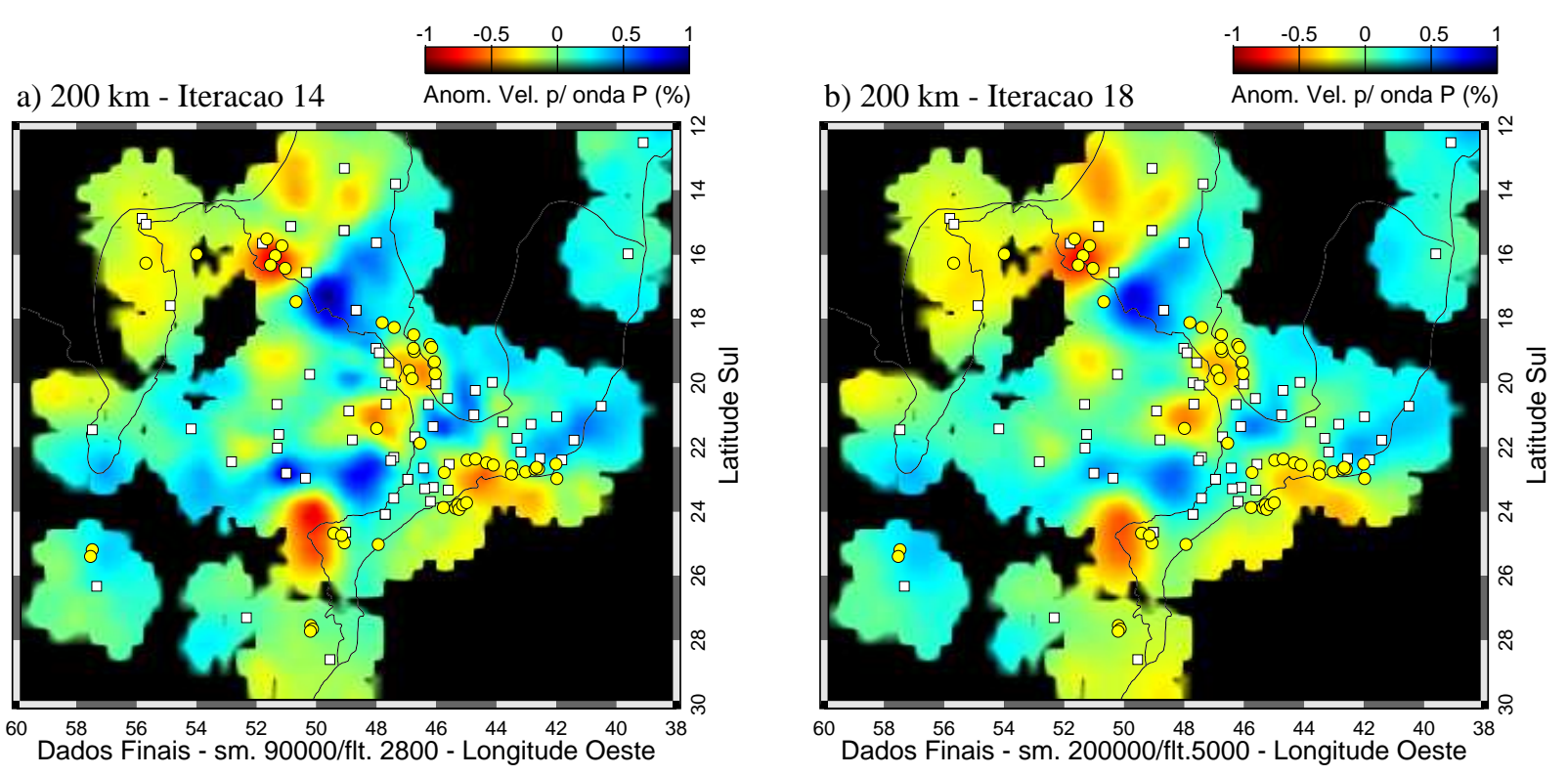

FiguRA 4.8 - Modelos com diferentes valores para os parâmetros de regularização e com mesmo ajuste (rms) para os dados $(\sigma=0,035 s)$. a) Suavidade 90000 e flatness 2800. b) Suavidade 200000 e flatness 5000 .

Na Figura 4.8 estão dois modelos gerados para $200 \mathrm{~km}$ de profundidade com valores de regularização diferentes, que explicam os dados com um mesmo ajuste ( $\mathrm{rms}=0,035 \mathrm{~s}$ ). $\mathrm{Na}$ Figura 4.8a a imagem foi gerada na $14^{a}$ iteração com valores de 90000 e 2800 para suavidade e flatness respectivamente. A Figura 4.8b foi gerada com suavidade de 200000 e flatness de 5000 
na iteração 18. As maiores diferenças entre elas se concentram nas regiões com menos estações.

Estas figuras representam um exemplo do comportamento observado nas curvas de ajuste da Figura 4.7, onde inversões com maiores valores de regularização necessitam de mais iterações para diminuição dos pesos (down-weighting) para ajustar os dados com mesmo rms. No entanto, as inversões com menores valores de regularização (menos suaves) introduzem mais estruturas para explicar os dados, levando os resultados para soluções mais complexas, contrariando o conceito da Inversão Occam³ ${ }^{3}$. Desta forma, as imagens tomográficas que serão utilizadas durante a interpretação (Capítulo 5), terão como valores de regularização 200000 para suavidade e 5000 para flatness. Utilizaremos, com base na Figura 4.7, imagens geradas a partir dos resultados da iteração 16.

A Figura 4.9 mostra a distribuição dos ângulos de incidência dos raios em função do azimute da estação ao evento, a uma profundidade de $400 \mathrm{~km}$. Cada ponto indica um raio, onde os círculos pretos indicam fases $\mathrm{P}$ e os vermelhos indicam as fases PKPdf. A linha sólida preta mostra o rms dos dados totais antes de se iniciar a modelagem final $(\sigma=0,412 s)$, as demais mostram o rms do ajuste para as iterações $02,03,16$ e 20.

Como na Figura 4.7, observamos na figura 4.9 que a variação do rms durante o ajuste é maior nas primeiras iterações, e pouco significativa durante as últimas iterações. Os modelos explicam em torno de $88,5 \%$ da variação dos dados (0,412 para 0,047 na iteração 16$)$.

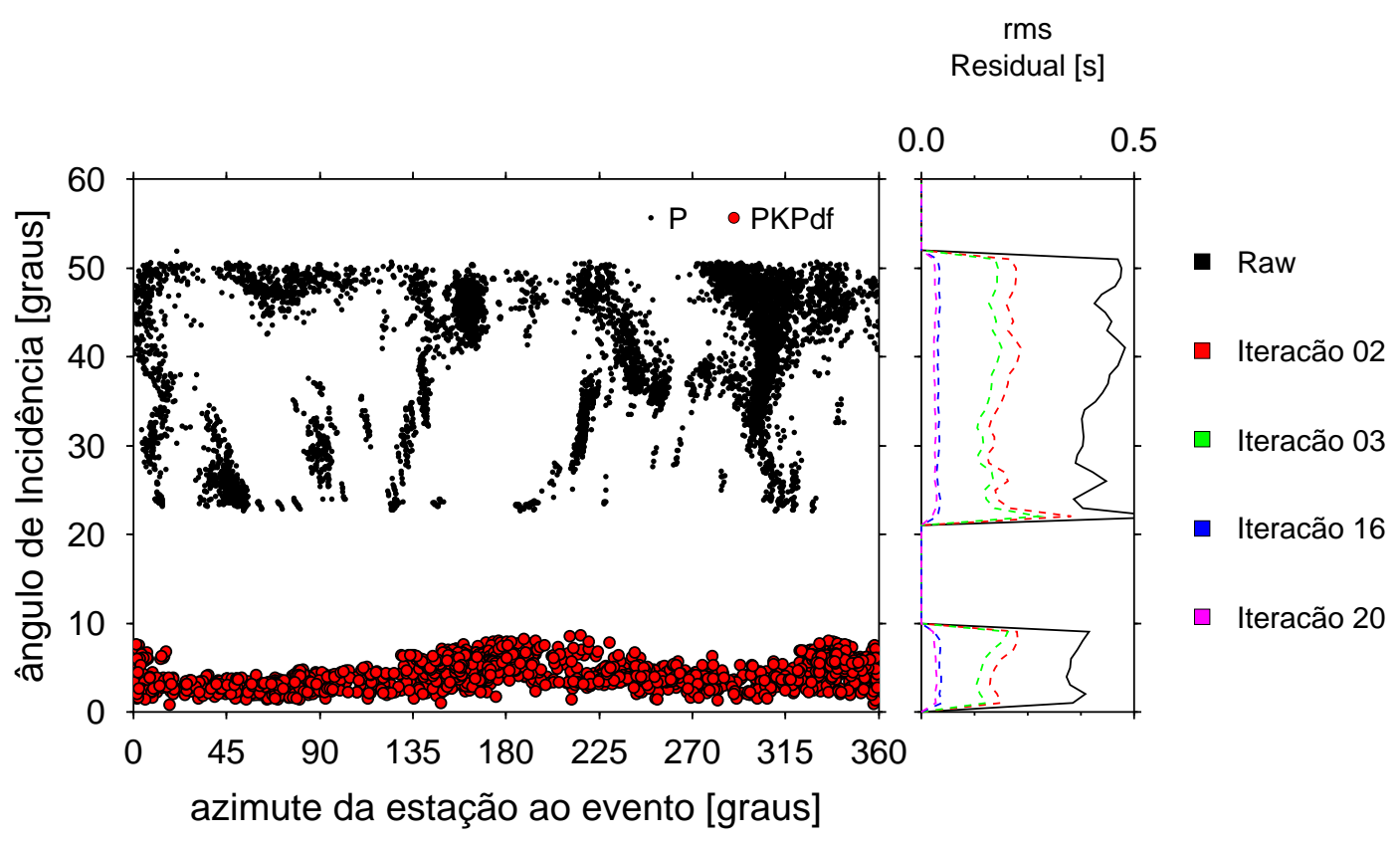

FIgURA 4.9 - Distribuição dos ângulos de incidência dos raios a $400 \mathrm{~km}$ de profundidade como função dos back azimuths, e o erro do ajuste para o conjunto de dados de ondas P.

\footnotetext{
${ }^{3}$ Inversão Occam - Mínimo de estrutura para explicar os dados (Constable et al. 1987)
} 


\section{Capítulo 5}

\section{Discuss Ão DOS RESUltados}

Neste capítulo serão mostrados os resultados das inversões tomográficas na região Sudeste e Centro-Oeste do Brasil, através de seções horizontais para várias profundidades e também por perfis verticais. Serão mostradas também inversões retirando algumas estações localizadas em zonas de anomalias mais pronunciadas, para mostrar a importância de cada estação na determinação das anomalias, bem como observar se estas são robustas.

\subsection{Resultados Finais}

Nossos resultados são reconstruções tomográficas geradas pela inversão com dados de 1992 a 2002, mostrados por seções horizontais para várias profundidades, e perfis verticais dispostos de acordo com as regiões de maior interesse.

A partir de um modelo médio de velocidade (IASP91), como no exemplo da Figura 5.1, as anomalias serão determinadas nas figuras pela diferença de cores (tons tendendo ao azul para zonas de maior velocidade, e tendendo para o vermelho para zonas de menor velocidade com relação ao modelo médio). Nas imagens, regiões com densidades de raio menores que 20 raios por cada milhão de kilometros cúbicos são mostradas em preto. As anomalias mostradas representam heterogeneidades laterais do modelo.

Para os perfis verticais, devido a pouca resolução ${ }^{1}$, os primeiros $50 \mathrm{~km}$ foram ocultados. Nas seções horizontais, os quadrados brancos e os círculos amarelos (Figura 5.2 e 5.3) representam, respectivamente, as estações utilizadas e a localização de intrusões alcalinas do magmatismo ocorrido entre 90 e 55 Ma. A Figura 5.1 mostra uma seção horizontal a uma profundidade de $200 \mathrm{~km}$ como o resultado da tomografia sísmica para nossa área de estudo, caso esta não possuísse heterogenidades.

De acordo com os resultados obtidos por Escalante (2002), observa-se para menores profun-

\footnotetext{
${ }^{1}$ pouco cruzamento de raios por nó
} 
didades (150 e $200 \mathrm{~km}$ ) que existe uma correlação entre a distribuição das anomalias de baixa velocidade na região de estudo e a localização das intrusões alcalinas do Cretácio Superior. Em nossos resultados (Figuras 5.2 e 5.3), observamos que este mesmo comportamento permanece para as anomalias de baixa velocidade, reafirmando a possibilidade de que estas indicariam anomalias de alta temperatura na região das alcalinas, originadas na litosfera sub-continental mais afinada (Gibson et al. 1999).

A anomalia de baixa velocidade sob a Bacia do Paraná, interpretada por VanDecar et al. (1995) e Schimmel et al. (2003) como sendo o resto fóssil da pluma de Tristan da Cunha, em nossos resultados pode ser notada a partir de aproximadamente $250 \mathrm{~km}$ de profundidade (Figura 5.3) chegando a profundidade máxima de $1000 \mathrm{~km}$. Comparados aos resultados de Escalante (2002) podemos observar uma melhor delimitação vertical desta anomalia em nossos resultados.

As imagens de Escalante (2002) relacionadas a esta anomalia mostram uma leve separação desta em duas partes mais intensas. Na Figura 5.13 esta anomalia aparece de forma mais compacta nas partes mais rasas, porém, podemos ver pelas Figuras 5.7, 5.8 e 5.19 que em regiões mais profundas (a partir de $700 \mathrm{~km}$ ) esta anomalia agrega-se a outra anomalia de baixa velocidade espalhada pela região sudeste da área.

Esta outra anomalia aparece em todos os resultados, principalmente nas profundidades superiores a $300 \mathrm{~km}$ (Figuras 5.4 - 5.10). Testes feitos por Escalante (2002) mostraram que esta anomalia é um artifício gerado durante o processo de inversão. Desta maneira, a anomalia de baixa velocidade relacionada à pluma de Tristan da Cunha não pode ser completamente definida em maiores profundidades.

Um dos principais resultados obtidos por Escalante (2002) é a definição de uma anomalia de baixa velocidade muito intensa sob a região de Iporá em Goiás. Segundo ele, esta anomalia estaria se correlacionando muito bem ao impacto inicial da pluma de Trindade como proposto por Gibson et al. (1997). Segundo Thompson et al. (1998), o impacto desta pluma em 80 Ma teve como centro a atual Província Ígnea de Iporá atingindo uma área com raio de aproximadamente $500 \mathrm{~km}$. Nossos resultados confirmam a presença da anomalia de Iporá em Goiás (Figuras 5.2, $5.3,5.4,5.5,5.11,5.17$ e 5.21), mostrando que esta é robusta.

As Figuras 5.11, 5.17 e 5.21 mostram perfis cortando a anomalia de Iporá. Nos perfis A-A' e D-D' observamos um prolongamento desta anomalia em profundidade para a direção noroeste, causado pela grande quantidade de chegadas vindas do NW da América do Sul e América Central (Figuras 5.12 e 5.18). Comparando estes resultados com os de Escalante (2002), observamos que houve uma diminuição significativa do prolongamento desta anomalia, o que acreditamos ser devido a uma melhor distribuição azimutal dos eventos registrados na rede de estações (principalmente nas estações sobre esta região). 
Observamos a oeste da anomalia de Iporá (região sul do Estado de Mato Grosso) uma tendência de baixa velocidade, que sugere que esta região possa ser uma continuidade do processo de magmatismo do Cretáceo Superior, com mais estruturas relacionadas ao efeito inicial da pluma de Trindade em regiões de litosfera mais finas. Estas anomalias se correlacionam muito bem com a localização das intrusões alcalinas da Província Ígnea de Poxoréu, como nas demais regiões com anomalias de baixa velocidade. A Figura 5.21 mostra o perfil F-F' cortando as Províncias Ígneas de Iporá e Poxoréu e as regiões anômalas de baixa velocidade. Para a região da Província de Poxoréu, faltam dados para melhorar a resolução das anomalias. A cobertura de estações nesta região é baixa e as estações existentes (MAN1, MAN2 e pp1b) possuem poucos dados. Não é possível afirmar que exista uma boa robustez das anomalias, sendo observada uma certa instabilidade que discutiremos mais adiante.

Ao norte da anomalia de Iporá (Figura 5.3), observamos uma outra anomalia de baixa velocidade, que aparece espalhada por toda região de Goiás, sem a presença de intrusões alcalinas mapeadas na região. Isto sugere que de um modo geral toda esta região possui uma tendência de baixas velocidade, não necessariamente ligadas às alcalinas. Esta tendência é observada nos testes de inversão discutidos.

Outra anomalia significativa de baixa velocidade (Figuras 5.2, 5.3, 5.4 e 5.15) encontra-se na região sudeste da Bacia do Paraná. Esta anomalia é correlacionada com as intrusões alcalinas localizadas no Arco de Ponta Grossa mostrando definitivamente a ótima correlação entre as anomalias de baixa velocidade nas regiões mais rasas encontradas nas reconstruções tomográficas e as intrusões alcalinas datadas de 90 a 55 Ma.

Para anomalias de alta velocidade, observamos primeiramente o Cráton do São Francisco na Figura 5.2 muito bem delimitado horizontalmente a uma profundidade de $150 \mathrm{~km}$. Esta anomalia também é observada para profundidade de $200 \mathrm{~km}$ (Figura 5.3). Nos perfis mostrados nas Figuras 5.11 e 5.13 (Perfia A-A' e B-B') observamos a raiz do Cráton do São Francisco a uma profundidade de aproximadamente $250 \mathrm{~km}$.

Sob a Bacia do Paraná, diferente dos resultados de Escalante (2002), observamos uma diminuição da intensidade da anomalia de alta velocidade na Figura $5.2(150 \mathrm{~km})$ presente nesta região. Para uma profundidade maior $(300 \mathrm{~km})$ no entanto, a diferença entre os resultados não é tão significativa. Segundo Schimmel et al. (2003) e Escalante (2002) esta anomalia poderia ser um indicativo do núcleo cratônico da Bacia do Paraná inferido por Cordani et al. (1984) e Brito Neves et al. (1984) nesta região. Esta anomalia pode ser observada ainda no perfil B-B' (Figura 5.13) chegando a uma profundidade de $250 \mathrm{~km}$ aproximadamente.

Uma outra anomalia de alta velocidade localizada no centro da Bacia do Paraná relacionada 
a subducção da Placa de Nazca (Escalante 2002) está mostrada nas Figuras 5.5-5.10 e 5.13. Com base na Figura 5.13 observamos, diferente dos resultados de Escalante (2002), que a anomalia relacionada à litosfera subduzida de Nazca aparece como segmentos separados à esquerda da anomalia relacionada a pluma de Tristan da Cunha. A forma desta anomalia nestes resultados aproxima-se mais à encontrada nos resultados de Schimmel et al. (2003). De qualquer maneira esta anomalia é bem representativa da feição esperada para a litosfera subduzida da Placa de Nazca.

As Figuras 5.12, 5.14, 5.16, 5.18, 5.20 e 5.22 mostram a densidade de raios por células indicando as regiões com a maior quantidade de raios e principalmente onde ocorrem maior número de cruzamentos destes raios. Alguns autores (Spakman, 1988; Spakman \& Nolet, 1988; Sambridge, 1990) usam a densidade de raios para estimar as regiões de maior resolução.

Temos que, quanto menos uniforme for a distribuição da densidade de raios, menos resolvidas serão as estruturas de velocidade. Assim, com base nestas figuras, verificamos que nossa distribuição de raios é muito variada, e que a região de maior resolução (maior número de raios cruzados) se mostra normalmente no centro do volume estudado (Figura 4.2). Existe uma super amostragem de raios que vêm do noroeste, devido à grande quantidade de eventos desta direção. Entre as principais consequências desta super amostragem, verificamos prolongamentos de algumas anomalias nesta direção (Figura 5.11).

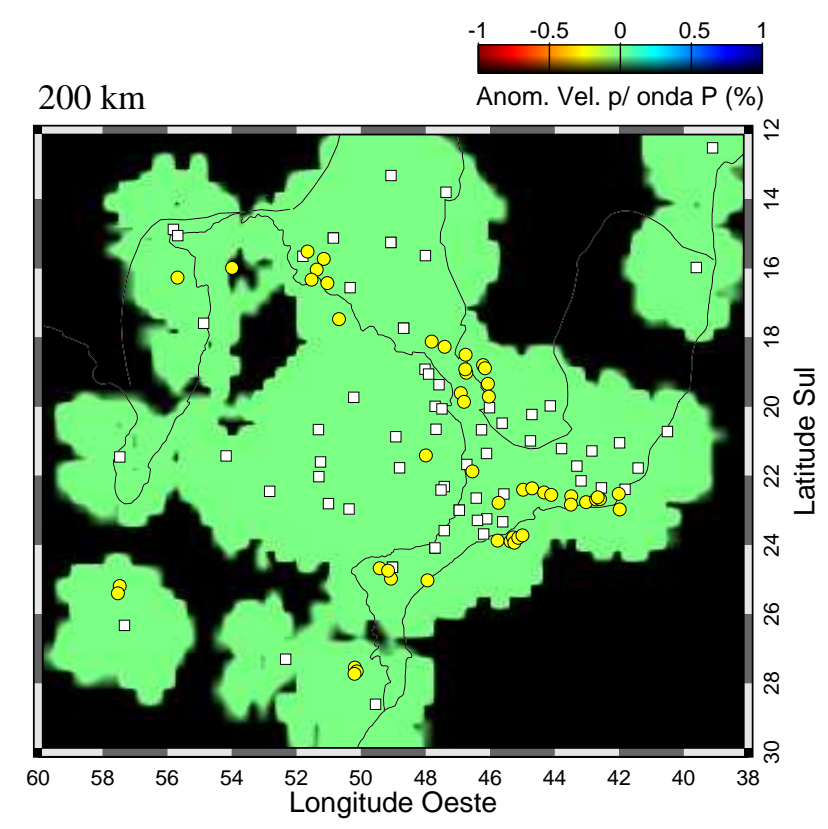

FiguRA 5.1 - Imagem tomográfica a uma profundidade de $200 \mathrm{~km}$ para um modelo de Terra, homogênio e isotrópico. 


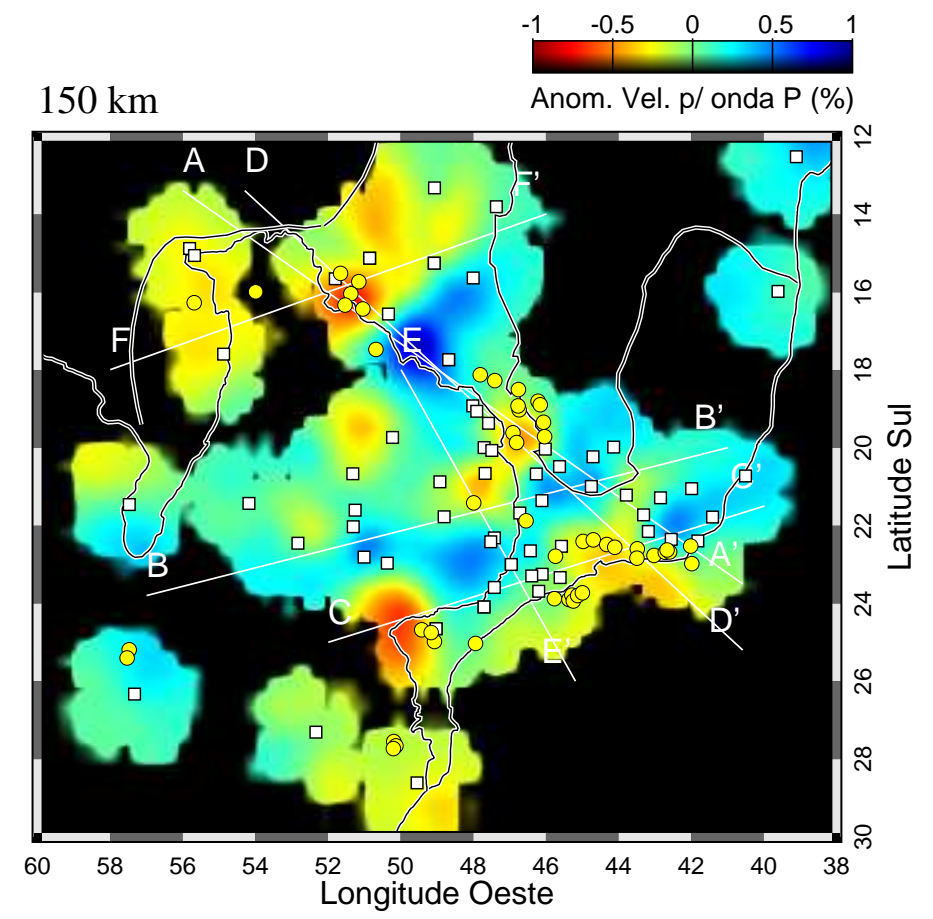

FiguRA 5.2 - Imagem tomográfica horizontal a uma profundidade de $150 \mathrm{~km}$, mostrando anomalias de alta e baixa velocidade em relação ao modelo médio de velocidades. Os círculos amarelos representam as intrusões alcalinas do Cretáceo Superior, os quadrados brancos são estações da rede e as linhas brancas perfis verticais.

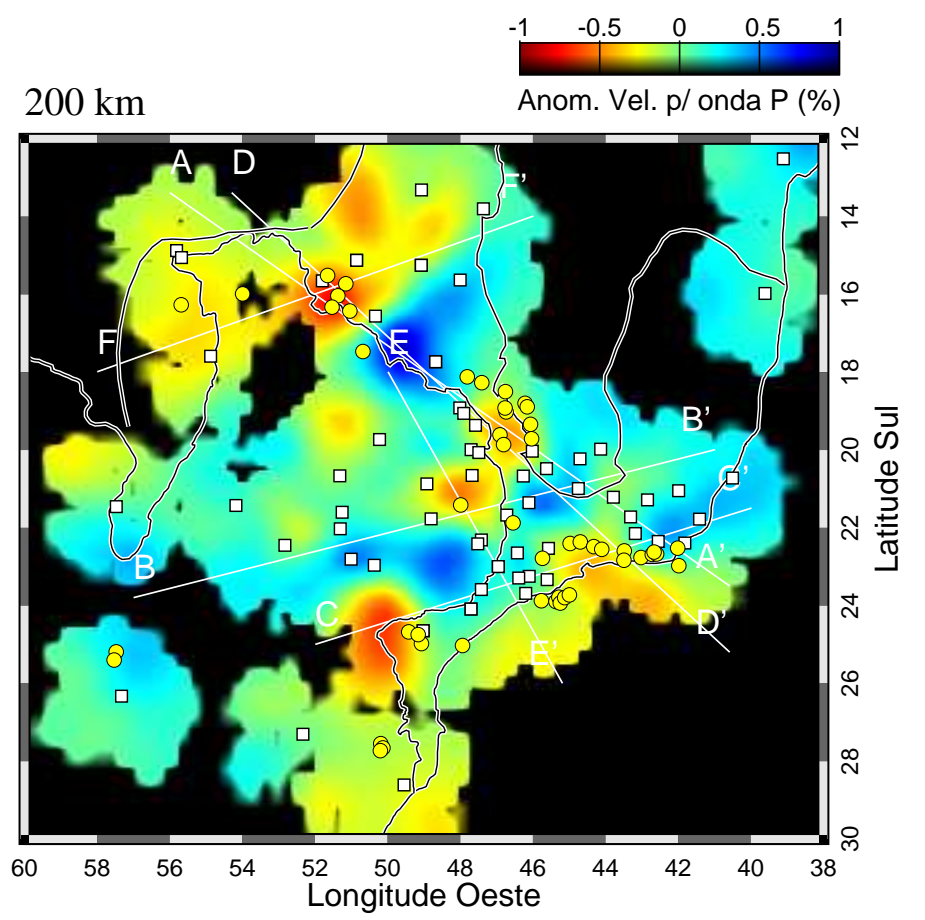

FIgURA 5.3 - Imagem tomográfica horizontal a uma profundidade de $200 \mathrm{~km}$, mostrando anomalias de alta e baixa velocidade em relação ao modelo médio de velocidades. 


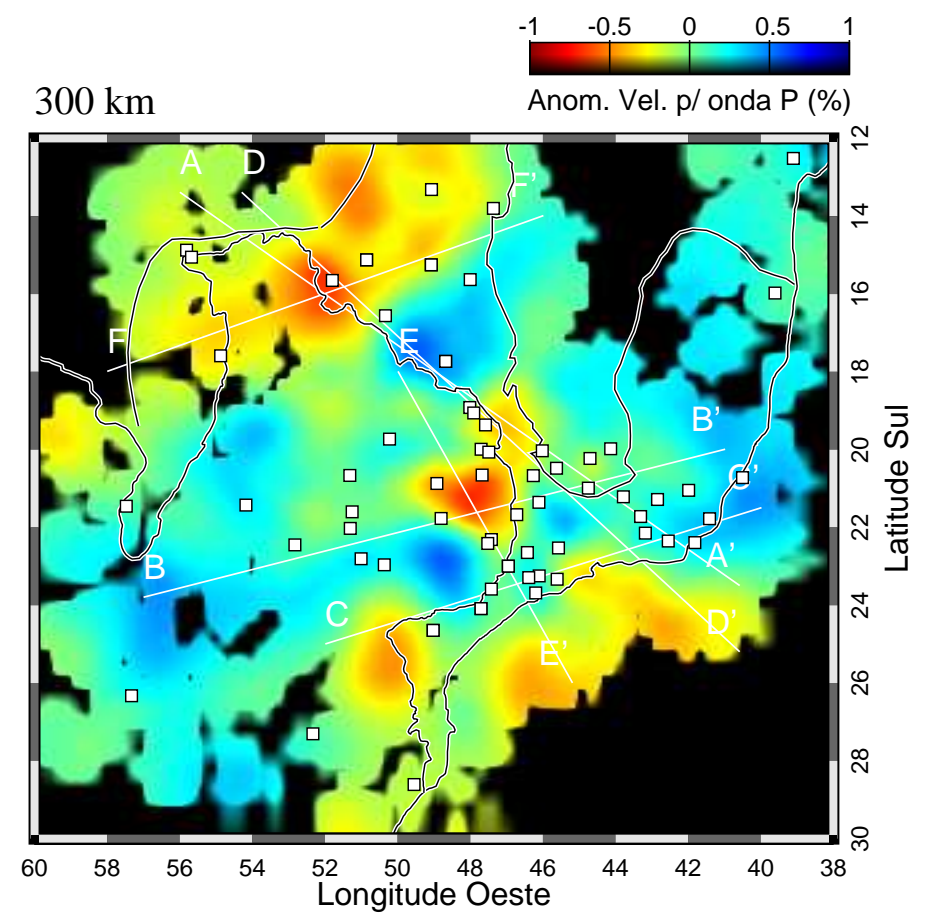

FigurA 5.4 - Imagem tomográfica horizontal a uma profundidade de $300 \mathrm{~km}$, mostrando anomalias de alta e baixa velocidade em relação ao modelo médio de velocidades. Os quadrados brancos são estações da rede e as linhas brancas perfis verticais.

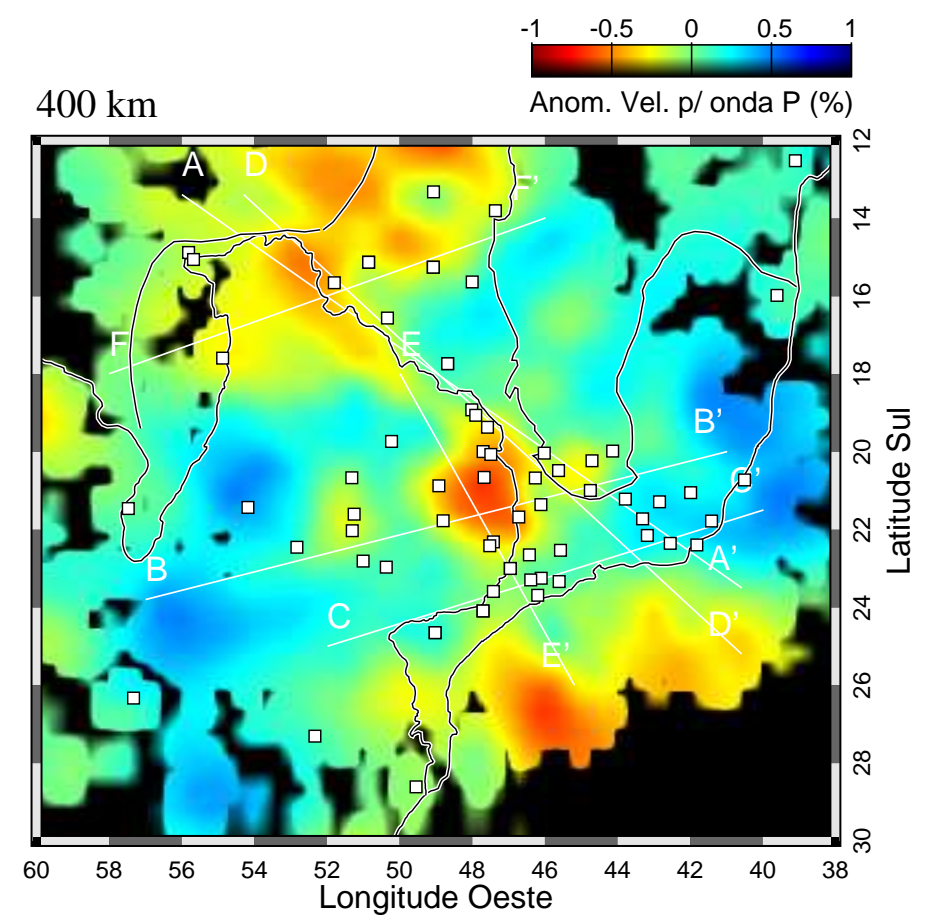

FigurA 5.5 - Imagem tomográfica horizontal a uma profundidade de $400 \mathrm{~km}$, mostrando anomalias de alta e baixa velocidade em relação ao modelo médio de velocidades. 


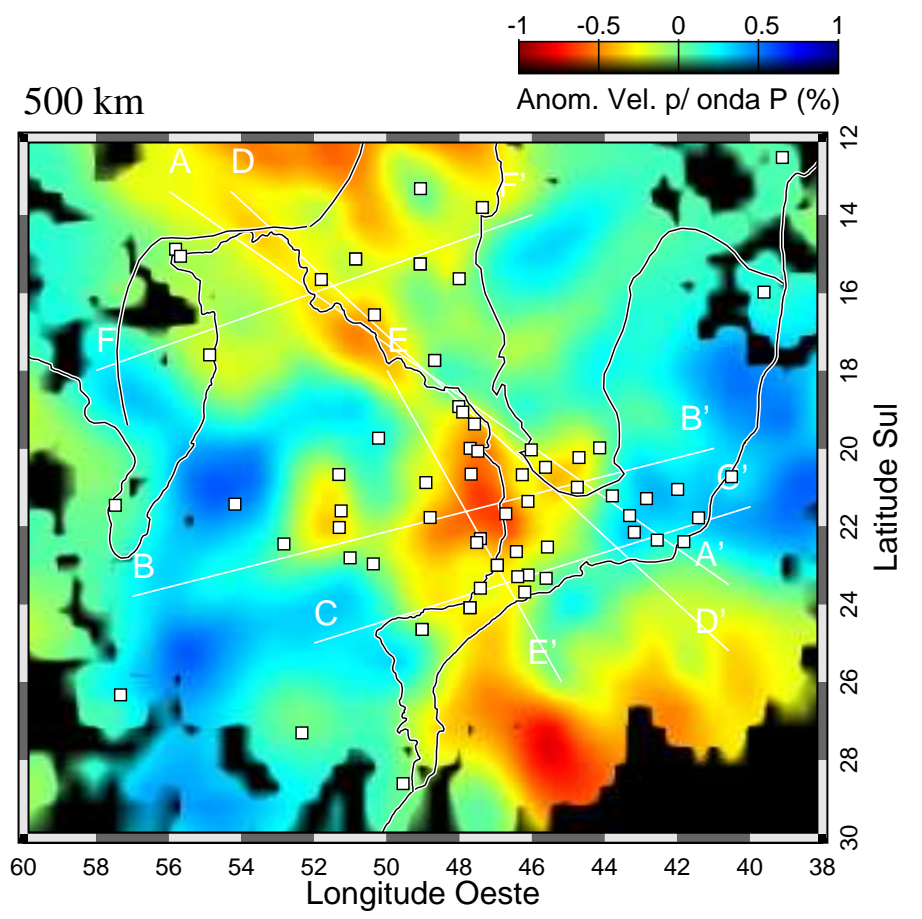

FIgURA 5.6 - Imagem tomográfica horizontal a uma profundidade de $500 \mathrm{~km}$, mostrando anomalias de alta e baixa velocidade em relação ao modelo médio de velocidades.

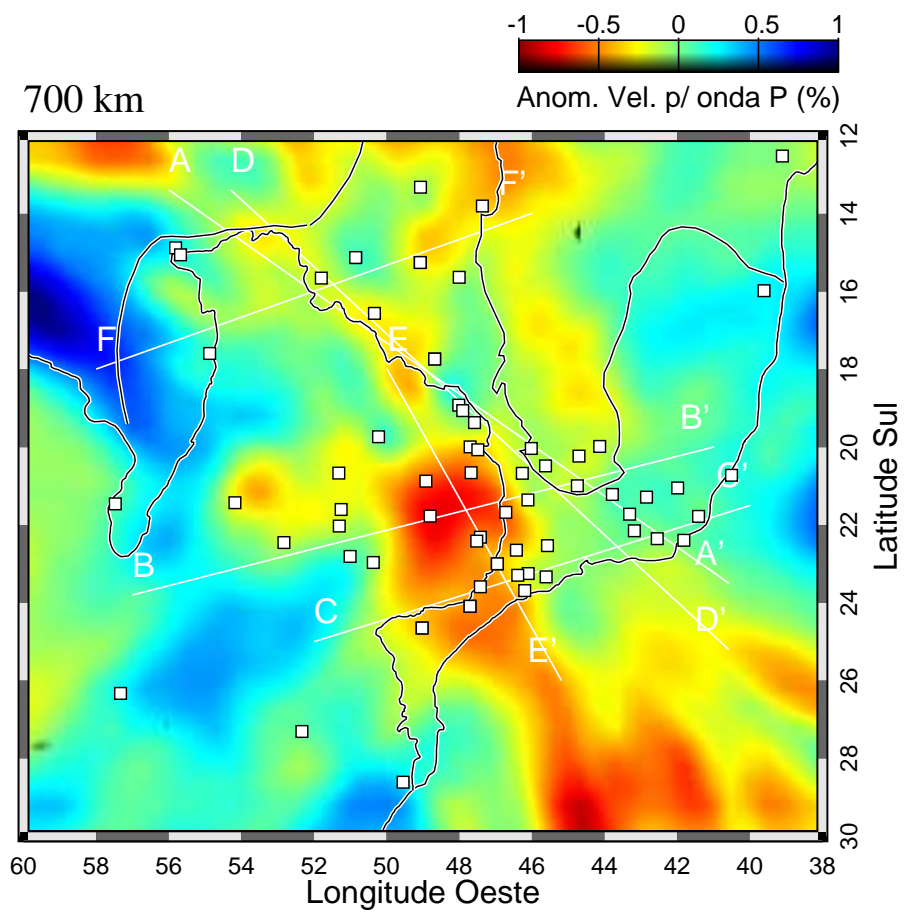

FIgURA 5.7 - Imagem tomográfica horizontal a uma profundidade de $700 \mathrm{~km}$, mostrando anomalias de alta e baixa velocidade em relação ao modelo médio de velocidades. 


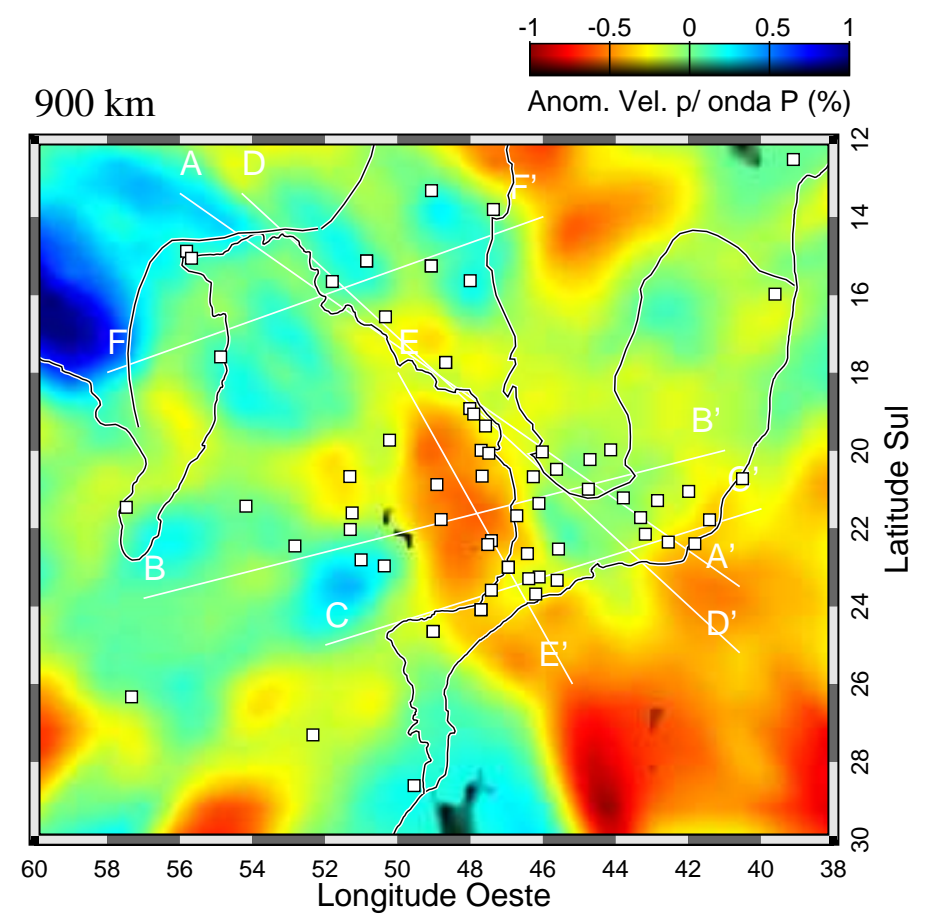

FIgURA 5.8 - Imagem tomográfica horizontal a uma profundidade de $900 \mathrm{~km}$, mostrando anomalias de alta e baixa velocidade em relação ao modelo médio de velocidades.

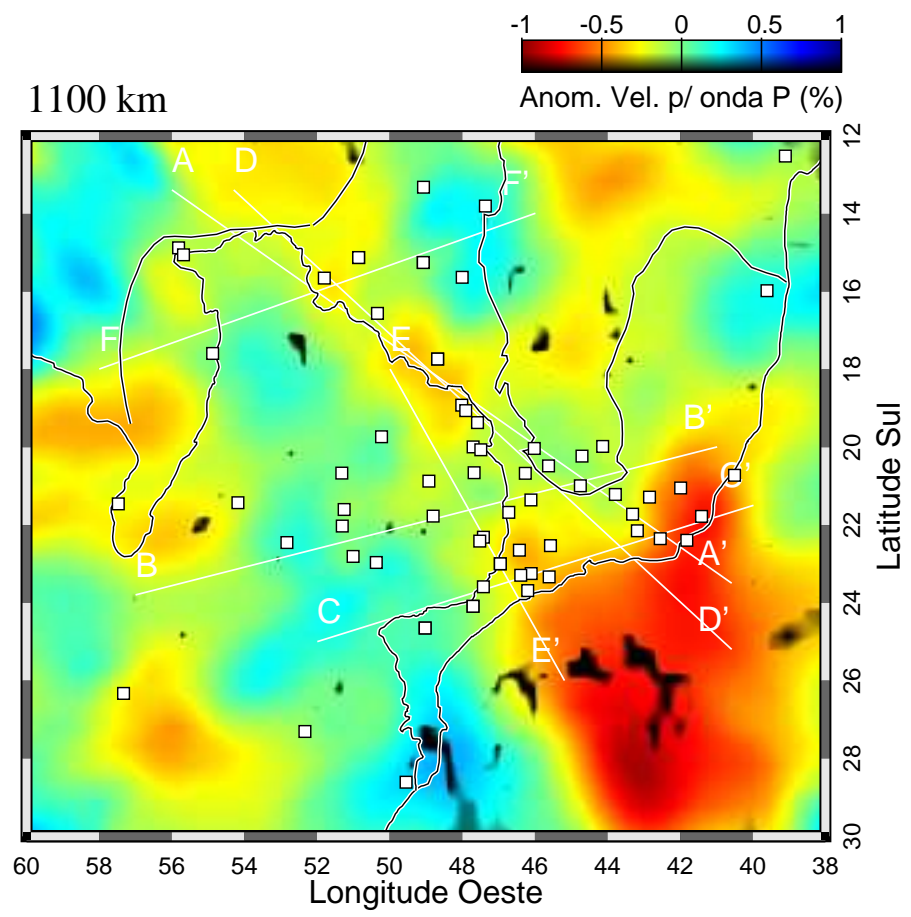

FIgURA 5.9 - Imagem tomográfica horizontal a uma profundidade de $1100 \mathrm{~km}$, mostrando anomalias de alta e baixa velocidade em relação ao modelo médio de velocidades. 


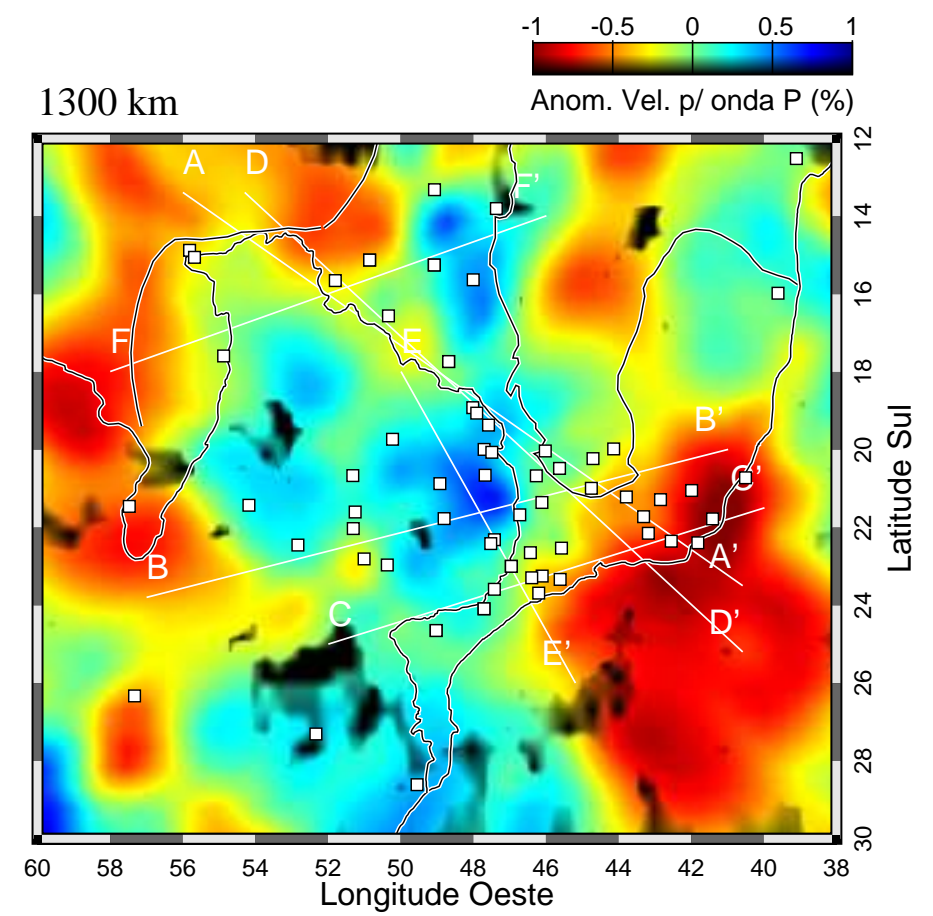

FiguRA 5.10 - Imagem tomográfica horizontal a uma profundidade de $1300 \mathrm{~km}$, mostrando anomalias de alta e baixa velocidade em relação ao modelo médio de velocidades. 


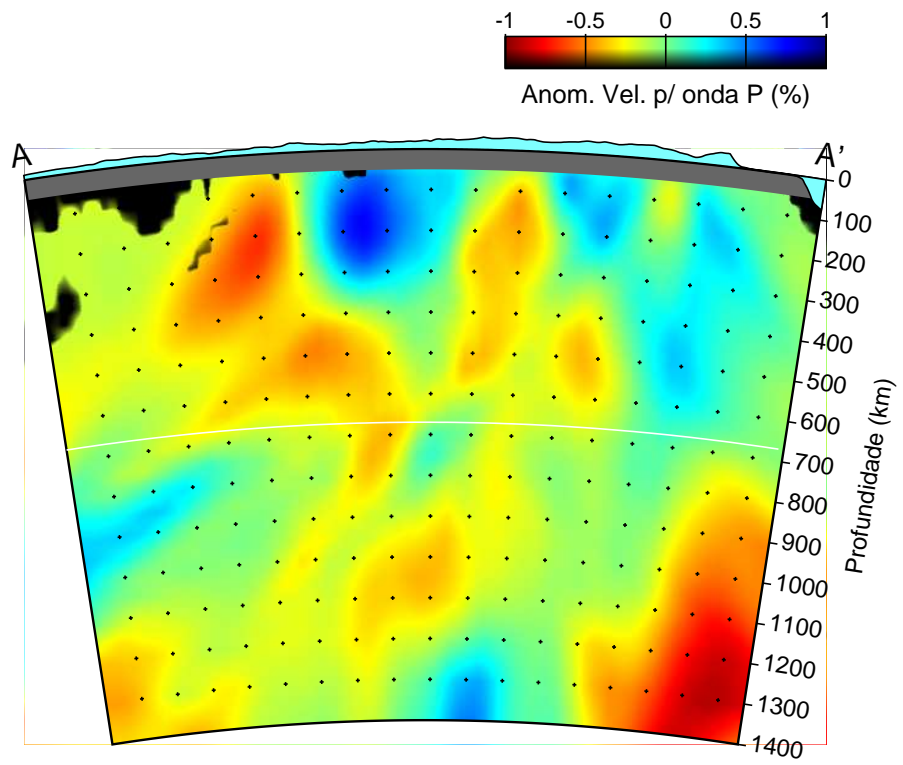

Figura 5.11 - Perfil vertical A-A' até uma profundidade de $1400 \mathrm{~km}$ destacando principalmente a anomalia de baixa velocidade de Iporá.
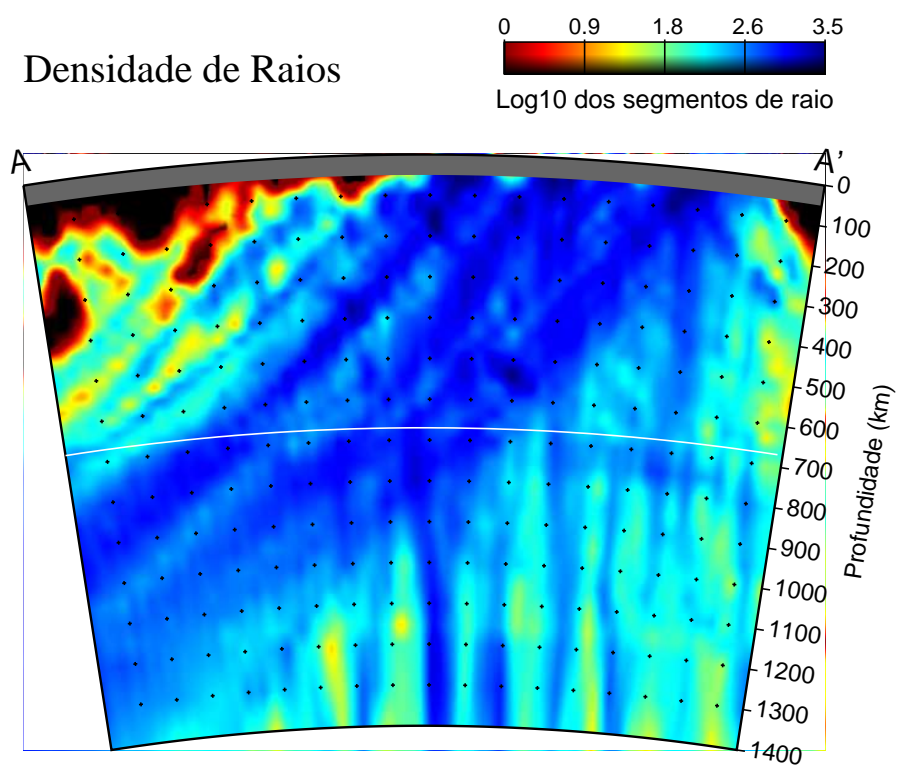

FiguRA 5.12 - Perfil vertical A-A' mostrando a distribuição da densidade dos raios (em $\log 10)$ por célula. 


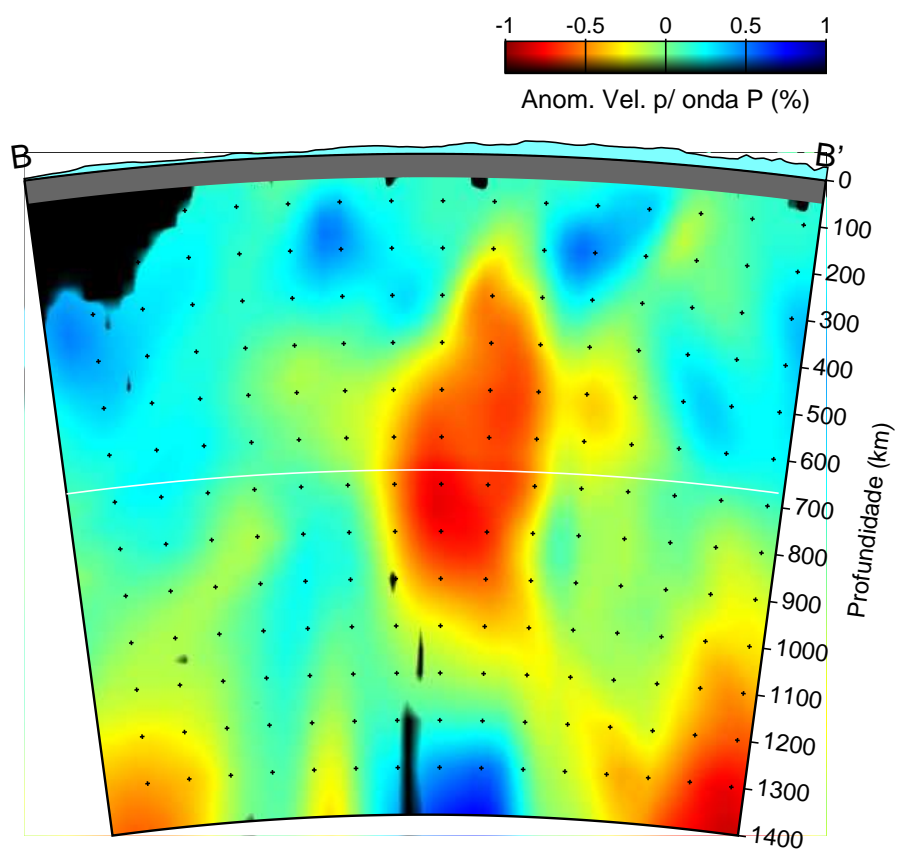

Figura 5.13 - Perfil vertical B-B' destacando no centro a anomalia de baixa velocidade atribuída à pluma de Tristan da Cunha de acordo com Schimmel et al. (2003) e VanDecar et al. (1995). A placa de Nazca aparece a esquerda da anomalia de Tristan da Cunha como segmentos de alta velocidade separados.
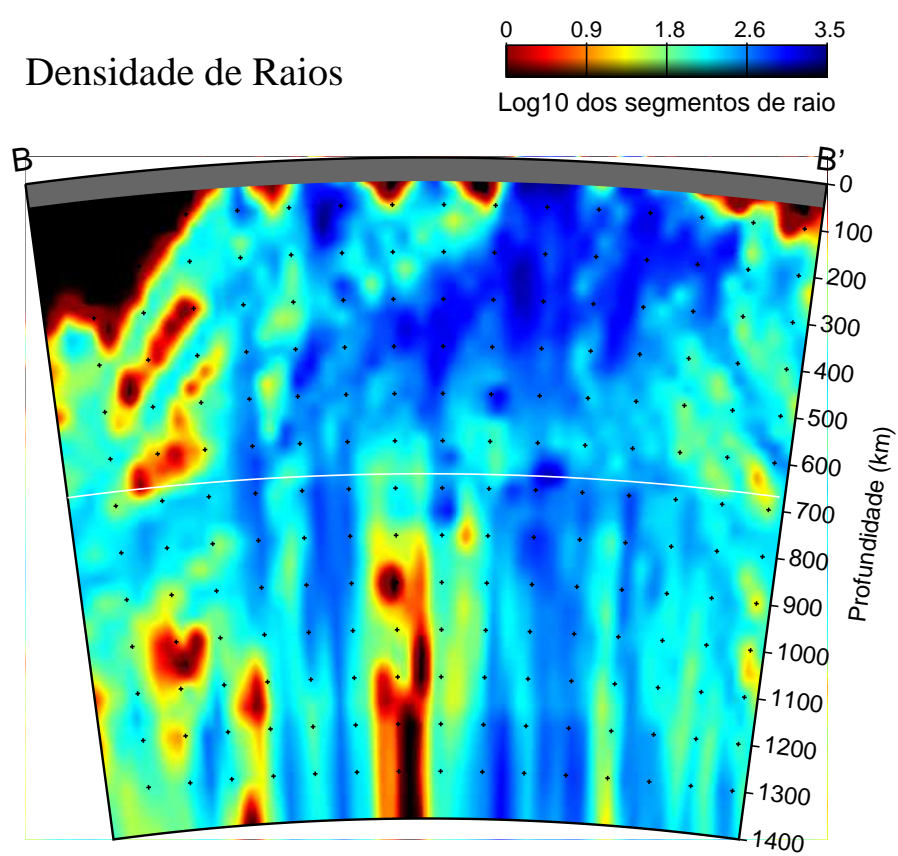

Figura 5.14 - Perfil vertical B-B' até uma profundidade de $1400 \mathrm{~km}$ mostrando a distribuição da densidade dos raios (em $\log 10)$ por célula. 


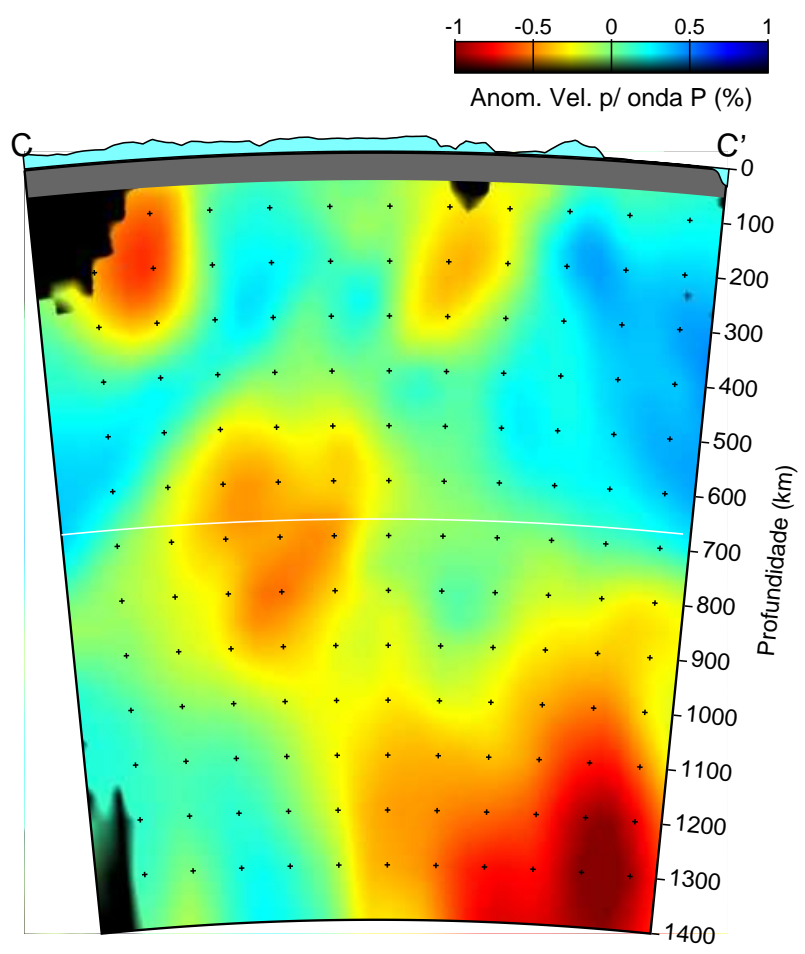

Figura 5.15 - Perfil vertical C-C' até uma profundidade de $1400 \mathrm{~km}$ destacando principalmente anomalias de baixa velocidade relacionadas a intrusões alcalinas datadas de $90-55$ Ma.

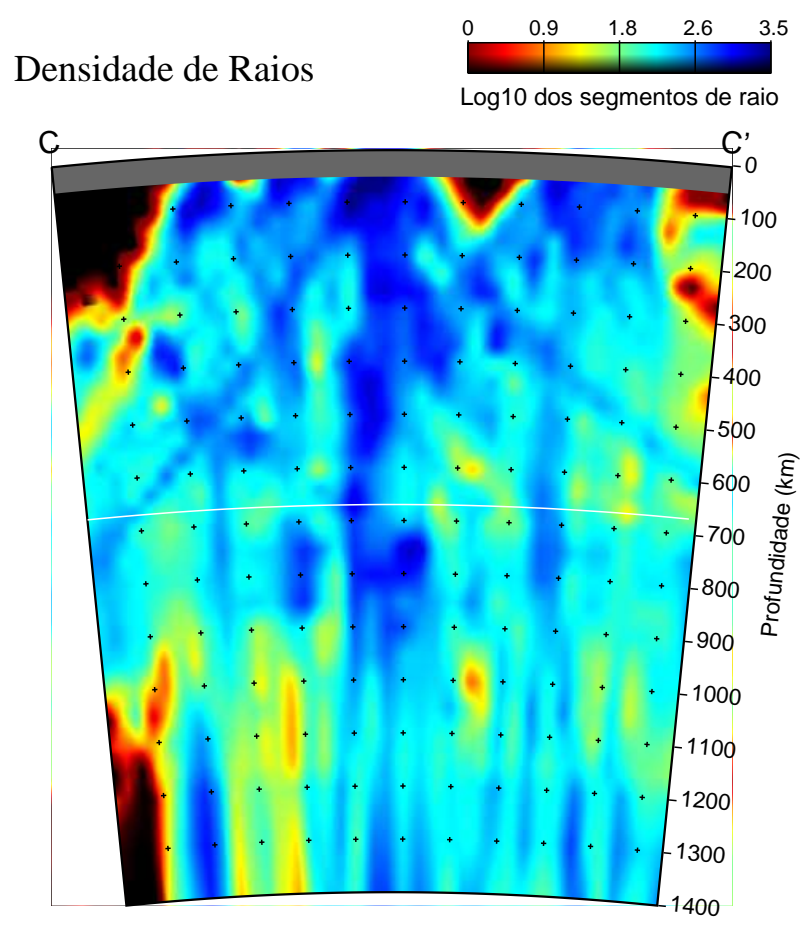

Figura 5.16 - Perfil vertical C-C' até uma profundidade de $1400 \mathrm{~km}$ mostrando a distribuição da densidade dos raios (em log10) por célula. 


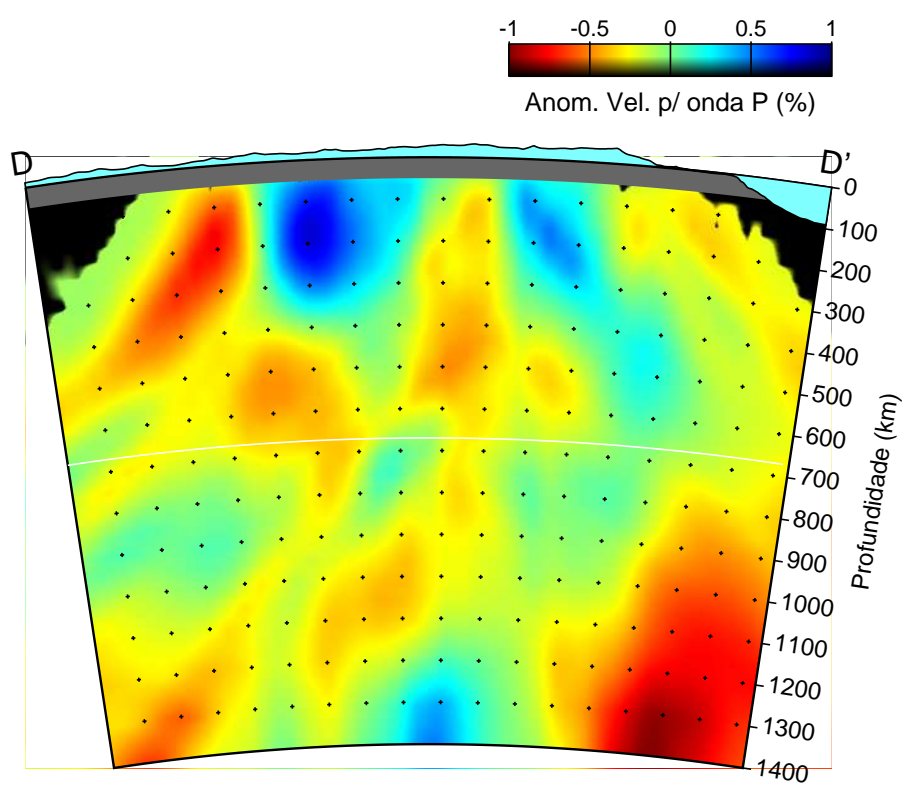

Figura 5.17 - Perfil vertical D-D' até uma profundidade de $1400 \mathrm{~km}$ destacando principalmente as anomalias de baixa velocidade de Iporá e de alta velocidade relacionada à parte sul da Faixa Brasília (Escalante 2002).

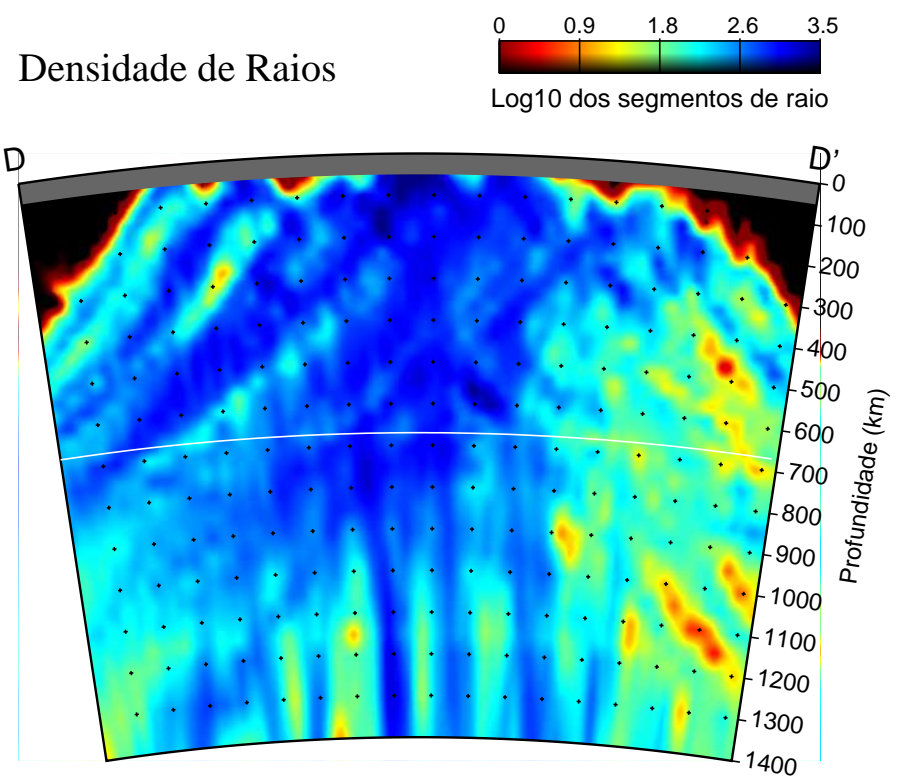

FiguRA 5.18 - Perfil vertical D-D' até uma profundidade de $1400 \mathrm{~km}$ mostrando a distribuição da densidade dos raios (em $\log 10)$ por célula. 


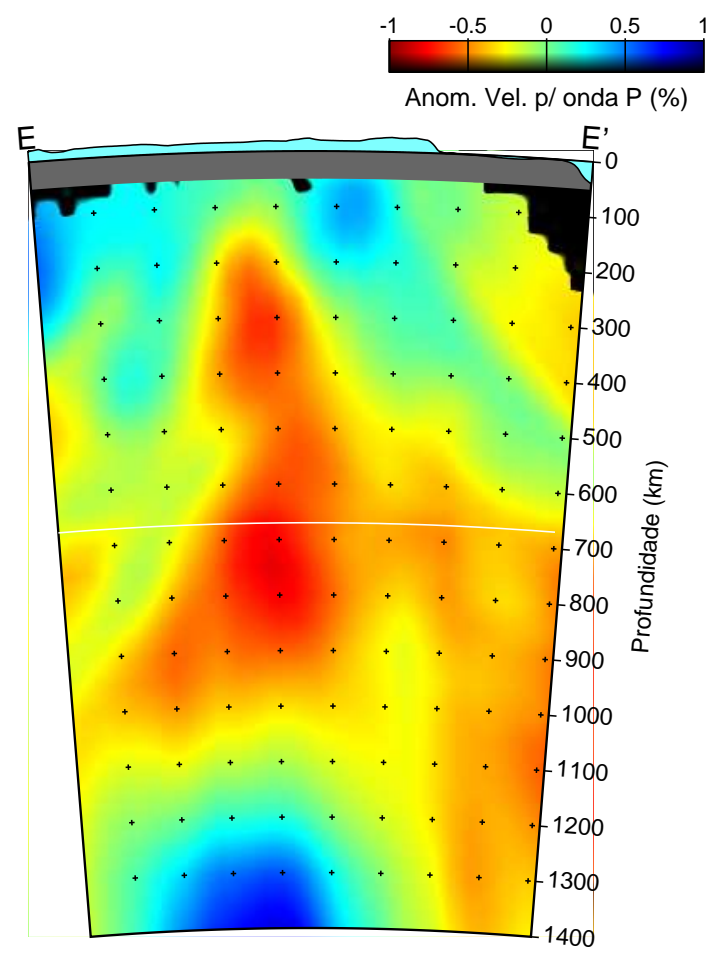

FigurA 5.19 - Perfil vertical E-E' até uma profundidade de $1400 \mathrm{~km}$ mostrando principalmente a junção da anomalia de baixa velocidade atribuída à pluma de Tristan da Cunha com uma anomalia (baixa velocidade) espúria (Escalante 2002) a partir dos $500 \mathrm{~km}$.

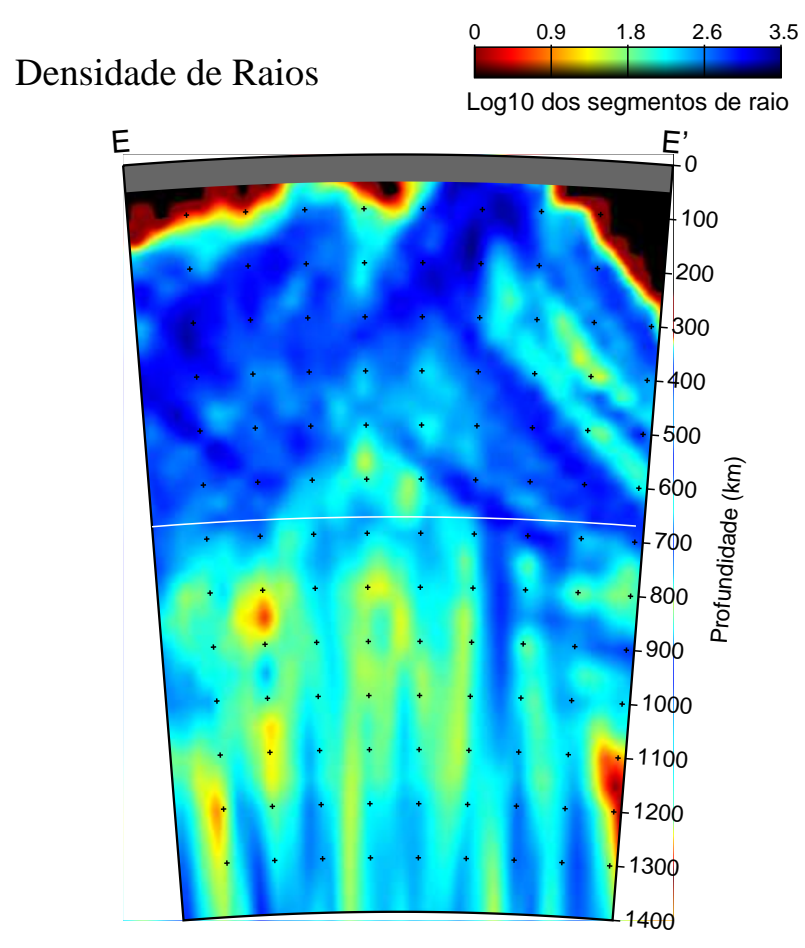

Figura 5.20 - Perfil vertical E-E' até uma profundidade de $1400 \mathrm{~km}$ mostrando a distribuição da densidade dos raios (em $\log 10)$ por célula. 


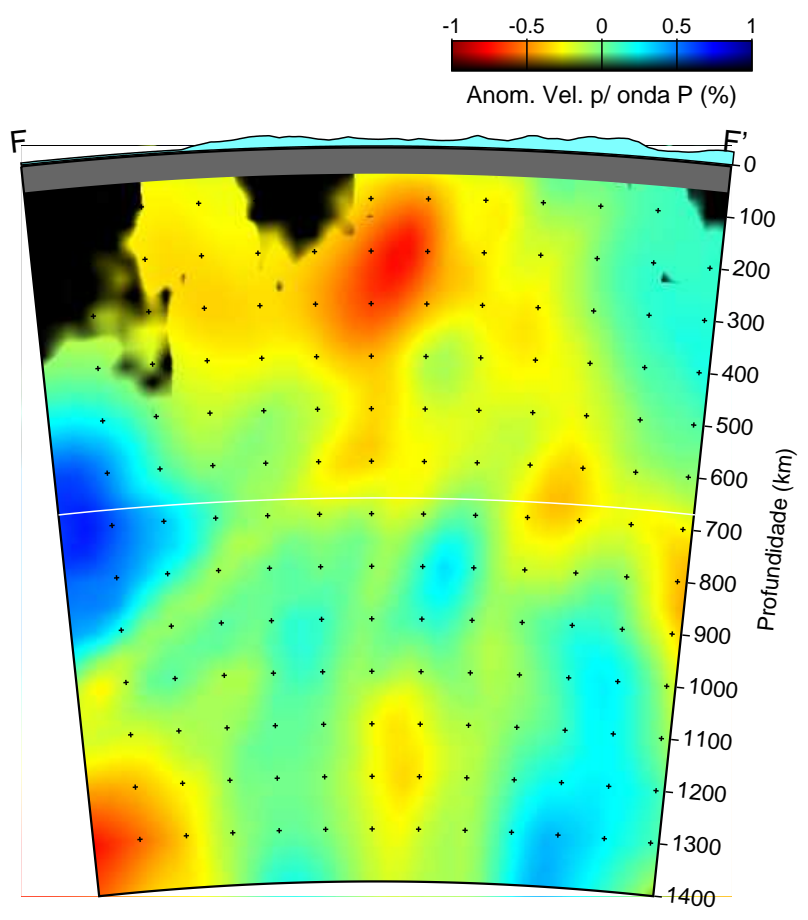

FigurA 5.21 - Perfil vertical F-F' até uma profundidade de $1400 \mathrm{~km}$ destacando principalmente a anomalia de baixa velocidade de Iporá e a tendência de baixa velocidade da região da Província Ígnea de Poxoréu em Mato Grosso.

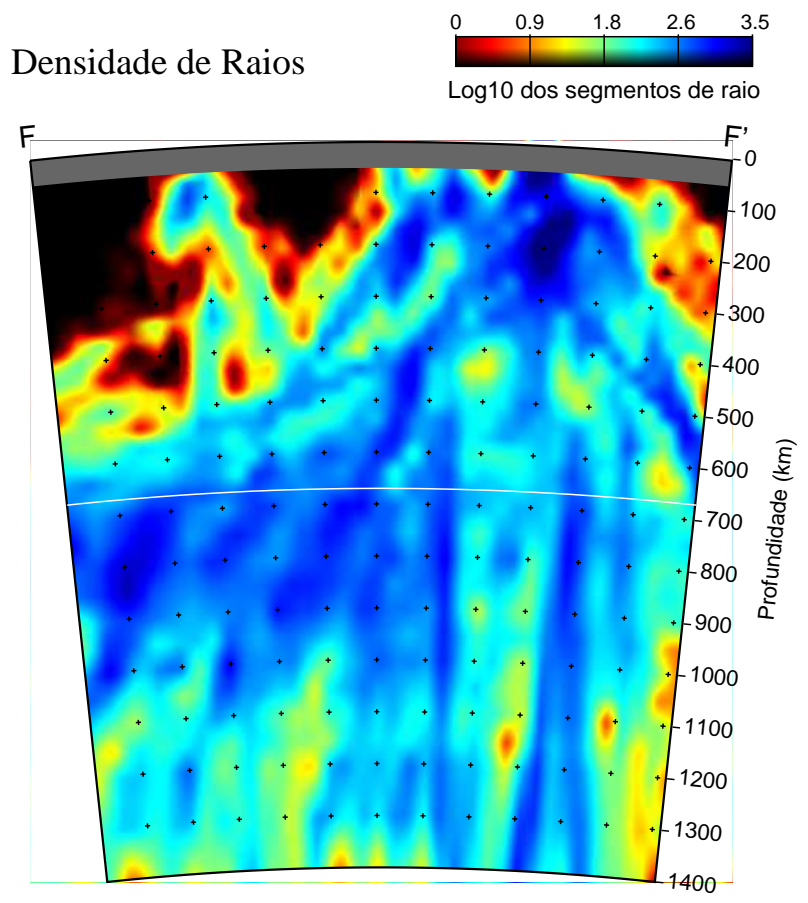

FIgURA 5.22 - Perfil vertical F-F' até uma profundidade de $1400 \mathrm{~km}$ mostrando a distribuição da densidade dos raios (em $\log 10)$ por célula. 


\subsection{Resultados Retirando EstaÇÕes}

A retirada sistemática dos dados de uma ou mais estações localizadas em regiões específicas, permite a observação da dependência das anomalias presentes, em relação às estações retiradas. Alguns testes foram feitos para estimar este tipo de dependência em algumas regiões de interesse.

A Figura 5.23 (e a Figura 5.24d) mostra a imagem de uma inversão (smoothness 90000 e flatness 2800) realizada para todos os dados (Figura 5.23a) e ainda inversões com retirada das estações localizadas nas Províncias Ígneas de Iporá e Poxoréu (Figuras 5.23a, 5.23b, 5.23c, 5.23d, $5.23 \mathrm{e}$ e $5.23 \mathrm{f}$ ). As Figuras 5.23 e 5.24 mostram seções horizontais a profundidades de $200 \mathrm{~km}$.

As Figuras 5.23b, 5.23d, 5.23f mostram as inversões retirando as estações argb, pazb ${ }^{2}$ e slmb. Estas estações localizam-se sobre a anomalia de baixa velocidade da Província Ígnea de Iporá em Goiás. Observamos que esta anomalia sofreu uma mudança de intensidade muito grande com a retirada da estação slmb (Figura 5.23f). Acreditamos que isso se deve à grande influência dos raios vindos de noroeste da rede, já que a estação slmb localiza-se no lado oposto ao das estações argb e pazb na direção NW-SE com relação a anomalia. De uma forma geral, mesmo com a retirada da estação slmb, a região da anomalia apresenta uma tendência (menos intensa) para baixas velocidades.

A anomalia de alta velocidade localizada ao sul de Goiás perde intensidade quando se retira slmb (Figura 5.23a). No entanto não existe uma mudança significativa em sua forma. Esta anomalia é robusta, pois com a retirada de outras estações não ocorrem grandes mudanças de sua forma e feição. Ainda não existe uma explicação geológica para ela.

Nas Figuras 5.23c, 5.23e e 5.24d, observa-se as imagens tomográficas para as inversões retirando as estações de Manso (MAN1 e MAN2), a estação pp1b, e retirando somente a estação MAN2 respectivamente, as quais estão localizadas na Província Ígnea de Poxoréu (PIP). É evidente nestas figuras que a maior intensidade da anomalia de baixa velocidade desta região se deve à estação MAN2 (Figura 5.24d). Sem esta estação esta anomalia fica pouco expressiva. A estação MAN2 possui um rms dos dados muito alto (Capítulo 3), de aproximadamente 1,5 vezes maior que o desvio da base total. Desta forma, para uma melhor definição e confiança na anomalia de baixa velocidade em PIP, seriam necessários mais dados, ou ainda uma maior cobertura de estações. As outras anomalias próximas das regiões de Iporá e Poxoréu não sofrem grandes alterações.

A Figura 5.24 mostra os resultados das inversões retirando as estações UnB (Figura 5.24b), estações RESUSP e RSBC (Figura 5.24f), estações rsta e rstb ${ }^{3}$ localizadas no Arco de Ponta Grossa (Figura 5.23) e canb, localizada na região sudeste da Bacia do Paraná (Figura 5.24c).

\footnotetext{
${ }^{2}$ A estação pazb (banda larga) está na mesma posição onde operou estação paz4 (período curto).

${ }^{3}$ As estações rstb (banda larga) e rsta (período curto) operaram na mesma posição.
} 

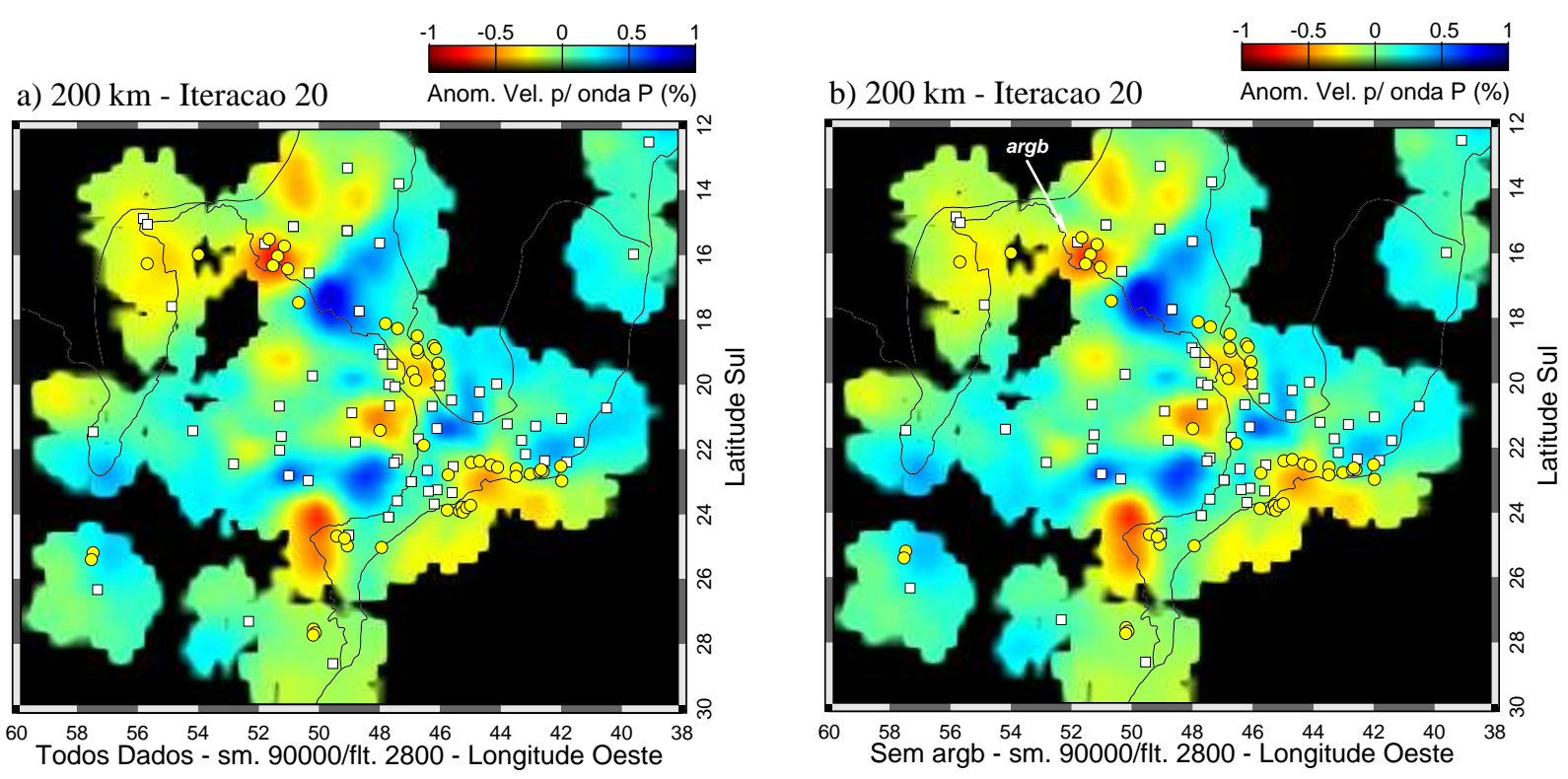

c) $200 \mathrm{~km}$ - Iteracao 20

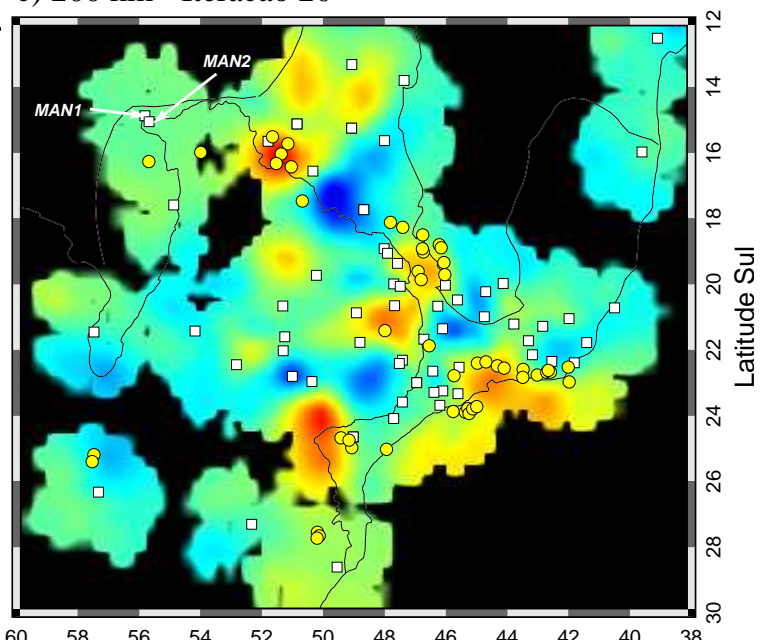

d) $200 \mathrm{~km}$ - Iteracao 20

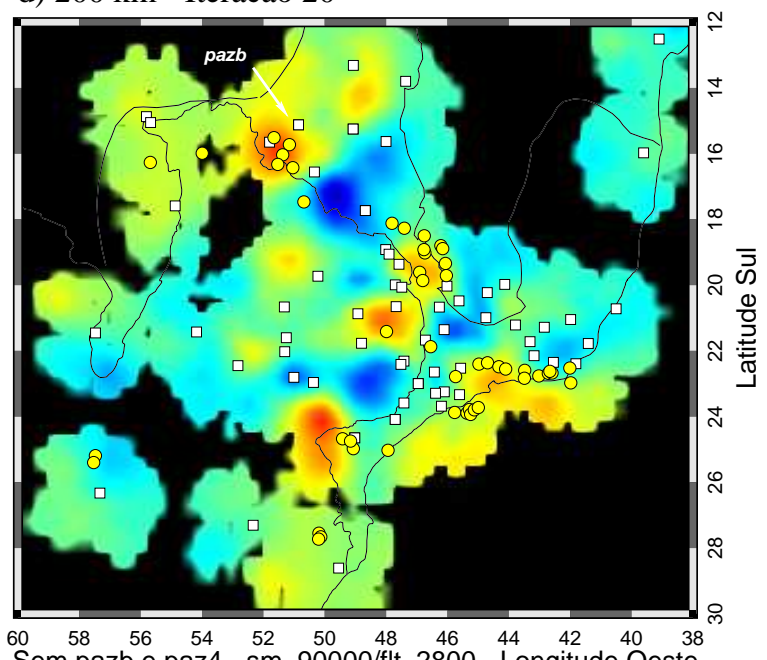

Sem Manso 1 e 2 - sm. $90000 / f$ flt. 2800 - Longitude Oeste

e) $200 \mathrm{~km}$ - Iteracao 20
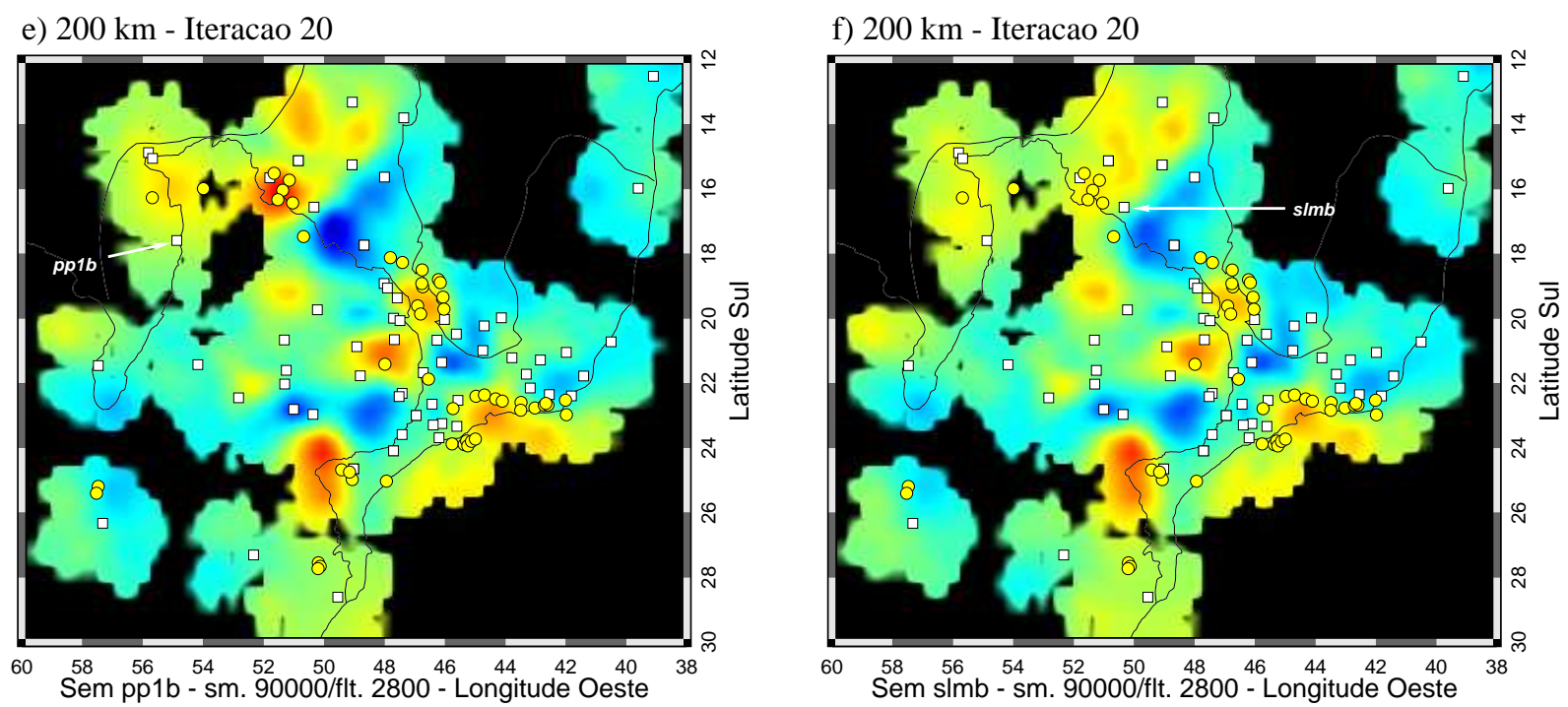

FIGURA 5.23 - Comparação entre as imagens tomográficas geradas para a) todos os dados, b) retirando argb, c) retirando as estações de Manso (1 e 2), d) retirando paz4 e pazb (mesma posição), e) retirando pp1b e f) retirando slmb. 

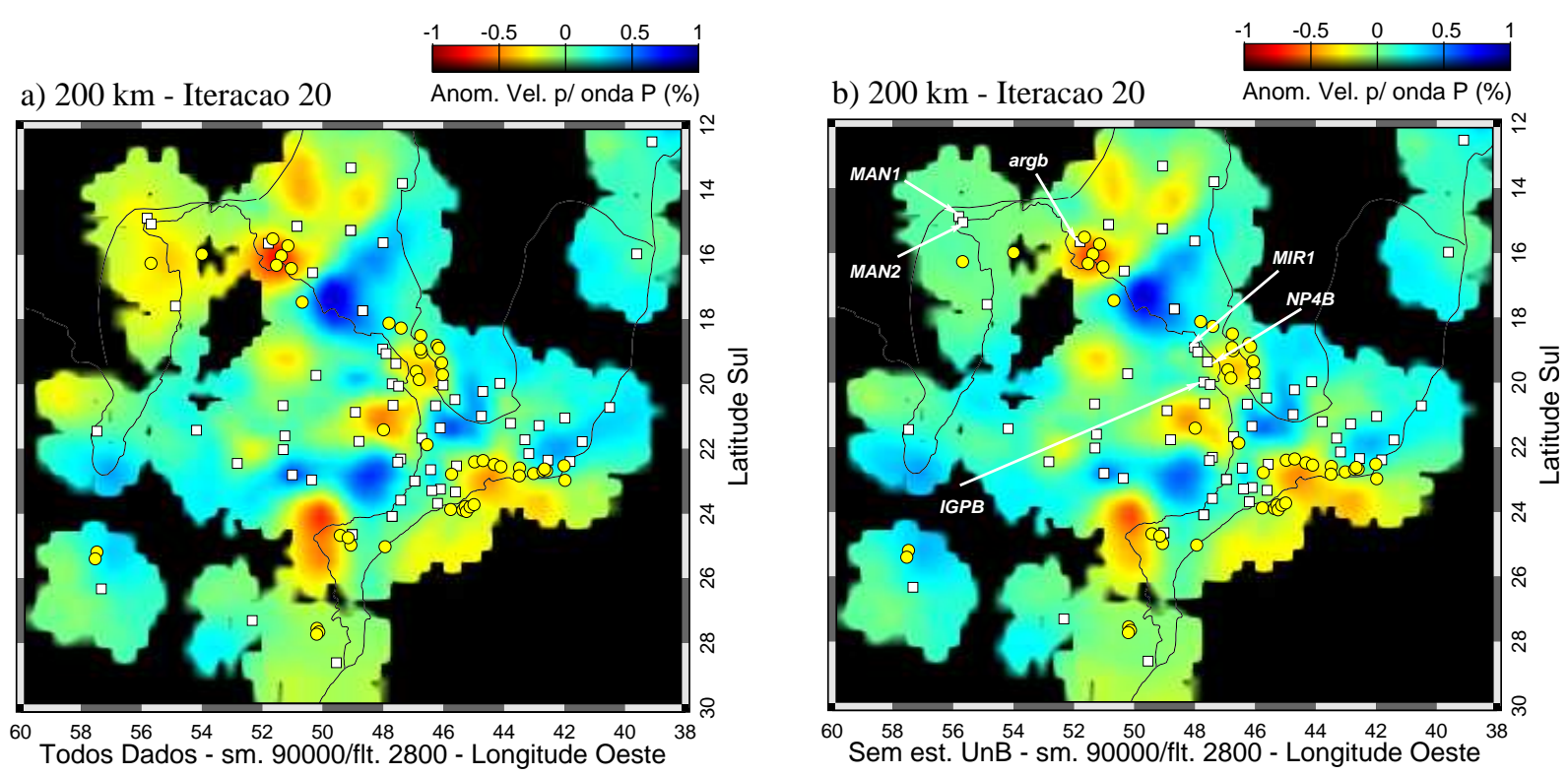

c) $200 \mathrm{~km}$ - Iteracao 20

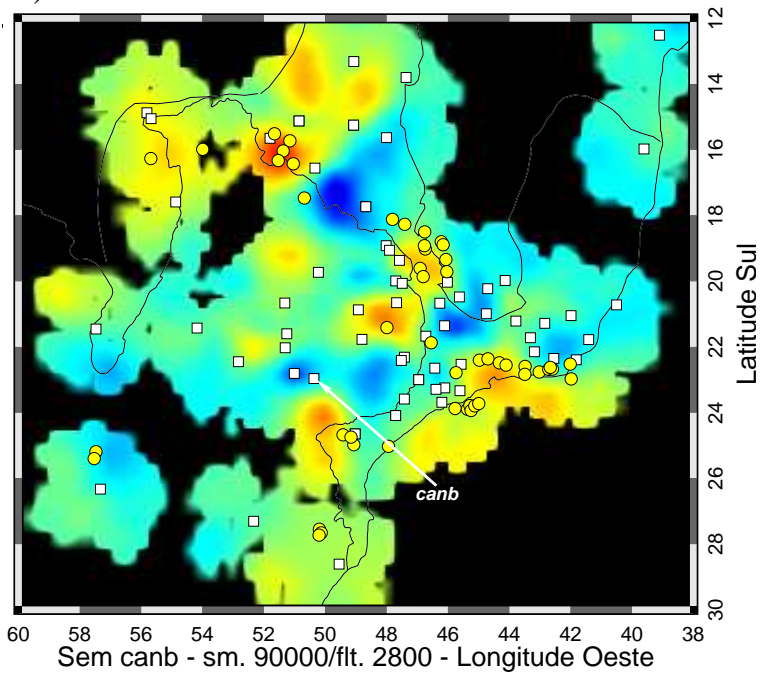

d) $200 \mathrm{~km}$ - Iteracao 20

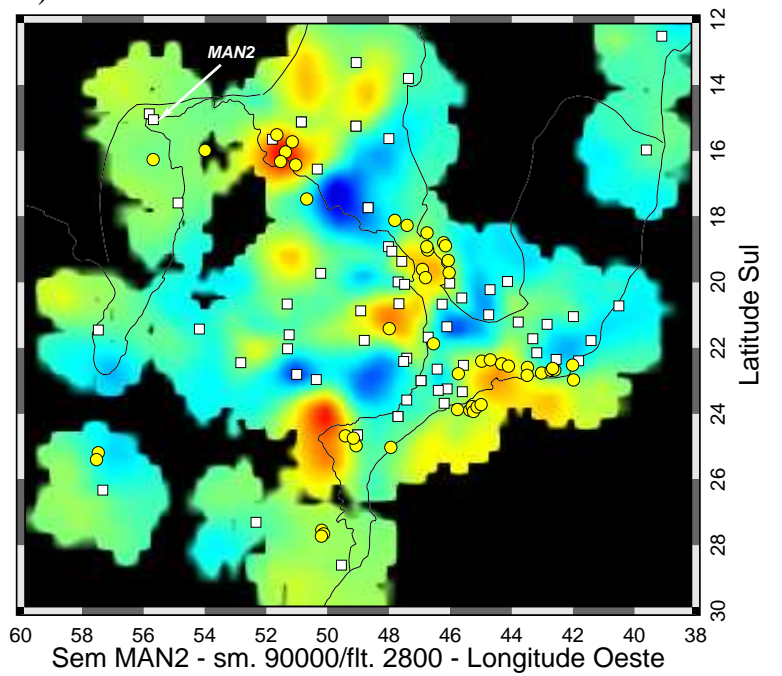

e) $200 \mathrm{~km}$ - Iteracao 20

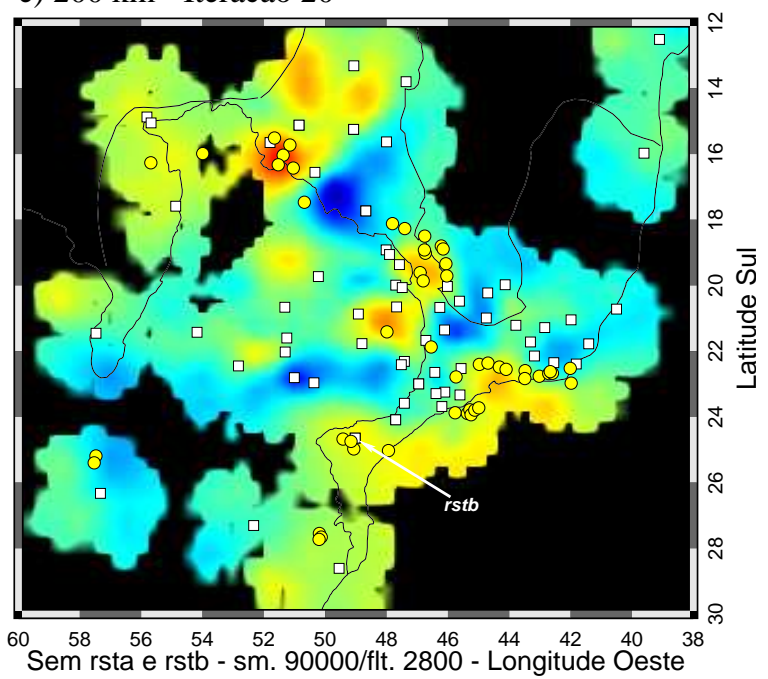

f) $200 \mathrm{~km}$ - Iteracao 20

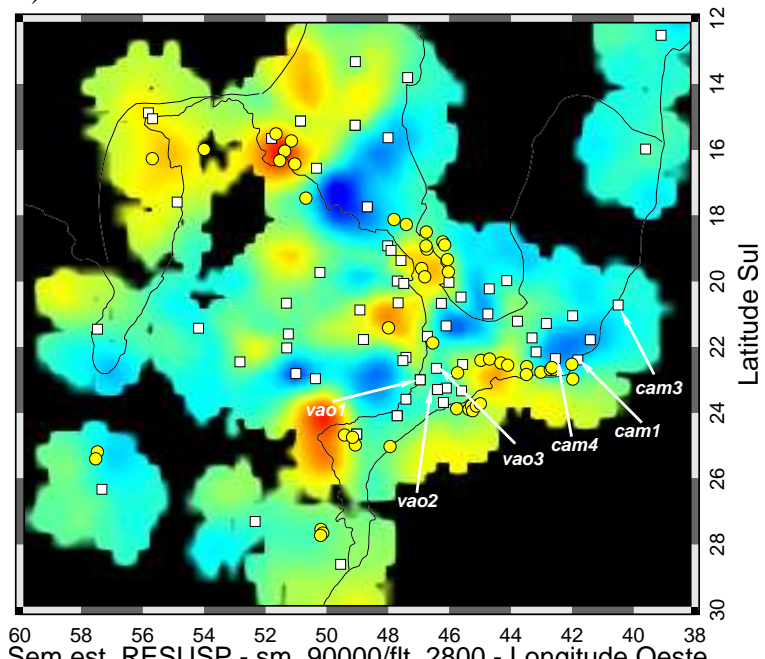

FiguRA 5.24 - Comparação entre as imagens tomográficas geradas para a) todos os dados, b) retirando estações UnB, c) retirando canb, d) retirando MAN2, e) retirando rsta e rstb (mesma posição) e f) retirando estações RESUSP e RSBC. 
$\mathrm{Na}$ Figura 5.24b observamos, com a retirada das estações da UnB (além do que já foi discutido para as estações MAN1, MAN2 e argb), apenas uma diminuição da intensidade e forma da anomalia de baixa velocidade da Província Ígnea do Alto Paranaíba (APIP), sugerindo de uma forma geral, que em regiões com muitas estações próximas (muitos raios), a retirada de algumas não afeta de forma expressiva a anomalia. Para o caso da Figura 5.24b, a retirada das estações MIR1, NP4B e IGPB da região de APIP alteram sutilmente a forma e a magnitude das anomalias. Como existem mais estações nesta região, podemos considerar que as anomalias de baixa velocidade APIP possuem um caráter robusto.

A Figura 5.24c e 5.24e mostram a retirada, durante a inversão, das estações canb e rstb respectivamente. Observamos que a retirada de ambas estações diminuem a intensidade da anomalia de baixa velocidade próxima das intrusões alcalinas do Arco de Ponta Grossa. A retirada da estação rstb influencia muito mais esta anomalia, porém permanecendo a tendência de baixa velocidade na região. Acreditamos que a maior influência de rstb se deve à posição da estação em relação à anomalia. Esta estação encontra-se do lado oposto aos Andes tomando como referência o eixo norte-sul da anomalia. Isto reflete a influência da grande quantidade de eventos ocorridos nesta região. Como no caso de slmb, seria interessante a presença de mais estações próximas e na mesma situação de rstb.

A retirada das estações da rede RESUSP e da rede RSBC (Figura 5.24f) não influenciaram significativamente as anomalias na região onde estas estações estão localizadas. 


\section{CAPítulo 6}

\section{Conclusões e Perspectivas}

Com o aumento da quantidade de raios e estações, foi possível melhorar a resolução das anomalias indicadas nos trabalhos anteriores na região de estudo. Também foi possível imagear novas regiões anômalas.

Com relação aos trabalhos anteriores, nossos resultados confirmaram todas as anomalias anteriormente reveladas. A anomalia de baixa velocidade sob a Bacia do Paraná, interpretada por VanDecar et al. (1995) como resto fóssil da pluma de Tristan da Cunha, foi observada a partir dos $250 \mathrm{~km}$ de profundidade, chegando até $1000 \mathrm{~km}$. Na parte mais profunda (de 700 a $1000 \mathrm{~km}$ ) não foi possível delimitar esta anomalia com precisão, mostrando desta forma, de acordo com Escalante (2002), que apenas em partes mais rasas ela pode ser bem definida. Em nossos resultados esta anomalia apareceu de forma mais compacta comparada com os resultados de Escalante (2002).

A correlação entre as intrusões alcalinas do Cretáceo Superior e as anomalias de baixa velocidade observadas anteriormente por Schimmel et al. (2003) e Escalante (2002) também foi observada, reafirmando que estas anomalias estariam relacionadas a regiões de alta temperatura e que as intrusões alcalinas teriam sua origem na parte inferior da litosfera.

O Cráton do São Francisco aparece bem delimitado para profundidades mais rasas (150 km), com suas raízes chegando até $250 \mathrm{~km}$.

A anomalia de baixa velocidade sob a região de Iporá em Goiás (Escalante 2002), também apareceu em nossas imagens. A persistência desta anomalia indica-lhe um caráter robusto. No entanto, testes retirando estações nesta região mostraram a grande influência da estação slmb (São Luis de montes Belos - GO) sobre sua intensidade. Concluímos que isso se deve à posição desta estação, que fica a sudeste da anomalia. Isto faz com que a estação registre a maior parte dos eventos que vêm do noroeste (Andes) e que atravessam a região anômala. De qualquer maneira mesmo sem a estação slmb, a região possui uma tendência para baixas velocidades.

Da mesma forma para a anomalia de baixa velocidade próxima das intrusões alcalinas do Arco de Ponta Grossa, observamos uma diminuição de intensidade com a retirada da estação 
rstb (Adianópolis - PR). Acreditamos que isso ocorre pelo mesmo motivo descrito para slmb, já que a estação rstb está localizada a leste da anomalia. Para estudos tomográficos futuros, sugerimos a instalação de novas estações nestas duas regiões.

A anomalia de alta velocidade sob a Bacia do Paraná (profundidades rasas) interpretada inicialmente por Schimmel et al. (2003) como possível núcleo cratônico desta Bacia (Cordani et al. 1984) foi também observada. Em nossos resultados não foi observada nenhuma diferença significativa para esta anomalia em relação aos resultados anteriores.

Sob a Bacia do Paraná a profudidades maiores, interpretamos uma anomalia de alta velocidade como a litosfera subduzida da Placa de Nazca. Esta anomalia pode ser inferida até os 1300 $\mathrm{km}$ aproximadamente.

Com a inclusão dos dados das novas estações na parte sul do estado de Mato Grosso (MAN1, MAN2 e pp1b), foi observada uma nova anomalia de baixa velocidade. Devido à proximidade desta anomalia com as intrusões alcalinas da província ígnea de Poxoréu em Mato Grosso, ela pode ser explicada como uma continuidade do processo de magmatismo do Cretáceo Superior relacionado ao afinamento litosferico. Isto indica que nesta região podem existir mais estruturas relacionadas ao efeito inicial da pluma de Trindade. Porém a cobertura de estações é baixa, tendo as estações presentes poucos dados e um desvio padrão relativamente alto. Desta forma há a necessidade de instalação de mais estações nesta região para confirmar estas anomalias. 


\section{APÊNDICE A}

\section{Novas EstaÇÕES}

TABELA A.1 - Localização das novas estações incluídas na rede utilizada.

\begin{tabular}{|c|c|c|c|l|c|}
\hline $\begin{array}{c}\text { Estação } \\
\text { Nome }\end{array}$ & $\begin{array}{c}\text { Latitude } \\
\text { Sul }\end{array}$ & $\begin{array}{c}\text { Longitude } \\
\text { Oeste }\end{array}$ & $\begin{array}{c}\text { Elevação } \\
\text { (Metros) }\end{array}$ & Localidade & Projeto \\
\hline bamb & -20.0398 & -46.0308 & 705 & Bambuí- SP & BLSP \\
cv1b & -13.8142 & -47.3767 & 801 & Cavalcante - GO & BLSP \\
itab & -27.3082 & -52.3411 & 459 & Ita-1 - RS & ETH/BLSP02 \\
itpb & -15.9887 & -39.6282 & 307 & Itapebi - BA & ETH/BLSP02 \\
MAN1 & -14.8872 & -55.8168 & 320 & Hidroel. do Rio Manso - MT & UnB \\
MAN2 & -15.0672 & -55.6815 & 360 & Hidroel. do Rio Manso - MT & UnB \\
novb & -28.6105 & -49.5582 & 135 & Nova Vaneza - SC & BLSP \\
pacb & -21.6074 & -51.2618 & 341 & Pacaembu - SP & BLSP \\
pdcb & -12.5306 & -39.1238 & 220 & Pedra do Cavalo - BA & ETH/BLSP \\
pp1b & -17.6009 & -54.8797 & 370 & Sonora - MS & BLSP \\
rcla & -22.4191 & -47.5310 & 660 & Rio Claro - SP & BLSP \\
\hline
\end{tabular}




\section{APÊNDICE B}

\section{Eventos UtilizAdos - 2002}

TABela B.1 - Novos eventos incluídos durante este trabalho na base de dados total.

\begin{tabular}{|c|c|c|c|c|c|c|c|}
\hline Data & Dia Jul. & Hora & $\mathrm{Loc}$ & zação & Prof. & Magnitude & Fase \\
\hline $\mathrm{dd} / \mathrm{mm} / \mathrm{aaaa}$ & $\mathrm{jjj}$ & (UTC) & Latitude & Longitude & $(\mathrm{km})$ & $m_{b}$ & Tipo \\
\hline $01 / 01 / 2002$ & $(001)$ & $11: 29: 22.700$ & 6.303 & 125.65 & 138 & 5.9 & PKP \\
\hline $06 / 01 / 2002$ & $(006)$ & $18: 49: 22.700$ & 12.538 & -87.672 & 059 & 5.2 & $\mathrm{P}$ \\
\hline $07 / 01 / 2002$ & $(007)$ & $13: 26: 26.400$ & 18.957 & 144.96 & 599 & 5.7 & PKP \\
\hline $12 / 01 / 2002$ & $(012)$ & $08: 26: 52.900$ & 28.279 & -69.566 & 010 & 5.7 & $\mathrm{P}$ \\
\hline $14 / 01 / 2002$ & $(014)$ & $06: 21: 23.100$ & -0.994 & -77.957 & 010 & 4.6 & $\mathrm{P}$ \\
\hline $14 / 01 / 2002$ & $(014)$ & 11:05:53.801 & -30.14 & -111.85 & 010 & 5.0 & $\mathrm{P}$ \\
\hline $14 / 01 / 2002$ & $(014)$ & $15: 26: 38.801$ & -55.547 & -25.91 & 033 & 4.7 & $\mathrm{P}$ \\
\hline $15 / 01 / 2002$ & $(015)$ & $14: 41: 28.101$ & 11.67 & -86.147 & 120 & 5.0 & $\mathrm{P}$ \\
\hline $18 / 01 / 2002$ & $(018)$ & $22: 43: 33.700$ & 11.296 & -87.781 & 033 & 4.8 & $\mathrm{P}$ \\
\hline $20 / 01 / 2002$ & $(020)$ & $10: 17: 19.600$ & -55.638 & -30.061 & 033 & 4.7 & $\mathrm{P}$ \\
\hline $20 / 01 / 2002$ & $(020)$ & $13: 07: 11.400$ & -45.923 & 34.891 & 010 & 5.2 & $\mathrm{P}$ \\
\hline $21 / 01 / 2002$ & $(021)$ & $04: 39: 21.599$ & -1.776 & 29.041 & 010 & 4.9 & $\mathrm{P}$ \\
\hline $21 / 01 / 2002$ & $(021)$ & $07: 52: 29.400$ & -41.465 & -85.638 & 010 & 5.2 & $\mathrm{P}$ \\
\hline $22 / 01 / 2002$ & $(022)$ & $04: 53: 52.600$ & 35.79 & 26.617 & 088 & 6.1 & $\mathrm{P}$ \\
\hline $22 / 01 / 2002$ & $(022)$ & $19: 29: 48.600$ & -5.572 & -11.391 & 010 & 4.7 & $\mathrm{P}$ \\
\hline $26 / 01 / 2002$ & $(026)$ & 22:03:27.300 & -59.803 & -26.42 & 033 & 4.8 & $\mathrm{P}$ \\
\hline $28 / 01 / 2002$ & $(028)$ & $02: 49: 16.600$ & 10.724 & -85.052 & 010 & 5.3 & $\mathrm{P}$ \\
\hline $03 / 02 / 2002$ & $(034)$ & $02: 15: 13.500$ & -0.045 & -17.277 & 010 & 4.6 & $\mathrm{P}$ \\
\hline $03 / 02 / 2002$ & $(034)$ & $07: 11: 28.400$ & 38.573 & 31.271 & 005 & 5.7 & $\mathrm{P}$ \\
\hline $03 / 02 / 2002$ & $(034)$ & 09:26:43.301 & 38.632 & 30.902 & 010 & 5.8 & $\mathrm{P}$ \\
\hline $10 / 02 / 2002$ & $(041)$ & $01: 47: 06.200$ & -55.912 & -29.004 & 193 & 5.6 & $\mathrm{P}$ \\
\hline $11 / 02 / 2002$ & $(042)$ & $12: 27: 33.199$ & 8.105 & -39.153 & 010 & 4.9 & $\mathrm{P}$ \\
\hline $12 / 02 / 2002$ & $(043)$ & $16: 35: 29.900$ & -59.778 & -26.243 & 033 & 5.2 & $\mathrm{P}$ \\
\hline $13 / 02 / 2002$ & $(044)$ & $18: 16: 57.600$ & -55.333 & -29.254 & 033 & 4.8 & $\mathrm{P}$ \\
\hline $14 / 02 / 2002$ & $(045)$ & $23: 23: 13.400$ & 14.995 & -92.638 & 075 & 5.3 & $\mathrm{P}$ \\
\hline $15 / 02 / 2002$ & $(046)$ & 09:13:39.800 & -60.541 & -28.551 & 033 & 4.8 & $\mathrm{P}$ \\
\hline $18 / 02 / 2002$ & $(049)$ & 07:14:11.999 & 51.608 & 16.148 & 005 & 5.2 & $\mathrm{P}$ \\
\hline $19 / 02 / 2002$ & $(050)$ & $12: 33: 24.100$ & -56.741 & -25.436 & 033 & 5.4 & $\mathrm{P}$ \\
\hline $20 / 02 / 2002$ & $(051)$ & $15: 53: 23.900$ & -52.125 & 15.721 & 010 & 5.0 & $\mathrm{P}$ \\
\hline $20 / 02 / 2002$ & $(051)$ & 19:07:17.100 & -7.679 & 31.895 & 038 & 5.6 & $\mathrm{P}$ \\
\hline $22 / 02 / 2002$ & $(053)$ & $19: 32: 41.699$ & 32.319 & -115.32 & 007 & 5.3 & $\mathrm{P}$ \\
\hline $26 / 02 / 2002$ & $(057)$ & $11: 54: 27.601$ & 16.471 & -93.987 & 103 & 4.7 & $\mathrm{P}$ \\
\hline $03 / 03 / 2002$ & $(062)$ & $07: 16: 15.600$ & -45.837 & -76.119 & 010 & 5.3 & $\mathrm{P}$ \\
\hline 03/03/2002 & $(062)$ & 11:57:10.900 & -45.718 & -75.682 & 010 & 5.2 & $\mathrm{P}$ \\
\hline $04 / 03 / 2002$ & $(063)$ & $20: 21: 22.801$ & 28.446 & 143.27 & 045 & 5.5 & PKP \\
\hline $05 / 03 / 2002$ & $(064)$ & 05:23:43.801 & 40.664 & 25.622 & 019 & 4.8 & $\mathrm{P}$ \\
\hline $05 / 03 / 2002$ & $(064)$ & $17: 07: 42.301$ & -11.779 & 24.762 & 010 & 5.2 & $\mathrm{P}$ \\
\hline $05 / 03 / 2002$ & $(064)$ & $21: 16: 09.101$ & 6.033 & 124.25 & 031 & 6.3 & PKP \\
\hline $05 / 03 / 2002$ & $(064)$ & $21: 48: 26.901$ & 6.192 & 124.09 & 033 & 5.4 & PKP \\
\hline
\end{tabular}


Tabela B.1 (Continuação)

\begin{tabular}{|c|c|c|c|c|c|c|c|}
\hline $\begin{array}{c}\text { Data } \\
\mathrm{dd} / \mathrm{mm} / \text { aaaa }\end{array}$ & $\begin{array}{c}\text { Dia Jul. } \\
\text { jjj }\end{array}$ & $\begin{array}{c}\text { Hora } \\
\text { (UTC) }\end{array}$ & $\begin{array}{r}\text { Loce } \\
\text { Latitude }\end{array}$ & $\begin{array}{l}\text { ização } \\
\text { Longitude }\end{array}$ & $\begin{array}{l}\text { Prof. } \\
(\mathrm{km})\end{array}$ & $\begin{array}{c}\text { Magnitude } \\
m_{b}\end{array}$ & $\begin{array}{l}\text { Fase } \\
\text { Tipo }\end{array}$ \\
\hline $07 / 03 / 2002$ & $(066)$ & $04: 25: 51.801$ & 12.261 & -88.225 & 071 & 4.6 & $\mathrm{P}$ \\
\hline $07 / 03 / 2002$ & $(066)$ & 05:07:15.201 & 14.634 & -91.411 & 118 & 4.7 & $\mathrm{P}$ \\
\hline $07 / 03 / 2002$ & $(066)$ & 07:10:13.501 & -1.319 & -24.481 & 010 & 5.0 & $\mathrm{P}$ \\
\hline $08 / 03 / 2002$ & (067) & $18: 27: 53.100$ & 5.871 & 124.27 & 023 & 5.6 & PKP \\
\hline $09 / 03 / 2002$ & $(068)$ & $12: 27: 11.200$ & -56.019 & -27.332 & 118 & 5.6 & $\mathrm{P}$ \\
\hline $11 / 03 / 2002$ & $(070)$ & $01: 46: 20.601$ & 30.599 & 141.57 & 033 & 5.9 & PKP \\
\hline $11 / 03 / 2002$ & $(070)$ & $14: 24: 07.900$ & 19.475 & -64.355 & 033 & 4.8 & $\mathrm{P}$ \\
\hline $11 / 03 / 2002$ & $(070)$ & $23: 45: 14.701$ & -44.536 & -79.7 & 033 & 5.1 & $\mathrm{P}$ \\
\hline $16 / 03 / 2002$ & $(075)$ & $21: 52: 30.301$ & 9.025 & -78.955 & 033 & 4.8 & $\mathrm{P}$ \\
\hline $17 / 03 / 2002$ & $(076)$ & 09:00:59.600 & 12.567 & -87.884 & 068 & 5.0 & $\mathrm{P}$ \\
\hline $17 / 03 / 2002$ & $(076)$ & $12: 09: 30.601$ & 2.669 & -79.741 & 010 & 4.8 & $\mathrm{P}$ \\
\hline $17 / 03 / 2002$ & $(076)$ & 19:33:33.701 & -45.221 & 35.105 & 010 & 5.5 & $\mathrm{P}$ \\
\hline $17 / 03 / 2002$ & $(076)$ & $20: 22: 09.601$ & -3.048 & -79.671 & 069 & 5.2 & $\mathrm{P}$ \\
\hline $18 / 03 / 2002$ & $(077)$ & 02:01:58.101 & -8.616 & -79.979 & 048 & 5.2 & $\mathrm{P}$ \\
\hline $19 / 03 / 2002$ & $(078)$ & $22: 08: 46.700$ & -60.235 & -28.346 & 161 & 5.0 & $\mathrm{P}$ \\
\hline $20 / 03 / 2002$ & $(079)$ & 04:00:18.600 & 30.512 & 141.96 & 010 & 5.5 & PKP \\
\hline $22 / 03 / 2002$ & $(081)$ & $17: 36: 59.201$ & 4.585 & 126.32 & 076 & 5.4 & PKP \\
\hline $23 / 03 / 2002$ & $(082)$ & $05: 15: 51.300$ & 1.395 & 128.11 & 115 & 5.4 & PKP \\
\hline $24 / 03 / 2002$ & $(083)$ & $12: 11: 48.301$ & -43.032 & -82.697 & 010 & 5.1 & $\mathrm{P}$ \\
\hline $24 / 03 / 2002$ & $(083)$ & $14: 35: 56.100$ & 24.362 & -46.355 & 010 & 5.1 & $\mathrm{P}$ \\
\hline $26 / 03 / 2002$ & $(085)$ & $03: 45: 48.700$ & 23.346 & 124.09 & 033 & 5.9 & PKP \\
\hline $26 / 03 / 2002$ & $(085)$ & $04: 22: 10.501$ & -36.068 & -102.87 & 010 & 4.9 & $\mathrm{P}$ \\
\hline $27 / 03 / 2002$ & $(086)$ & $21: 46: 26.901$ & -35.673 & -103.82 & 010 & 4.6 & $\mathrm{P}$ \\
\hline $28 / 03 / 2002$ & (087) & $05: 48: 25.900$ & 22.638 & -45.15 & 010 & 5.4 & $\mathrm{P}$ \\
\hline $28 / 03 / 2002$ & $(087)$ & $05: 50: 38.100$ & 22.603 & -45.164 & 010 & 5.2 & $\mathrm{P}$ \\
\hline $28 / 03 / 2002$ & $(087)$ & $16: 38: 42.901$ & 14.769 & -91.142 & 169 & 4.6 & $\mathrm{P}$ \\
\hline $31 / 03 / 2002$ & $(090)$ & $06: 52: 50.401$ & 24.279 & 122.18 & 032 & 6.3 & PKP \\
\hline $31 / 03 / 2002$ & $(090)$ & 19:07:45.901 & 53.87 & -35.374 & 010 & 5.0 & $\mathrm{P}$ \\
\hline $31 / 03 / 2002$ & $(090)$ & $22: 49: 09.500$ & 53.876 & -35.366 & 010 & 5.1 & $\mathrm{P}$ \\
\hline $31 / 03 / 2002$ & $(090)$ & $23: 09: 56.800$ & 14.355 & -92.593 & 062 & 5.1 & $\mathrm{P}$ \\
\hline $01 / 04 / 2002$ & (091) & $00: 29: 37.501$ & 53.753 & -35.353 & 010 & 4.8 & $\mathrm{P}$ \\
\hline $01 / 04 / 2002$ & $(091)$ & $19: 20: 25.400$ & -58.652 & -25.087 & 033 & 5.0 & $\mathrm{P}$ \\
\hline $02 / 04 / 2002$ & $(092)$ & 17:09:58.101 & -49.531 & -116.07 & 010 & 5.0 & $\mathrm{P}$ \\
\hline $03 / 04 / 2002$ & (093) & $11: 45: 46.901$ & -7.108 & -80.613 & 025 & 4.6 & $\mathrm{P}$ \\
\hline $03 / 04 / 2002$ & (093) & 14:08:57.601 & -7.1 & -80.553 & 028 & 4.8 & $\mathrm{P}$ \\
\hline $07 / 04 / 2002$ & $(097)$ & $07: 41: 38.400$ & -1.352 & -15.344 & 010 & 4.7 & $\mathrm{P}$ \\
\hline $07 / 04 / 2002$ & $(097)$ & $18: 17: 36.701$ & 19.614 & -109.21 & 010 & 4.7 & $\mathrm{P}$ \\
\hline $07 / 04 / 2002$ & (097) & $18: 34: 37.801$ & 19.687 & -109.27 & 010 & 4.9 & $\mathrm{P}$ \\
\hline $07 / 04 / 2002$ & (097) & $20: 19: 23.000$ & 19.704 & -109.16 & 010 & 4.6 & $\mathrm{P}$ \\
\hline $08 / 04 / 2002$ & (098) & 05:08:27.601 & 19.539 & -109.27 & 010 & 4.7 & $\mathrm{P}$ \\
\hline $10 / 04 / 2002$ & $(100)$ & $00: 13: 43.200$ & -44.132 & -15.993 & 010 & 5.2 & $\mathrm{P}$ \\
\hline $10 / 04 / 2002$ & $(100)$ & 10:04:50.600 & -44.176 & -15.86 & 010 & 5.2 & $\mathrm{P}$ \\
\hline $10 / 04 / 2002$ & $(100)$ & $12: 17: 33.100$ & -56.064 & -27.489 & 103 & 4.7 & $\mathrm{P}$ \\
\hline $10 / 04 / 2002$ & $(100)$ & $16: 24: 53.400$ & -44.152 & -15.898 & 010 & 4.8 & $\mathrm{P}$ \\
\hline $11 / 04 / 2002$ & $(101)$ & 02:19:14.101 & 19.299 & -66.711 & 047 & 4.6 & $\mathrm{P}$ \\
\hline $12 / 04 / 2002$ & (102) & 18:09:44.901 & -30.819 & 59.535 & 010 & 4.9 & $\mathrm{P}$ \\
\hline $14 / 04 / 2002$ & $(104)$ & 04:05:23.901 & 7.316 & 126.66 & 033 & 5.4 & PKP \\
\hline $14 / 04 / 2002$ & $(104)$ & $06: 35: 42.901$ & 14.936 & -45.134 & 010 & 4.8 & $\mathrm{P}$ \\
\hline $15 / 04 / 2002$ & (105) & 03:52:06.201 & 13.079 & 143.79 & 116 & 5.5 & PKP \\
\hline $15 / 04 / 2002$ & $(105)$ & 05:08:56.000 & -10.086 & -79.761 & 033 & 4.8 & $\mathrm{P}$ \\
\hline $15 / 04 / 2002$ & (105) & $07: 11: 26.990$ & -60.009 & -26.471 & 033 & 4.9 & $\mathrm{P}$ \\
\hline $17 / 04 / 2002$ & (107) & $06: 42: 54.301$ & 39.7 & 16.843 & 005 & 4.8 & $\mathrm{P}$ \\
\hline $18 / 04 / 2002$ & (108) & 05:02:46.101 & 16.985 & -100.86 & 024 & 5.4 & $\mathrm{P}$ \\
\hline $18 / 04 / 2002$ & (108) & $14: 17: 23.901$ & -60.657 & -25.843 & 010 & 5.4 & $\mathrm{P}$ \\
\hline $18 / 04 / 2002$ & $(108)$ & $17: 57: 27.701$ & 17.233 & -101.25 & 033 & 4.9 & $\mathrm{P}$ \\
\hline $18 / 04 / 2002$ & (108) & 18:00:40.700 & 17.037 & -101.32 & 033 & 4.8 & $\mathrm{P}$ \\
\hline $20 / 04 / 2002$ & (110) & 10:50:47.500 & 44.513 & -73.699 & 011 & 5.1 & $\mathrm{P}$ \\
\hline $20 / 04 / 2002$ & (110) & 18:50:44.200 & -57.709 & -25.325 & 033 & 4.6 & $\mathrm{P}$ \\
\hline $21 / 04 / 2002$ & $(111)$ & $19: 50: 51.800$ & 13.909 & -92.041 & 055 & 4.6 & $\mathrm{P}$ \\
\hline
\end{tabular}


Tabela B.1 (Continuação)

\begin{tabular}{|c|c|c|c|c|c|c|c|}
\hline Data & Dia Jul. & Hora & Loca & zação & Prof. & Magnitude & Fase \\
\hline $\mathrm{dd} / \mathrm{mm} / \mathrm{aaaa}$ & $\mathrm{jjj}$ & (UTC) & Latitude & Longitude & $(\mathrm{km})$ & $m_{b}$ & Tipo \\
\hline $21 / 04 / 2002$ & $(111)$ & $22: 24: 07.990$ & -5.784 & -81.033 & 033 & 5.0 & $\mathrm{P}$ \\
\hline $24 / 04 / 2002$ & (114) & 10:51:50.900 & 42.436 & 21.466 & 010 & 5.6 & $\mathrm{P}$ \\
\hline $24 / 04 / 2002$ & (114) & 11:00:00.800 & -56.135 & -122.31 & 010 & 5.6 & $\mathrm{P}$ \\
\hline $24 / 04 / 2002$ & (114) & $15: 08: 18.400$ & -56.199 & -26.506 & 033 & 4.6 & $\mathrm{P}$ \\
\hline $26 / 04 / 2002$ & $(116)$ & $01: 36: 25.500$ & 6.639 & -73.61 & 033 & 5.1 & $\mathrm{P}$ \\
\hline $26 / 04 / 2002$ & (116) & $16: 06: 07.000$ & 13.088 & 144.62 & 085 & 6.6 & PKP \\
\hline $27 / 04 / 2002$ & $(117)$ & $03: 41: 35.400$ & 1.099 & -79.565 & 023 & 4.6 & $\mathrm{P}$ \\
\hline $28 / 04 / 2002$ & (118) & 08:03:20.101 & -23.507 & -115.06 & 010 & 4.6 & $\mathrm{P}$ \\
\hline $28 / 04 / 2002$ & (118) & $19: 56: 42.601$ & 17.206 & -100.97 & 025 & 4.7 & $\mathrm{P}$ \\
\hline $28 / 04 / 2002$ & (118) & $20: 16: 59.301$ & 1.793 & -102.07 & 010 & 4.9 & $\mathrm{P}$ \\
\hline $29 / 04 / 2002$ & (119) & $02: 43: 14.800$ & 7.205 & -79.698 & 033 & 4.7 & $\mathrm{P}$ \\
\hline $30 / 04 / 2002$ & $(120)$ & $14: 56: 29.101$ & -23.535 & -115.49 & 010 & 4.8 & $\mathrm{P}$ \\
\hline $30 / 04 / 2002$ & $(120)$ & $18: 55: 57.901$ & 12.461 & -88.08 & 033 & 4.6 & $\mathrm{P}$ \\
\hline $05 / 05 / 2002$ & $(125)$ & $11: 35: 06.300$ & -1.04 & -78.292 & 010 & 4.7 & $\mathrm{P}$ \\
\hline $06 / 05 / 2002$ & (126) & 04:05:02.000 & -55.287 & -28.266 & 033 & 4.7 & $\mathrm{P}$ \\
\hline $07 / 05 / 2002$ & $(127)$ & 09:19:54.100 & 12.151 & -88.26 & 061 & 4.6 & $\mathrm{P}$ \\
\hline $08 / 05 / 2002$ & (128) & $14: 59: 53.500$ & -56.129 & -26.625 & 033 & 4.7 & $\mathrm{P}$ \\
\hline $09 / 05 / 2002$ & (129) & $23: 41: 30.801$ & 2.646 & 128.3 & 173 & 5.6 & PKP \\
\hline $11 / 05 / 2002$ & (131) & $10: 43: 07.800$ & -10.424 & -78.506 & 046 & 5.7 & $\mathrm{P}$ \\
\hline $12 / 05 / 2002$ & $(132)$ & 11:00:12.499 & -17.819 & -13.992 & 010 & 4.6 & $\mathrm{P}$ \\
\hline $13 / 05 / 2002$ & (133) & $13: 20: 48.400$ & -12.499 & -14.717 & 010 & 4.9 & $\mathrm{P}$ \\
\hline $13 / 05 / 2002$ & (133) & 19:54:43.990 & 19.141 & 121.24 & 033 & 5.4 & PKP \\
\hline $13 / 05 / 2002$ & (133) & $19: 57: 22.899$ & 19.132 & 121.24 & 033 & 5.5 & PKP \\
\hline $15 / 05 / 2002$ & (135) & $03: 46: 05.700$ & 24.636 & 121.92 & 010 & 5.5 & PKP \\
\hline $17 / 05 / 2002$ & (137) & $07: 14: 21.990$ & 9.63 & -99.776 & 033 & 4.7 & $\mathrm{P}$ \\
\hline $17 / 05 / 2002$ & (137) & $10: 40: 10.699$ & 48.168 & -27.808 & 010 & 5.6 & $\mathrm{P}$ \\
\hline $20 / 05 / 2002$ & $(140)$ & $20: 32: 23.400$ & -32.735 & 57.175 & 010 & 4.9 & $\mathrm{P}$ \\
\hline $21 / 05 / 2002$ & (141) & 06:02:59.900 & 17.779 & -81.911 & 010 & 5.3 & $\mathrm{P}$ \\
\hline $21 / 05 / 2002$ & (141) & $20: 53: 29.700$ & 36.627 & 24.274 & 097 & 5.4 & $\mathrm{P}$ \\
\hline $22 / 05 / 2002$ & $(142)$ & $18: 57: 19.400$ & -36.344 & -97.908 & 010 & 5.3 & $\mathrm{P}$ \\
\hline $26 / 05 / 2002$ & (146) & 00:10:21.000 & 1.832 & 127.24 & 109 & 5.8 & PKP \\
\hline $26 / 05 / 2002$ & $(146)$ & 19:18:55.399 & 14.618 & -90.977 & 160 & 4.9 & $\mathrm{P}$ \\
\hline $27 / 05 / 2002$ & $(147)$ & $00: 55: 56.500$ & -29.464 & -111.75 & 010 & 4.6 & $\mathrm{P}$ \\
\hline $27 / 05 / 2002$ & $(147)$ & $16: 22: 36.399$ & -26.962 & 26.715 & 005 & 4.9 & $\mathrm{P}$ \\
\hline $28 / 05 / 2002$ & (148) & $16: 45: 17.100$ & 24.069 & 122.26 & 033 & 5.8 & PKP \\
\hline $28 / 05 / 2002$ & (148) & $16: 56: 41.799$ & -56.031 & -27.71 & 133 & 4.9 & $\mathrm{P}$ \\
\hline $28 / 05 / 2002$ & $(148)$ & $21: 33: 55.100$ & 16.438 & -99.359 & 009 & 5.1 & $\mathrm{P}$ \\
\hline $29 / 05 / 2002$ & (149) & $11: 11: 28.799$ & -3.08 & 33.902 & 010 & 4.9 & $\mathrm{P}$ \\
\hline $02 / 06 / 2002$ & (153) & $12: 52: 25.200$ & 9.279 & -83.681 & 039 & 4.7 & $\mathrm{P}$ \\
\hline $05 / 06 / 2002$ & $(156)$ & $12: 45: 17.300$ & 35.472 & -36.291 & 010 & 5.5 & $\mathrm{P}$ \\
\hline $06 / 06 / 2002$ & (157) & $22: 35: 41.901$ & 35.648 & 26.183 & 087 & 5.1 & $\mathrm{P}$ \\
\hline $07 / 06 / 2002$ & $(158)$ & 00:05:48.990 & 8.715 & -77.621 & 085 & 5.1 & $\mathrm{P}$ \\
\hline $07 / 06 / 2002$ & (158) & $16: 02: 57.399$ & 16.076 & -96.698 & 033 & 4.7 & $\mathrm{P}$ \\
\hline $07 / 06 / 2002$ & $(158)$ & 17:00:51.499 & 16.107 & -96.749 & 033 & 5.5 & $\mathrm{P}$ \\
\hline $10 / 06 / 2002$ & (161) & $20: 53: 07.500$ & 11.282 & -87.191 & 033 & 5.1 & $\mathrm{P}$ \\
\hline $10 / 06 / 2002$ & (161) & $20: 55: 48.199$ & 11.279 & -87.229 & 033 & 5.2 & $\mathrm{P}$ \\
\hline $10 / 06 / 2002$ & (161) & $22: 48: 36.200$ & 10.985 & 140.69 & 033 & 5.9 & PKP \\
\hline $11 / 06 / 2002$ & $(162)$ & 02:32:31.899 & 17.612 & -94.52 & 154 & 4.9 & $\mathrm{P}$ \\
\hline $11 / 06 / 2002$ & $(162)$ & $13: 26: 15.499$ & 11.411 & -86.981 & 071 & 4.6 & $\mathrm{P}$ \\
\hline $11 / 06 / 2002$ & (162) & 17:58:01.600 & -40.511 & -16.682 & 010 & 5.0 & $\mathrm{P}$ \\
\hline $12 / 06 / 2002$ & (163) & $19: 52: 47.300$ & -0.676 & -20.722 & 010 & 5.4 & $\mathrm{P}$ \\
\hline $13 / 06 / 2002$ & $(164)$ & $00: 59: 14.600$ & 5.14 & -82.219 & 010 & 4.6 & $\mathrm{P}$ \\
\hline $13 / 06 / 2002$ & (164) & $05: 20: 19.401$ & 8.818 & -83.916 & 043 & 4.6 & $\mathrm{P}$ \\
\hline $14 / 06 / 2002$ & (165) & 02:11:36.999 & 7.593 & 124.02 & 033 & 5.4 & PKP \\
\hline $14 / 06 / 2002$ & $(165)$ & $15: 24: 09.500$ & 22.542 & -45.136 & 010 & 5.2 & $\mathrm{P}$ \\
\hline $14 / 06 / 2002$ & $(165)$ & $16: 15: 22.899$ & 22.56 & -45.111 & 010 & 5.1 & $\mathrm{P}$ \\
\hline $15 / 06 / 2002$ & $(166)$ & $13: 23: 08.199$ & -53.222 & 23.571 & 010 & 4.9 & $\mathrm{P}$ \\
\hline $16 / 06 / 2002$ & (167) & $02: 46: 14.000$ & 8.784 & -83.992 & 035 & 5.4 & $\mathrm{P}$ \\
\hline $16 / 06 / 2002$ & (167) & $17: 59: 20.499$ & -53.34 & 23.685 & 010 & 5.1 & $\mathrm{P}$ \\
\hline
\end{tabular}


Tabela B.1 (Continuação)

\begin{tabular}{|c|c|c|c|c|c|c|c|}
\hline $\begin{array}{c}\text { Data } \\
\mathrm{dd} / \mathrm{mm} / \text { aaaa }\end{array}$ & $\begin{array}{c}\text { Dia Jul. } \\
\text { jjj }\end{array}$ & $\begin{array}{c}\text { Hora } \\
\text { (UTC) }\end{array}$ & $\begin{array}{r}\text { Loce } \\
\text { Latitude }\end{array}$ & $\begin{array}{l}\text { ização } \\
\text { Longitude }\end{array}$ & $\begin{array}{l}\text { Prof. } \\
(\mathrm{km})\end{array}$ & $\begin{array}{c}\text { Magnitude } \\
m_{b}\end{array}$ & $\begin{array}{l}\text { Fase } \\
\text { Tipo }\end{array}$ \\
\hline $16 / 06 / 2002$ & $(167)$ & $22: 43: 04.600$ & 8.992 & -84.078 & 041 & 4.6 & $\mathrm{P}$ \\
\hline $17 / 06 / 2002$ & (168) & $08: 38: 38.100$ & -55.058 & -129.71 & 010 & 4.8 & $\mathrm{P}$ \\
\hline $17 / 06 / 2002$ & (168) & 13:13:06.799 & -5.699 & -105.15 & 010 & 4.7 & $\mathrm{P}$ \\
\hline $17 / 06 / 2002$ & (168) & 13:18:01.700 & -4.628 & -105.15 & 010 & 5.1 & $\mathrm{P}$ \\
\hline $17 / 06 / 2002$ & $(168)$ & $13: 25: 56.300$ & -4.651 & -105.38 & 010 & 5.2 & $\mathrm{P}$ \\
\hline $19 / 06 / 2002$ & $(170)$ & $21: 50: 10.500$ & 16.595 & -97.822 & 033 & 5.2 & $\mathrm{P}$ \\
\hline $21 / 06 / 2002$ & $(172)$ & $19: 35: 41.800$ & 11.062 & -60.194 & 033 & 4.6 & $\mathrm{P}$ \\
\hline $23 / 06 / 2002$ & (174) & $13: 55: 08.000$ & -60.192 & -32.977 & 010 & 4.6 & $\mathrm{P}$ \\
\hline $24 / 06 / 2002$ & $(175)$ & $01: 20: 35.600$ & 35.767 & 9.87 & 010 & 5.0 & $\mathrm{P}$ \\
\hline $25 / 06 / 2002$ & $(176)$ & 04:06:44.500 & 3.972 & -82.442 & 010 & 5.0 & $\mathrm{P}$ \\
\hline $25 / 06 / 2002$ & $(176)$ & $19: 55: 58.799$ & -4.8 & -12.294 & 010 & 4.8 & $\mathrm{P}$ \\
\hline $25 / 06 / 2002$ & $(176)$ & $20: 15: 57.799$ & -5.007 & -12.33 & 010 & 5.1 & $\mathrm{P}$ \\
\hline $25 / 06 / 2002$ & (176) & 20:50:43.499 & -4.873 & -12.404 & 010 & 4.7 & $\mathrm{P}$ \\
\hline $25 / 06 / 2002$ & $(176)$ & $21: 47: 23.200$ & -4.975 & -12.332 & 010 & 5.2 & $\mathrm{P}$ \\
\hline $25 / 06 / 2002$ & $(176)$ & $22: 59: 11.700$ & -4.927 & -12.407 & 010 & 5.0 & $\mathrm{P}$ \\
\hline $25 / 06 / 2002$ & $(176)$ & $23: 28: 24.400$ & -4.377 & -12.152 & 010 & 4.7 & $\mathrm{P}$ \\
\hline $26 / 06 / 2002$ & (177) & 01:00:11.000 & -4.717 & -12.341 & 010 & 4.8 & $\mathrm{P}$ \\
\hline $26 / 06 / 2002$ & $(177)$ & $01: 25: 27.399$ & -4.934 & -12.321 & 010 & 4.8 & $\mathrm{P}$ \\
\hline $26 / 06 / 2002$ & (177) & $03: 24: 50.200$ & -4.916 & -12.327 & 010 & 4.6 & $\mathrm{P}$ \\
\hline $27 / 06 / 2002$ & $(178)$ & $17: 13: 42.990$ & 19.856 & -71.549 & 033 & 4.8 & $\mathrm{P}$ \\
\hline $27 / 06 / 2002$ & $(178)$ & $22: 41: 06.800$ & 38.48 & 22.82 & 004 & 5.2 & $\mathrm{P}$ \\
\hline $28 / 06 / 2002$ & $(179)$ & $17: 19: 30.300$ & 43.747 & 130.7 & 566 & 6.8 & PKP \\
\hline $29 / 06 / 2002$ & $(180)$ & $11: 50: 53.500$ & 7.394 & -36.33 & 010 & 4.8 & $\mathrm{P}$ \\
\hline $30 / 06 / 2002$ & (181) & $06: 23: 48.990$ & -5.568 & -76.918 & 033 & 4.7 & $\mathrm{P}$ \\
\hline $30 / 06 / 2002$ & (181) & $20: 24: 20.600$ & 14.545 & -91.544 & 070 & 4.6 & $\mathrm{P}$ \\
\hline $01 / 07 / 2002$ & $(182)$ & $13: 41: 51.900$ & 13.382 & -90.063 & 067 & 4.8 & $\mathrm{P}$ \\
\hline $01 / 07 / 2002$ & $(182)$ & $20: 23: 01.301$ & -55.892 & -26.969 & 033 & 4.7 & $\mathrm{P}$ \\
\hline $02 / 07 / 2002$ & $(183)$ & $10: 15: 59.200$ & -29.85 & -112.4 & 010 & 5.2 & $\mathrm{P}$ \\
\hline $02 / 07 / 2002$ & $(183)$ & $16: 24: 29.100$ & 5.017 & -77.405 & 010 & 5.5 & $\mathrm{P}$ \\
\hline $05 / 07 / 2002$ & (186) & $13: 41: 44.700$ & -40.007 & -155.7 & 010 & 4.9 & $\mathrm{P}$ \\
\hline $06 / 07 / 2002$ & (187) & $05: 42: 28.600$ & 25.539 & -45.285 & 010 & 5.0 & $\mathrm{P}$ \\
\hline $11 / 07 / 2002$ & $(192)$ & $02: 56: 28.900$ & 21.584 & 142.94 & 317 & 5.4 & PKP \\
\hline $11 / 07 / 2002$ & $(192)$ & 07:36:25.999 & 24.075 & 122.29 & 043 & 5.5 & PKP \\
\hline $11 / 07 / 2002$ & $(192)$ & $09: 22: 22.300$ & -30.061 & -111.98 & 010 & 5.1 & $\mathrm{P}$ \\
\hline $11 / 07 / 2002$ & $(192)$ & $12: 42: 17.501$ & -1.635 & -12.928 & 010 & 4.6 & $\mathrm{P}$ \\
\hline $11 / 07 / 2002$ & $(192)$ & $14: 17: 24.999$ & 14.143 & -90.097 & 147 & 4.7 & $\mathrm{P}$ \\
\hline $12 / 07 / 2002$ & (193) & 18:07:59.700 & 6.733 & -73.021 & 155 & 4.8 & $\mathrm{P}$ \\
\hline $15 / 07 / 2002$ & (196) & 15:02:06.999 & -43.901 & -15.996 & 010 & 5.0 & $\mathrm{P}$ \\
\hline $16 / 07 / 2002$ & (197) & 03:04:55.400 & -55.793 & -27.849 & 100 & 4.9 & $\mathrm{P}$ \\
\hline $16 / 07 / 2002$ & (197) & 14:50:14.399 & -11.65 & 41.071 & 010 & 5.2 & $\mathrm{P}$ \\
\hline $18 / 07 / 2002$ & (199) & $14: 26: 51.600$ & -58.688 & -25.275 & 033 & 4.9 & $\mathrm{P}$ \\
\hline $18 / 07 / 2002$ & (199) & $21: 53: 12.799$ & -44.715 & -79.754 & 010 & 5.2 & $\mathrm{P}$ \\
\hline $19 / 07 / 2002$ & $(200)$ & $08: 25: 44.999$ & -56.693 & -141.18 & 010 & 4.8 & $\mathrm{P}$ \\
\hline $22 / 07 / 2002$ & $(203)$ & $05: 45: 03.000$ & 50.889 & 6.103 & 017 & 4.9 & $\mathrm{P}$ \\
\hline $23 / 07 / 2002$ & $(204)$ & $20: 05: 31.800$ & 37.251 & 142.22 & 033 & 5.5 & PKP \\
\hline $25 / 07 / 2002$ & $(206)$ & $15: 58: 48.700$ & 9.942 & 125.67 & 104 & 5.4 & PKP \\
\hline $26 / 07 / 2002$ & $(207)$ & $22: 33: 23.301$ & 8.369 & -82.905 & 033 & 4.6 & $\mathrm{P}$ \\
\hline $29 / 07 / 2002$ & $(210)$ & 07:26:09.700 & -55.741 & -26.871 & 033 & 5.5 & $\mathrm{P}$ \\
\hline $30 / 07 / 2002$ & (211) & $06: 55: 07.700$ & -57.889 & -23.242 & 033 & 5.7 & $\mathrm{P}$ \\
\hline $30 / 07 / 2002$ & $(211)$ & 17:02:49.301 & -55.788 & -26.844 & 033 & 4.9 & $\mathrm{P}$ \\
\hline $31 / 07 / 2002$ & $(212)$ & $04: 45: 14.200$ & 7.909 & -82.786 & 010 & 5.3 & $\mathrm{P}$ \\
\hline $02 / 08 / 2002$ & $(214)$ & $23: 11: 39.101$ & 29.28 & 138.97 & 426 & 5.7 & PKP \\
\hline $03 / 08 / 2002$ & $(215)$ & 02:39:01.801 & 8.264 & -82.822 & 010 & 5.6 & $\mathrm{P}$ \\
\hline $03 / 08 / 2002$ & $(215)$ & $14: 18: 13.400$ & -1.506 & -14.374 & 010 & 5.3 & $\mathrm{P}$ \\
\hline $04 / 08 / 2002$ & $(216)$ & $09: 50: 25.201$ & -45.022 & -80.732 & 010 & 5.4 & $\mathrm{P}$ \\
\hline $06 / 08 / 2002$ & (218) & $14: 26: 12.201$ & -5.355 & -76.616 & 106 & 5.1 & $\mathrm{P}$ \\
\hline $07 / 08 / 2002$ & (219) & $16: 44: 43.400$ & 7.017 & -104.24 & 010 & 5.0 & $\mathrm{P}$ \\
\hline $08 / 08 / 2002$ & $(220)$ & 13:39:58.201 & 4.98 & -77.819 & 043 & 5.4 & $\mathrm{P}$ \\
\hline $11 / 08 / 2002$ & $(223)$ & 02:00:36.200 & 15.982 & -98.448 & 010 & 4.9 & $\mathrm{P}$ \\
\hline
\end{tabular}


Tabela B.1 (Continuação)

\begin{tabular}{|c|c|c|c|c|c|c|c|}
\hline \multirow{2}{*}{$\begin{array}{c}\text { Data } \\
\mathrm{dd} / \mathrm{mm} / \text { aaaa }\end{array}$} & \multirow{2}{*}{$\begin{array}{l}\text { Dia Jul. } \\
\text { jjj }\end{array}$} & \multirow{2}{*}{$\begin{array}{l}\text { Hora } \\
\text { (UTC) }\end{array}$} & \multicolumn{2}{|c|}{ Localização } & \multirow{2}{*}{$\begin{array}{l}\text { Prof. } \\
(\mathrm{km})\end{array}$} & \multirow{2}{*}{$\begin{array}{c}\text { Magnitude } \\
m_{b}\end{array}$} & \multirow{2}{*}{$\begin{array}{l}\text { Fase } \\
\text { Tipo }\end{array}$} \\
\hline & & & Latitude & Longitude & & & \\
\hline $11 / 08 / 2002$ & $(223)$ & $05: 06: 32.200$ & -5.576 & -71.882 & 567 & 4.8 & $\mathrm{P}$ \\
\hline $11 / 08 / 2002$ & $(223)$ & $12: 48: 54.901$ & -54.236 & -58.006 & 010 & 4.9 & $\mathrm{P}$ \\
\hline $12 / 08 / 2002$ & $(224)$ & $12: 54: 00.500$ & -59.557 & -25.739 & 033 & 4.8 & $\mathrm{P}$ \\
\hline $14 / 08 / 2002$ & $(226)$ & $13: 12: 39.800$ & 7.831 & 136.88 & 010 & 6.1 & PKP \\
\hline $20 / 08 / 2002$ & $(232)$ & $10: 59: 32.100$ & 30.986 & 141.97 & 009 & 5.4 & PKP \\
\hline $23 / 08 / 2002$ & $(235)$ & $13: 11: 38.701$ & -20.902 & -110.85 & 010 & 4.7 & $\mathrm{P}$ \\
\hline $23 / 08 / 2002$ & $(235)$ & $15: 43: 57.801$ & 5.331 & -99.011 & 010 & 4.7 & $\mathrm{P}$ \\
\hline $24 / 08 / 2002$ & $(236)$ & $18: 40: 53.401$ & 43.11 & 146.12 & 042 & 5.9 & PKP \\
\hline $26 / 08 / 2002$ & (238) & $21: 49: 56.901$ & 8.365 & -82.769 & 042 & 4.7 & $\mathrm{P}$ \\
\hline $27 / 08 / 2002$ & $(239)$ & $05: 19: 14.200$ & 8.251 & -82.816 & 010 & 4.8 & $\mathrm{P}$ \\
\hline $27 / 08 / 2002$ & $(239)$ & 06:48:13.801 & -55.702 & -25.933 & 033 & 4.9 & $\mathrm{P}$ \\
\hline $27 / 08 / 2002$ & $(239)$ & $17: 08: 50.301$ & 16.305 & -97.319 & 046 & 5.0 & $\mathrm{P}$ \\
\hline $28 / 08 / 2002$ & $(240)$ & $17: 05: 33.801$ & 22.115 & 121.58 & 033 & 5.7 & PKP \\
\hline $30 / 08 / 2002$ & $(242)$ & $09: 55: 31.601$ & 57.514 & -33.138 & 010 & 4.8 & $\mathrm{P}$ \\
\hline $30 / 08 / 2002$ & $(242)$ & $21: 11: 43.600$ & 16.689 & -100.94 & 016 & 4.8 & $\mathrm{P}$ \\
\hline $30 / 08 / 2002$ & $(242)$ & $22: 39: 03.400$ & -56.008 & -26.612 & 033 & 4.6 & $\mathrm{P}$ \\
\hline $31 / 08 / 2002$ & $(243)$ & $05: 27: 18.200$ & 2.709 & -84.378 & 023 & 5.6 & $\mathrm{P}$ \\
\hline $01 / 09 / 2002$ & $(244)$ & $05: 56: 24.300$ & 24.056 & 122.27 & 039 & 5.5 & PKP \\
\hline $02 / 09 / 2002$ & $(245)$ & 09:23:45.101 & 35.081 & 26.522 & 054 & 5.0 & $\mathrm{P}$ \\
\hline $03 / 09 / 2002$ & $(246)$ & $14: 23: 48.500$ & 13.558 & 120.6 & 033 & 5.5 & PKP \\
\hline $05 / 09 / 2002$ & $(248)$ & $14: 25: 38.000$ & -36.36 & -97.773 & 010 & 4.8 & $\mathrm{P}$ \\
\hline $06 / 09 / 2002$ & (249) & $01: 21: 27.501$ & 38.371 & 13.698 & 010 & 5.8 & $\mathrm{P}$ \\
\hline $07 / 09 / 2002$ & $(250)$ & 18:08:36.901 & -57.951 & -25.088 & 033 & 5.1 & $\mathrm{P}$ \\
\hline $08 / 09 / 2002$ & $(251)$ & $23: 03: 45.100$ & -1.292 & -14.534 & 010 & 5.3 & $\mathrm{P}$ \\
\hline $15 / 09 / 2002$ & $(258)$ & 08:39:31.801 & 44.858 & 130.08 & 577 & 6.3 & PKP \\
\hline $16 / 09 / 2002$ & $(259)$ & $18: 48: 26.700$ & 66.917 & -18.5 & 010 & 5.5 & $\mathrm{P}$ \\
\hline $19 / 09 / 2002$ & $(262)$ & $11: 22: 29.700$ & -36.889 & -95.356 & 010 & 5.1 & $\mathrm{P}$ \\
\hline $20 / 09 / 2002$ & (263) & $13: 33: 42.000$ & -1.58 & 133.92 & 010 & 5.7 & PKP \\
\hline $20 / 09 / 2002$ & $(263)$ & $15: 43: 36.400$ & -1.538 & 134.35 & 010 & 6.0 & PKP \\
\hline $25 / 09 / 2002$ & $(268)$ & $18: 14: 48.600$ & 16.963 & -99.85 & 033 & 5.1 & $\mathrm{P}$ \\
\hline $26 / 09 / 2002$ & (269) & $12: 55: 29.000$ & -19.622 & -11.899 & 010 & 4.9 & $\mathrm{P}$ \\
\hline $26 / 09 / 2002$ & (269) & $13: 12: 25.100$ & 15.345 & -91.933 & 187 & 4.9 & $\mathrm{P}$ \\
\hline $27 / 09 / 2002$ & $(270)$ & 06:10:44.201 & 38.391 & 13.781 & 010 & 4.9 & $\mathrm{P}$ \\
\hline $27 / 09 / 2002$ & $(270)$ & 07:04:55.401 & 17.275 & -100.28 & 033 & 5.0 & $\mathrm{P}$ \\
\hline $28 / 09 / 2002$ & $(271)$ & $02: 46: 45.101$ & 38.25 & 13.649 & 010 & 4.8 & $\mathrm{P}$ \\
\hline $28 / 09 / 2002$ & $(271)$ & 03:53:57.100 & -53.251 & -117.46 & 010 & 5.1 & $\mathrm{P}$ \\
\hline $29 / 09 / 2002$ & $(272)$ & 09:44:28.301 & -33.384 & -109.39 & 010 & 5.1 & $\mathrm{P}$ \\
\hline $30 / 09 / 2002$ & $(273)$ & 13:05:58.101 & -35.086 & -70.396 & 096 & 5.4 & $\mathrm{P}$ \\
\hline $02 / 10 / 2002$ & $(275)$ & $12: 27: 15.200$ & 11.475 & -86.942 & 033 & 4.8 & $\mathrm{P}$ \\
\hline $03 / 10 / 2002$ & $(276)$ & $16: 08: 28.401$ & 23.227 & -108.49 & 010 & 5.4 & $\mathrm{P}$ \\
\hline $04 / 10 / 2002$ & $(277)$ & $12: 37: 16.200$ & -57.296 & -26.442 & 152 & 4.9 & $\mathrm{P}$ \\
\hline $04 / 10 / 2002$ & $(277)$ & $15: 43: 46.500$ & 10.322 & -62.662 & 033 & 5.0 & $\mathrm{P}$ \\
\hline $05 / 10 / 2002$ & $(278)$ & $05: 52: 17.300$ & -5.645 & -76.488 & 063 & 4.9 & $\mathrm{P}$ \\
\hline $06 / 10 / 2002$ & $(279)$ & $01: 18: 35.801$ & 58.476 & -31.797 & 010 & 5.2 & $\mathrm{P}$ \\
\hline $06 / 10 / 2002$ & $(279)$ & 04:19:37.700 & 6.43 & -71.452 & 031 & 4.7 & $\mathrm{P}$ \\
\hline $07 / 10 / 2002$ & $(280)$ & $17: 32: 19.200$ & 2.456 & 126.72 & 033 & 5.4 & PKP \\
\hline $07 / 10 / 2002$ & $(280)$ & 20:03:54.100 & 58.275 & -31.87 & 010 & 4.9 & $\mathrm{P}$ \\
\hline $08 / 10 / 2002$ & $(281)$ & $12: 40: 43.000$ & 9.061 & -84.048 & 012 & 4.8 & $\mathrm{P}$ \\
\hline $10 / 10 / 2002$ & $(283)$ & $10: 50: 19.900$ & -1.684 & 134.15 & 010 & 6.5 & PKP \\
\hline $10 / 10 / 2002$ & (283) & $12: 27: 52.100$ & -1.441 & 134.13 & 010 & 5.5 & PKP \\
\hline $10 / 10 / 2002$ & (283) & $12: 28: 25.700$ & -1.507 & 133.99 & 010 & 6.1 & PKP \\
\hline $10 / 10 / 2002$ & $(283)$ & $12: 29: 35.600$ & -1.299 & 133.91 & 010 & 6.0 & PKP \\
\hline $10 / 10 / 2002$ & (283) & $18: 33: 37.201$ & -1.42 & 134.08 & 010 & 5.4 & PKP \\
\hline $10 / 10 / 2002$ & (283) & $21: 19: 58.500$ & -1.437 & 134.07 & 010 & 5.7 & PKP \\
\hline $11 / 10 / 2002$ & $(284)$ & $14: 41: 24.100$ & 15.555 & -95.603 & 033 & 5.2 & $\mathrm{P}$ \\
\hline $12 / 10 / 2002$ & $(285)$ & $05: 58: 50.100$ & 34.77 & 26.377 & 010 & 5.0 & $\mathrm{P}$ \\
\hline $12 / 10 / 2002$ & $(285)$ & 10:59:33.801 & 37.771 & 142.6 & 030 & 5.4 & PKP \\
\hline $12 / 10 / 2002$ & (285) & $14: 48: 36.101$ & -58.861 & -14.283 & 033 & 4.9 & $\mathrm{P}$ \\
\hline $12 / 10 / 2002$ & $(285)$ & 20:09:11.200 & -8.27 & -71.695 & 532 & 6.5 & $\mathrm{P}$ \\
\hline
\end{tabular}


Tabela B.1 (Continuação)

\begin{tabular}{|c|c|c|c|c|c|c|c|}
\hline $\begin{array}{c}\text { Data } \\
\mathrm{dd} / \mathrm{mm} / \text { aaaa }\end{array}$ & $\begin{array}{c}\text { Dia Jul. } \\
\text { jjj }\end{array}$ & $\begin{array}{c}\text { Hora } \\
\text { (UTC) }\end{array}$ & $\begin{array}{r}\text { Loce } \\
\text { Latitude }\end{array}$ & $\begin{array}{l}\text { ização } \\
\text { Longitude }\end{array}$ & $\begin{array}{l}\text { Prof. } \\
(\mathrm{km})\end{array}$ & $\begin{array}{c}\text { Magnitude } \\
m_{b}\end{array}$ & $\begin{array}{l}\text { Fase } \\
\text { Tipo }\end{array}$ \\
\hline $14 / 10 / 2002$ & $(287)$ & $14: 12: 42.801$ & 41.201 & 142.25 & 053 & 5.8 & PKP \\
\hline $15 / 10 / 2002$ & $(288)$ & $23: 50: 28.500$ & -14.214 & -72.79 & 085 & 5.0 & $\mathrm{P}$ \\
\hline $16 / 10 / 2002$ & $(289)$ & 08:36:59.501 & 3.694 & 126.57 & 033 & 5.4 & PKP \\
\hline $17 / 10 / 2002$ & $(290)$ & $17: 52: 43.801$ & -3.593 & 140.1 & 033 & 5.6 & PKP \\
\hline $18 / 10 / 2002$ & (291) & $11: 16: 48.300$ & -57.087 & -142.43 & 010 & 5.1 & $\mathrm{P}$ \\
\hline $18 / 10 / 2002$ & (291) & $11: 33: 51.000$ & -39.063 & -92.22 & 010 & 4.9 & $\mathrm{P}$ \\
\hline $18 / 10 / 2002$ & $(291)$ & 12:04:41.000 & 19.397 & -64.142 & 033 & 4.7 & $\mathrm{P}$ \\
\hline $19 / 10 / 2002$ & $(292)$ & $15: 31: 23.000$ & 2.961 & -84.203 & 010 & 4.7 & $\mathrm{P}$ \\
\hline $19 / 10 / 2002$ & $(292)$ & 21:08:01.100 & -9.074 & -78.957 & 049 & 4.6 & $\mathrm{P}$ \\
\hline $20 / 10 / 2002$ & $(293)$ & 16:06:00.500 & 36.406 & 141.07 & 039 & 5.4 & PKP \\
\hline $22 / 10 / 2002$ & $(295)$ & 06:38:47.301 & -43.886 & 38.891 & 010 & 5.3 & $\mathrm{P}$ \\
\hline $23 / 10 / 2002$ & $(296)$ & $07: 37: 30.900$ & -32.178 & -109.53 & 010 & 5.1 & $\mathrm{P}$ \\
\hline $24 / 10 / 2002$ & (297) & $04: 35: 16.400$ & 25.154 & 123.49 & 033 & 5.5 & PKP \\
\hline $24 / 10 / 2002$ & (297) & 06:07:04.300 & 25.12 & 123.73 & 010 & 5.5 & PKP \\
\hline $24 / 10 / 2002$ & $(297)$ & 06:08:37.700 & -1.899 & 28.904 & 011 & 5.8 & $\mathrm{P}$ \\
\hline $24 / 10 / 2002$ & $(297)$ & 07:12:17.301 & -1.988 & 28.875 & 010 & 5.3 & $\mathrm{P}$ \\
\hline $27 / 10 / 2002$ & $(300)$ & 21:08:52.100 & 17.104 & -101.31 & 033 & 4.7 & $\mathrm{P}$ \\
\hline $28 / 10 / 2002$ & $(301)$ & $14: 40: 53.000$ & -57.893 & -25.67 & 033 & 4.8 & $\mathrm{P}$ \\
\hline $31 / 10 / 2002$ & $(304)$ & $10: 32: 58.700$ & 41.777 & 14.905 & 010 & 5.3 & $\mathrm{P}$ \\
\hline $31 / 10 / 2002$ & $(304)$ & $16: 09: 30.500$ & 18.581 & 146.13 & 033 & 5.4 & PKP \\
\hline $31 / 10 / 2002$ & $(304)$ & $20: 36: 54.100$ & -40.157 & -74.72 & 033 & 5.3 & $\mathrm{P}$ \\
\hline $01 / 11 / 2002$ & $(305)$ & 15:09:01.401 & 41.784 & 14.871 & 010 & 5.5 & $\mathrm{P}$ \\
\hline $03 / 11 / 2002$ & (307) & $03: 37: 43.200$ & 38.868 & 141.98 & 049 & 5.7 & PKP \\
\hline $04 / 11 / 2002$ & $(308)$ & 03:19:17.701 & -5.592 & 35.927 & 010 & 5.6 & $\mathrm{P}$ \\
\hline $04 / 11 / 2002$ & $(308)$ & $04: 35: 57.601$ & 32.369 & 131.52 & 033 & 5.5 & PKP \\
\hline $04 / 11 / 2002$ & $(308)$ & 08:25:53.301 & -5.947 & 36.18 & 010 & 4.9 & $\mathrm{P}$ \\
\hline $04 / 11 / 2002$ & $(308)$ & 10:00:47.500 & 17.571 & -101.28 & 033 & 5.1 & $\mathrm{P}$ \\
\hline $05 / 11 / 2002$ & $(309)$ & $14: 05: 19.900$ & 19.613 & -104.56 & 102 & 5.0 & $\mathrm{P}$ \\
\hline $06 / 11 / 2002$ & $(310)$ & 09:12:44.800 & 37.829 & 20.914 & 010 & 5.0 & $\mathrm{P}$ \\
\hline $06 / 11 / 2002$ & $(310)$ & $16: 02: 37.900$ & 16.562 & -98.855 & 033 & 4.8 & $\mathrm{P}$ \\
\hline $08 / 11 / 2002$ & $(312)$ & $23: 20: 43.500$ & 16.454 & -97.815 & 033 & 5.1 & $\mathrm{P}$ \\
\hline $09 / 11 / 2002$ & $(313)$ & $00: 14: 19.600$ & 13.928 & -91.211 & 033 & 5.5 & $\mathrm{P}$ \\
\hline $09 / 11 / 2002$ & (313) & 06:05:58.300 & -48.102 & -75.358 & 033 & 5.1 & $\mathrm{P}$ \\
\hline $11 / 11 / 2002$ & $(315)$ & $01: 27: 13.600$ & -31.717 & -71.709 & 033 & 4.8 & $\mathrm{P}$ \\
\hline $11 / 11 / 2002$ & $(315)$ & $23: 53: 11.100$ & -2.357 & -79.893 & 033 & 5.2 & $\mathrm{P}$ \\
\hline $12 / 11 / 2002$ & $(316)$ & 01:46:48.701 & -56.555 & -27.747 & 113 & 6.0 & $\mathrm{P}$ \\
\hline $12 / 11 / 2002$ & $(316)$ & 03:54:00.000 & 1.401 & -90.967 & 010 & 4.8 & $\mathrm{P}$ \\
\hline $13 / 11 / 2002$ & $(317)$ & 03:19:01.601 & -4.638 & -77.88 & 033 & 4.7 & $\mathrm{P}$ \\
\hline $13 / 11 / 2002$ & $(317)$ & $20: 26: 52.800$ & 18.734 & -64.096 & 038 & 5.0 & $\mathrm{P}$ \\
\hline $14 / 11 / 2002$ & $(318)$ & $15: 30: 32.600$ & -55.655 & -35.667 & 033 & 5.2 & $\mathrm{P}$ \\
\hline $14 / 11 / 2002$ & $(318)$ & $15: 53: 33.401$ & 16.325 & -91.001 & 033 & 4.7 & $\mathrm{P}$ \\
\hline $15 / 11 / 2002$ & $(319)$ & 13:05:40.301 & -55.647 & -35.662 & 033 & 5.9 & $\mathrm{P}$ \\
\hline $15 / 11 / 2002$ & (319) & 19:58:33.900 & -55.934 & -35.901 & 033 & 6.0 & $\mathrm{P}$ \\
\hline $16 / 11 / 2002$ & $(320)$ & $10: 16: 30.200$ & -55.82 & -35.309 & 033 & 5.4 & $\mathrm{P}$ \\
\hline $17 / 11 / 2002$ & $(321)$ & $10: 01: 57.300$ & 8.918 & -83.848 & 001 & 4.9 & $\mathrm{P}$ \\
\hline $18 / 11 / 2002$ & $(322)$ & $00: 31: 30.500$ & 28.985 & -43.461 & 010 & 5.0 & $\mathrm{P}$ \\
\hline $19 / 11 / 2002$ & $(323)$ & $18: 24: 06.701$ & 12.707 & -88.89 & 033 & 4.8 & $\mathrm{P}$ \\
\hline $20 / 11 / 2002$ & $(324)$ & $18: 19: 43.600$ & 12.686 & -88.209 & 114 & 5.1 & $\mathrm{P}$ \\
\hline $21 / 11 / 2002$ & $(325)$ & 02:53:18.601 & 12.315 & -82.284 & 033 & 5.3 & $\mathrm{P}$ \\
\hline $22 / 11 / 2002$ & $(326)$ & 18:34:30.301 & 12.214 & -87.045 & 074 & 4.8 & $\mathrm{P}$ \\
\hline $24 / 11 / 2002$ & $(328)$ & $12: 47: 56.101$ & -55.633 & -35.534 & 033 & 4.6 & $\mathrm{P}$ \\
\hline $24 / 11 / 2002$ & $(328)$ & $15: 09: 33.100$ & 10.862 & -62.672 & 112 & 4.8 & $\mathrm{P}$ \\
\hline $25 / 11 / 2002$ & $(329)$ & $11: 41: 59.501$ & 0.735 & -25.174 & 010 & 4.7 & $\mathrm{P}$ \\
\hline $26 / 11 / 2002$ & $(330)$ & $08: 17: 21.900$ & 15.154 & -93.623 & 033 & 4.6 & $\mathrm{P}$ \\
\hline $29 / 11 / 2002$ & $(333)$ & $11: 49: 28.301$ & 23.464 & -44.991 & 010 & 5.0 & $\mathrm{P}$ \\
\hline $01 / 12 / 2002$ & $(335)$ & 02:46:54.101 & -10.684 & -78.876 & 027 & 5.2 & $\mathrm{P}$ \\
\hline $01 / 12 / 2002$ & $(335)$ & 09:56:59.699 & 42.649 & 143.94 & 094 & 5.4 & PKP \\
\hline $02 / 12 / 2002$ & (336) & 02:18:33.301 & 11.111 & -86.326 & 033 & 4.8 & $\mathrm{P}$ \\
\hline $02 / 12 / 2002$ & $(336)$ & 04:58:55.101 & 37.747 & 21.087 & 010 & 5.2 & $\mathrm{P}$ \\
\hline
\end{tabular}


Tabela B.1 (Continuação)

\begin{tabular}{|cc|c|ccc|c|c|}
\hline $\begin{array}{c}\text { Data } \\
\text { dd/mm/aaaa }\end{array}$ & Dia Jul. & Hora & \multicolumn{2}{|c|}{ Localização } & Prof. & Magnitude & Fase \\
jjj & (UTC) & Latitude & Longitude & $(\mathrm{km})$ & $m_{b}$ & Tipo \\
\hline $02 / 12 / 2002$ & $(336)$ & $06: 19: 57.100$ & 13.278 & -89.063 & 125 & 4.8 & $\mathrm{P}$ \\
$02 / 12 / 2002$ & $(336)$ & $13: 42: 10.300$ & 1.511 & 126.39 & 010 & 5.7 & PKP \\
$09 / 12 / 2002$ & $(343)$ & $09: 35: 04.800$ & 37.869 & 19.973 & 010 & 5.0 & $\mathrm{P}$ \\
$10 / 12 / 2002$ & $(344)$ & $01: 28: 33.601$ & -50.028 & -114.12 & 010 & 5.3 & $\mathrm{P}$ \\
$10 / 12 / 2002$ & $(344)$ & $03: 09: 40.101$ & 17.884 & -100.91 & 085 & 5.1 & $\mathrm{P}$ \\
$10 / 12 / 2002$ & $(344)$ & $13: 51: 26.701$ & 36.195 & -7.472 & 010 & 5.1 & $\mathrm{P}$ \\
$11 / 12 / 2002$ & $(345)$ & $03: 49: 40.100$ & -3.81 & 135.12 & 010 & 5.9 & $\mathrm{PKP}$ \\
$11 / 12 / 2002$ & $(345)$ & $10: 00: 31.101$ & -3.737 & 135.23 & 010 & 5.6 & $\mathrm{PKP}$ \\
$12 / 12 / 2002$ & $(346)$ & $04: 16: 02.100$ & -57.97 & -25.187 & 033 & 5.0 & $\mathrm{P}$ \\
$12 / 12 / 2002$ & $(346)$ & $22: 44: 05.300$ & -41.852 & -83.564 & 010 & 5.6 & $\mathrm{P}$ \\
$15 / 12 / 2002$ & $(349)$ & $07: 23: 54.900$ & 6.985 & -72.814 & 202 & 4.7 & $\mathrm{P}$ \\
$16 / 12 / 2002$ & $(350)$ & $09: 46: 32.101$ & -26.784 & -107.21 & 010 & 5.0 & $\mathrm{P}$ \\
$17 / 12 / 2002$ & $(351)$ & $04: 32: 53.100$ & -56.952 & -24.825 & 010 & 5.5 & $\mathrm{P}$ \\
$18 / 12 / 2002$ & $(352)$ & $01: 47: 07.000$ & -56.996 & -25.205 & 010 & 5.1 & $\mathrm{P}$ \\
$18 / 12 / 2002$ & $(352)$ & $14: 12: 21.700$ & -57.092 & -24.981 & 010 & 5.7 & $\mathrm{P}$ \\
$19 / 12 / 2002$ & $(353)$ & $03: 42: 45.800$ & 0.911 & 126.27 & 033 & 5.4 & $\mathrm{PKP}$ \\
$19 / 12 / 2002$ & $(353)$ & $03: 48: 48.700$ & -57.014 & -24.905 & 010 & 4.8 & $\mathrm{P}$ \\
$20 / 12 / 2002$ & $(354)$ & $14: 14: 42.000$ & -3.076 & 147.94 & 033 & 5.8 & PKP \\
$21 / 12 / 2002$ & $(355)$ & $00: 46: 07.500$ & 3.711 & -79.001 & 010 & 5.4 & $\mathrm{P}$ \\
$21 / 12 / 2002$ & $(355)$ & $17: 41: 13.501$ & 4.983 & 123.16 & 602 & 5.4 & $\mathrm{PKP}$ \\
$21 / 12 / 2002$ & $(355)$ & $18: 50: 54.701$ & 18.357 & -62.38 & 052 & 4.9 & $\mathrm{P}$ \\
$23 / 12 / 2002$ & $(357)$ & $02: 50: 38.200$ & -1.724 & 34.971 & 010 & 5.0 & $\mathrm{P}$ \\
$23 / 12 / 2002$ & $(357)$ & $13: 46: 11.300$ & 16.957 & -85.578 & 033 & 5.6 & $\mathrm{P}$ \\
$25 / 12 / 2002$ & $(359)$ & $05: 09: 00.400$ & -54.742 & -118.61 & 010 & 4.9 & $\mathrm{P}$ \\
$29 / 12 / 2002$ & $(363)$ & $07: 31: 46.100$ & 17.595 & -95.188 & 131 & 4.8 & $\mathrm{P}$ \\
\hline
\end{tabular}




\section{BIBLIOGRAFIA}

Brito Neves, B. B., R. Fuck, U. G. Cordani \& A. Thomaz. Influence of basemente structures on the evolution of the major sedimentary basins of Brazil: A case of tectonic heritage. $J$. Geodyn., 1, 459-510, 1984.

Brito Neves, B. B., \& U. G. Cordani. Tectonic evolution of South America during the Late Proterozoic. Precambrian Res., 53, 23-40, 1991.

Cline, A. K., FITPACK - Software package for curve and surface fitting employing splines under tension, Department of Computer Sciences, University of Texas, Austin, 1981.

Constable, S. C., R. L. Parker \& C. G. Constable. Occam's inversion: A pratical algorithm for generation smooth models from eletromagnétic sounding data. Geophysics, 52, 289-300, 1987.

Cordani, U. G., B. B. Brito Neves, R. A. Fuck, R. Porto, A. T. Filho, \& F. M. Bezerra da Cunha. Estudo preliminar de integração do Pré-Cambriano com os eventos tectônicos das bacias sedimentares brasileiras. Revista Ciência Técnica Petróleo, Rep. 15, 70 pp., Petrobrás, Centro de Pesquisas e Desenvolvimento Leopoldo A. Maguez de Mello (CENPES), Rio de Janeiro, Brasil, 1984.

Escalante, Christian. Tomografia sísmica do manto superior sob o sudeste e centro oeste do Brasil. Dissertação de Mestrado, IAG - USP, pp. 74, 2002.

Evans, J. R., \& U. Achauer. Teleseismic velocity using the ACH metod: theory and application to continental-scale studies, in H. M. Iyer and K. Hirahara (Editores). Seismic Tomography: Theory and Practice, Chapman and Hall, London, pp. 319-360, 1993.

Gibson, S. A., R. N. Thompson, R. K. Weska, A. P. Dickin \& O. H. Leonards. Late Cretaceous rift-related upwellings and melting of the Trindade starting mantle plume head beneath western Brazil. Contrib. Mineral Petrol, 126, 303-314, 1997.

Gibson, S. A., R. N. Thompson, O. H. Leonards, A. P. Dickin \& J. G. Mitchell. The limited extent of plume-lithosphere interactions during continental flood-basalt genesis: Geochemical evidence from Cretaceous magmatism in southern Brazil. Contrib. Mineral Petrol, 137, 147$169,1999$.

Heintz, M., E. Debayle, A. Vauchez \& M. Assumpção. Seismic anisotropy and surface wave tomography of South America. AGU fall meeting, S52B-22, 2000.

Hubert, P. J., Robust statistics. Wiley, New York, 1981.

Kenneth, B. L. N., and E. R. Engdahl. Traveltimes for global earthquake location and phase identification. Geophys. J. Int., 105, 429-465, 1991.

Lay, T. \& T. C. Wallace. Modern Global Seismology. Academic Press, (Internatinal geophysics series: v. 58), 1995.

Lawson, C. L. and R. J. Hanson. Solving least squares problems. Prentice-Hall, New Jersey, 340 pp.,1974.

Marquardt, D. W., An algorithm for least-squares estimations of nonlinear parameters. J. Soc. Ind. Appl. Math., 11, 431-441, 1963. 
Meju, W. Geophysical Data Analysis: Understanding Inverse Problem Theory and Pratice, in S. N. Domenico, Editor. Courses notes series, vol 06, SEG, 1994.

Menke, W. Geophysical Data Analysis: Discrete Inverse Theory. Academic Press, Orlando, 260 pp., 1984.

Paige, C. C. \& M. A. Saunders. LSQR: An algorithm for sparse linear equations and sparse least squares. ACM Trans. Math. Software, 8, 43-71, 1982.

Pulliam, R. J., D. W. Vasco, \& L. R. Johnson. Tomografic Inversions for Mantle P Wave Velocity Structure Based on the Minimization of $l^{1}$ and $l^{2}$ Norms of Internatinonal Seismological Centre Travel Times Residuals. J. Geophys. Res., 98, 699-734, 1993.

Rocha, M. P. \& M. Assumpção. Tomografia sísmica do manto superior no SE do Brasil utilizando ondas P. 80 Congresso Internacional da Sociedade Brasileira de Geofísica, in press, Rio de Janeiro, 2003.

Sambridge, M. S., Non-linear arrival time inversion: constraining velocity anomalies by seeking smooth models in 3-D. Geophys. J. Int., 102, 653-677, 1990.

Schimmel, M. Phase Cross-Correlation: Design, Comparison, and Application. Bull. Seismol. Soc. Am., 89, 1366-1378, 1999.

Schimmel, M., M. Assumpção, \& J. C. VanDecar. Seismic velocity anomalies beneath SE Brazil from P and S wave travel time inversions. J. Geophys. Res., 108, doi: 10.1029/2001JB000187, 2003.

Silveira, G., E. Stutzmann, D. A. Griot, J. P. Montagner \& L. M. Victor. Anisotropic tomography of the Atlantic Ocean from Rayleigh surface waves. Phys. Earth. Planet. Inter., 106, 257-273, 1998.

Spakman, W., Upper mantle delay time tomography. Ph. D. thesis. University of Utrech, Utrech, The Netherlands, 200 pp., 1988.

Spakman, W. \& G. Nolet. Imaging algorithms, accuracy and resolution in delay time tomography. Mathematical Geophysics, edited by N. J. Vlaar, G. Nolet, M. J. R. Wortel \& S. A. P. L. Cloetingh, D. Riedel Publ. Co., Dordrech, The Netherlands, 155-187, 1988.

Thompson, R. N., S. A. Gibson, J. G. Mitchel, A. P. Dickin, O. H. Leonards, J. A. Broad \& J. C. Greenwood. Migrating Cretaceous-Eocene Magmatism in the Serra do Mar Alkaline Province, SE Brazil: Melts from Deflected Trindade Mantle Plume?. Jornal of Petrology, 39, 1493-1526, 1998.

VanDecar, J. C., \& R. S. Crosson. Determination of teleseismic relative phase arrival times using multi-channel cross-correlation and least squares. Bull. Seismol. Soc. Am., 80, 150-169, 1990.

VanDecar, J. C., D. E. James., M. Assumpção. Seismic evidence for a fossil mantle plume beneath South America and implications for plate driving forces. Nature, 378, 25-31, 1995.

Van der Lee, S., D. James \& P. Silver. Upper mantle S-velocity structure of central and western South America. J. Geophys. Res., 106, 30821-30834, 2001.

Vdovin, O., J. A. Levshin \& M. H. Ritzwoller. Group-velocity structure of South America and the surrounding oceans. Geophys. J. Int., 136, 324-340, 1999. 